Portland State University

PDXScholar

\title{
Understory Species Increase Project: Investigating the Revegetation of Native Herbaceous Species From Seed in Urban Forest Fragments
}

Erin McElroy

Portland State University

Follow this and additional works at: https://pdxscholar.library.pdx.edu/mem_gradprojects

Part of the Environmental Sciences Commons, Environmental Studies Commons, and the Forest Sciences Commons Let us know how access to this document benefits you.

\section{Recommended Citation}

McElroy, Erin, "Understory Species Increase Project: Investigating the Revegetation of Native Herbaceous Species From Seed in Urban Forest Fragments" (2021). Master of Environmental Management Project Reports. 66.

https://pdxscholar.library.pdx.edu/mem_gradprojects/66

https://doi.org/10.15760/mem.69

This Project is brought to you for free and open access. It has been accepted for inclusion in Master of Environmental Management Project Reports by an authorized administrator of PDXScholar. Please contact us if we can make this document more accessible: pdxscholar@pdx.edu. 


\title{
Understory Species Increase Project:
}

Investigating the revegetation of native herbaceous species from seed in urban forest fragments

by

Erin McElroy

\author{
In pursuit of \\ Master's Degree in Environmental Management \\ Environmental Science and Management Department \\ Portland State University
}

2021

\begin{abstract}
Committee Members:
Jennifer Morse, Ph.D. (Portland State University)

John Richard Goetz III (Clean Water Services)

Jeff Gerwing, Ph.D. (Portland State University)
\end{abstract}




\section{ABSTRACT:}

Management of urban forest fragments often aims to reduce invasive species and promote native species abundance and diversity. Often, these environments lack natural establishment of native forest species, including herbaceous species that are especially sensitive to site conditions. While herbaceous understory species may represent a small proportion of forest biomass, they perform important functions within forest environments, including nutrient cycling, erosion and runoff control, and providing habitat for wildlife, as well as hosting the greatest biodiversity among other forest strata. However, many restoration projects focus primarily on the revegetation of dominant woody forest species, such as hardwood trees and shrubs. Herbaceous understory species may be overlooked due to limited understanding of their importance, technical information, budget, and plant material availability. The Understory Species Increase Project (USIP) is a collaborative effort started by Clean Water Services, the City of Portland's Revegetation Program, and Metro that aims to fill this gap in knowledge and resources by researching, developing, and amplifying diverse herbaceous species in the region. The current stage involves two distinct but complementary investigations:

1) Examining seeding effectiveness, species performance, and environmental conditions related to germination and cover through the installation of in-situ trial plots in multiple forest sites, and

2) Examining the current commercial market, and challenges and opportunities in the production of native forest herbs through a survey of local plant material producers.

Results from trial plots show benefits of a seeding treatment, including increased cover of target species and native species richness. However, these benefits were not realized at all sites. Modeling analysis revealed that soil properties are the strongest predictors of whether a seeding 
treatment will be effective, as sites with degraded soil conditions failed to establish strong cover of target species and generally had a greater presence of invasive species. Additionally, seeding success varied across species. Unfortunately, many of the most successful species to establish from seed were also found to have limited commercial availability in the current market. While challenges to producing herbaceous species are numerous, producers identified the lack of a stable demand as the largest challenge to production. Recommendations to address this challenge include continued research and creation of guidance documents, education and outreach to share information and foster interest in these species, and ongoing support of diverse partnerships to help expand and stabilize demand. 


\section{Acknowledgements:}

First and foremost, I would like to thank my partner, Zachary Woolems, for his loving support throughout the last 2 years. From moving to Portland for me to pursue this opportunity, to enduring the COVID-19 pandemic, and two subsequent moves, I would not have been able to get through these trying times without you.

I would also like to thank my advisor, Jennifer Morse, and project manager, John Goetz III, for granting me the opportunity to become completely enveloped in this project. For offering their support and guidance but also allowing me to take the project in my own direction, I am sincerely grateful to you both.

I would like to thank the rest of my project team, without whom my work would not have been possible. Thank you, Adrienne St. Clair, for being my R guru, for always quizzing me on my plant identification when we were in the field together, and for being my sounding board at many phases of my analysis and writing. Adrienne also kept thorough records of the previous work that was done for the trial plots, without which it would have been nearly impossible for me to adequately describe in the methods of this document. Thank you to Christa von Behren for also being instrumental in training me on species identification, seed collection and cleaning techniques, and for always offering me valuable feedback on my writing and presentations. Thank you to Toby Query for all of the wonderful lessons on worms and plant IDs, and for always providing much needed laughs during our meetings. Thank you to Marsha Holt-Kingsley for your practical wisdom in the world of plant propagation and production. I hope you are enjoying your well-deserved retirement. Thank you to Jack Hayden and Hannah Spencer for help during annual plot monitoring and worm surveys. Finally, thank you to Laura Taylor and Michael Ahr from West Multnomah Soil and Water Conservation District, your staff time and 
financial contributions through a Conservation Innovation Grant have greatly strengthened this project and for that I am so appreciative.

Thank you to my committee member, Jeff Gerwing, for providing me valuable feedback on my literature review and thank you to Professor Pan for coaching me on how to work with my complicated data, even after I was no longer a student. Thank you to Sarah Carvill and Catherine de Rivera for being exceptional professors and helping me to improve my ability to effectively communicate my research in various forms and to various audiences. Thank you to the Bushby Foundation and Society of Ecological Restoration Northwest Chapter for providing monetary support that enabled this project to blossom into what it is today. Thank you to my lab mates and classmates for listening to me present my research at various stages over the last two years and providing valuable feedback. Thank you to the organizers at the Urban Ecological Research Consortium for allowing me to present my research.

Lastly, thank you to the various native plant producing businesses that participated in my survey to help improve our understanding of what challenges limit native plant production. This entire chapter of my graduate work would not have been possible without the feedback I received from you all. 


\section{Table of Contents}

ABSTRACT:

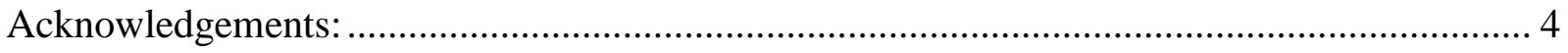

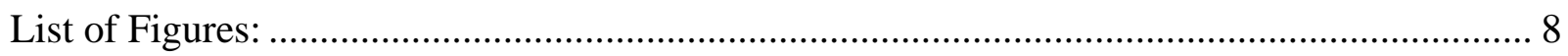

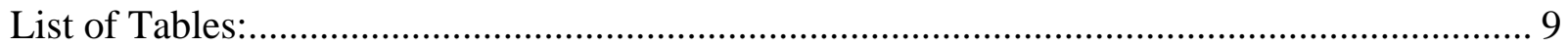

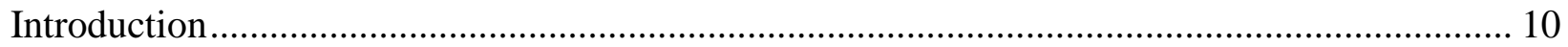

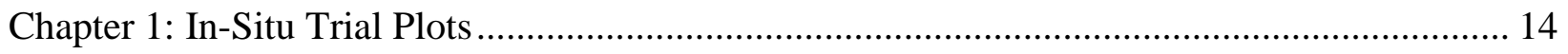

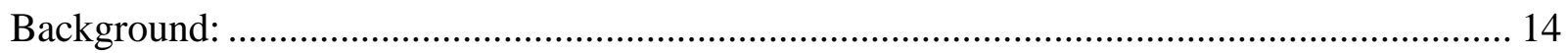

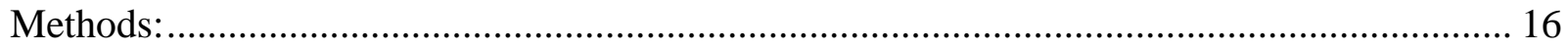

Plot Set-up

West Multnomah Trial Plots ....................................................................................... 19

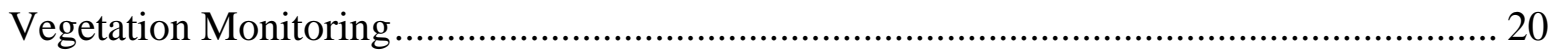

Collection of Environmental Predictors......................................................................... 20

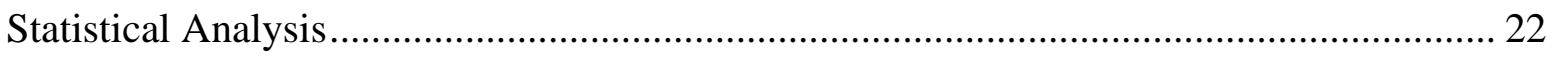

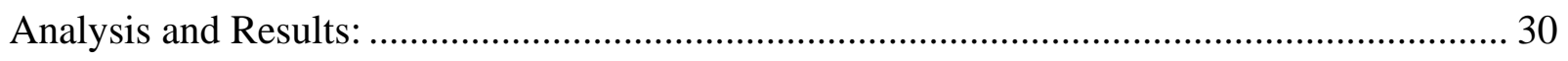

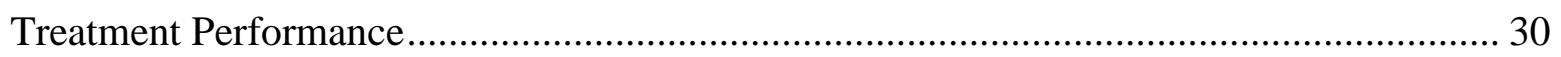

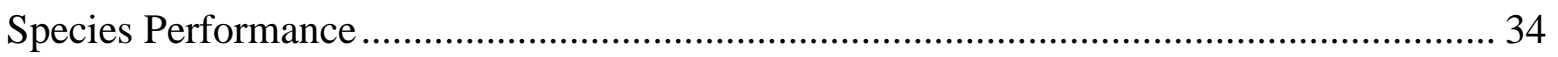

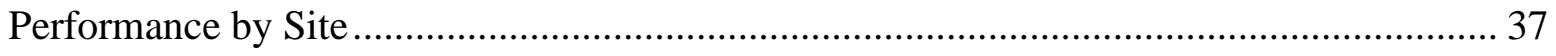

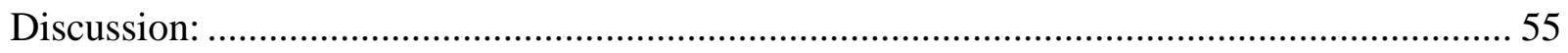

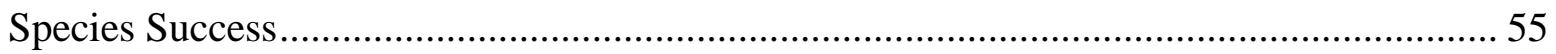

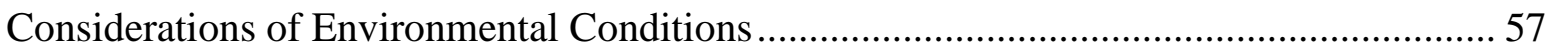

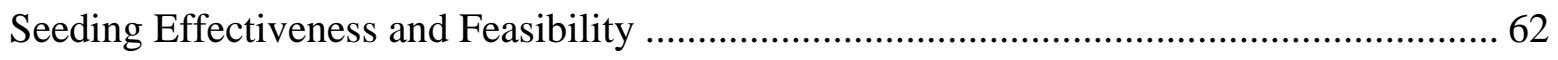

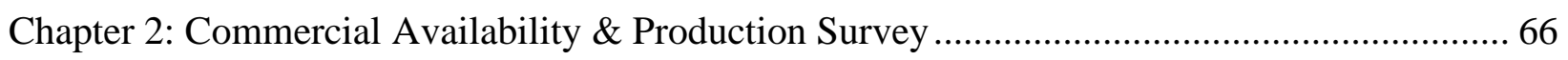

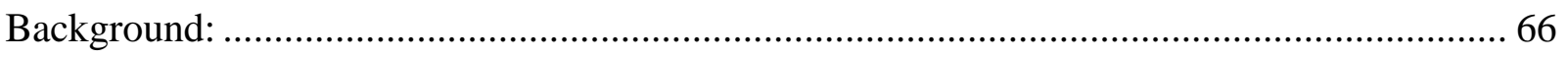

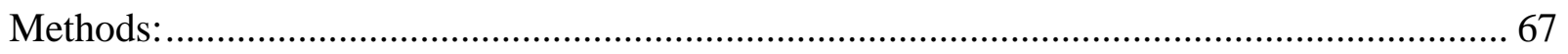




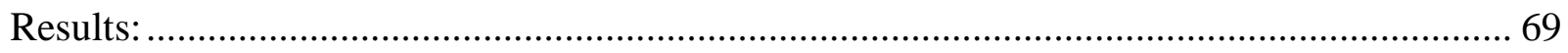

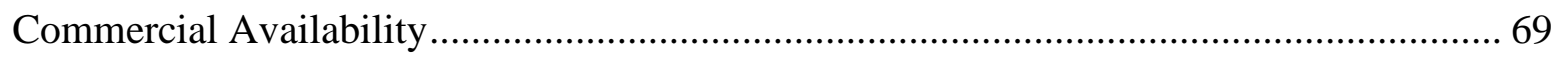

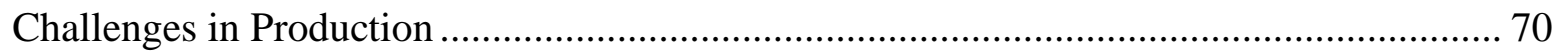

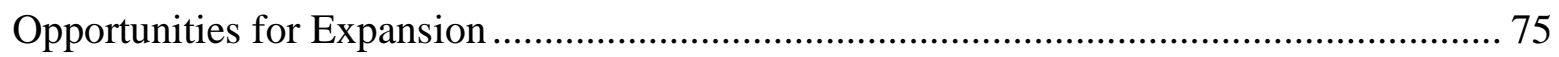

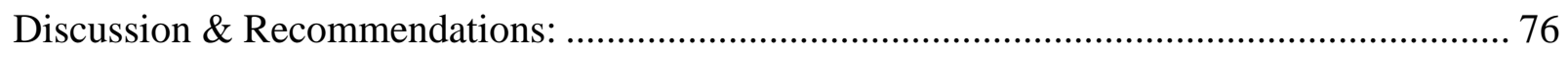

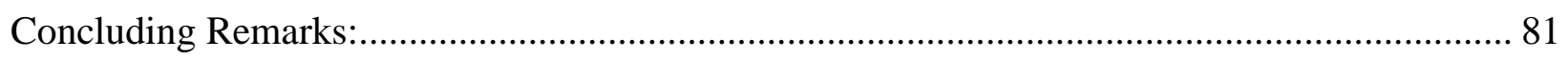

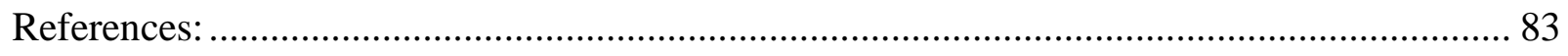

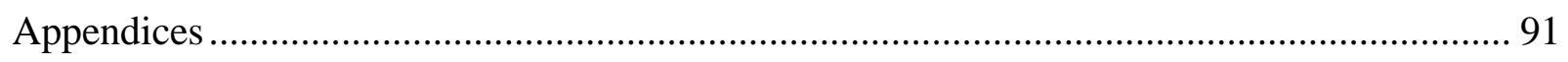

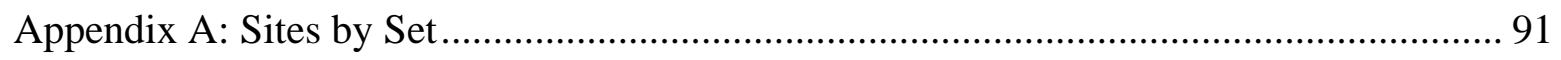

Appendix B: Seed Mixes .................................................................................... 92

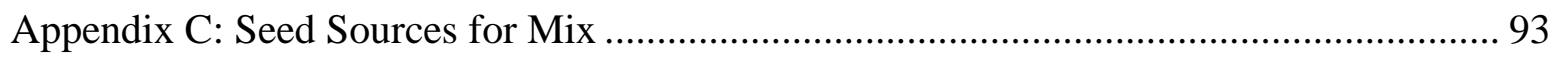

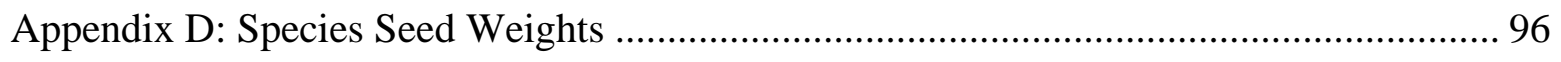

Appendix E: Data collection method details ............................................................. 97

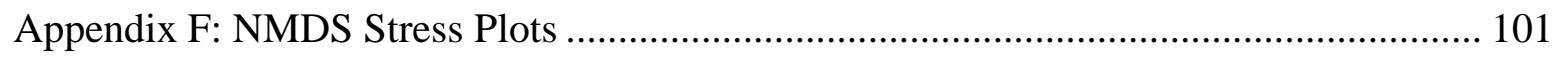

Appendix G: Species Performance Metric (1-2 years post-seeding data only) ................ 102

Appendix H: Additional Germination Graphs for GLMM predictors............................ 103

Appendix I: Germination GLMM Best Model DHARMa Diagnostics............................ 105

Appendix J: Germination \& Cover GLMM Forward Selection Process ......................... 106

Appendix K: Additional Cover Graphs for significant GLMM predictors ...................... 107

Appendix L: Cover GLMM Best Model DHARMa Diagnostics ................................... 108

Appendix M: Commercial Vendor Survey ........................................................... 109 


\section{List of Figures:}

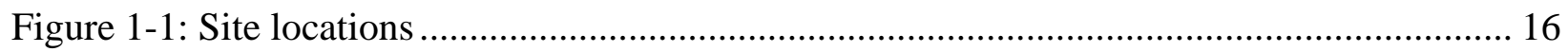

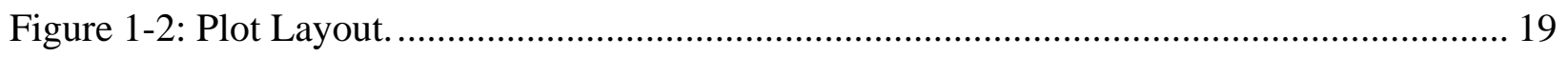

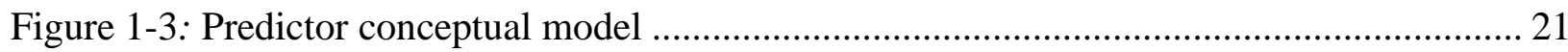

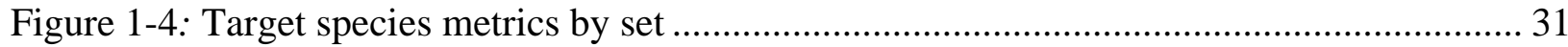

Figure 1-5:Target cover and invasive species stem counts relationship........................................ 33

Figure 1-6: Target cover and invasive species stem counts relationship by set ........................... 33

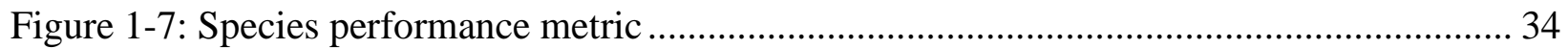

Figure 1-8: Species performance metric by set....................................................................... 36

Figure 1-9 Species performance metric showing percent presence .............................................. 37

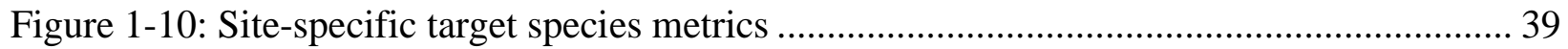

Figure 1-11: Pearson's correlation coefficients of target species stem counts ............................. 42

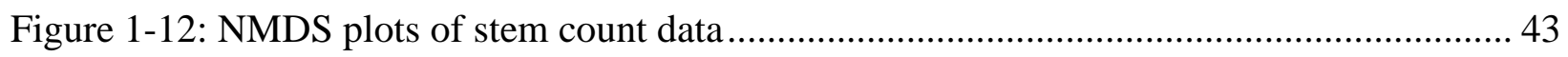

Figure 1-14:NMDS plot of the relationship between soil C:N and target stem counts ................ 45

Figure 1-13: NMDS plot with significant $(\mathrm{p}<0.05)$ environmental predictors ............................. 45

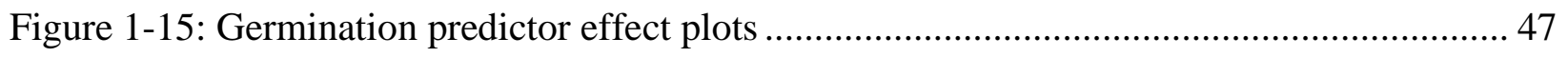

Figure 1-16: Pearson's correlation coefficients of target species cover ......................................... 48

Figure 1-17: Cover NMDS plot showing separation by treatment ............................................... 49

Figure 1-19: Cover NMDS plot with significant $(\mathrm{p}<0.05)$ environmental predictors ................... 50

Figure 1-19: Cover NMDS plot showing separation by site................................................... 50

Figure 1-20: Cover NMDS plots highlighting relationships between strongest predictors ........... 52

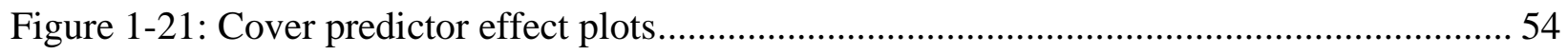

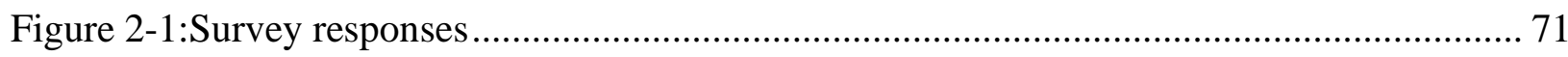

Figure 2-2: Overall survey responses identifying challenges ..................................................... 72

Figure 2-3: Species-specific responses identifying challenges ..................................................... 73 


\section{List of Tables:}

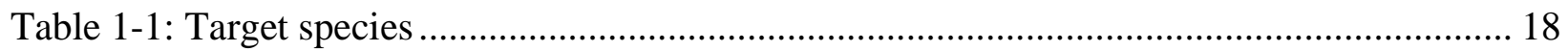

Table 1-2: Collection methods and units of environmental predictors..................................... 22

Table 1-3: Mean stem counts and cover of target species and native species richness ............... 30

Table 1-4: Mean cover and stem counts of invasive species .................................................... 32

Table 1-5:Site-wide averages of plot-level predictors. .................................................... 40

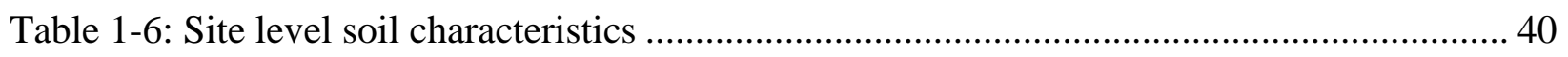

Table 1-7: Site-level averages for predictors collected at USIP sites only............................ 41

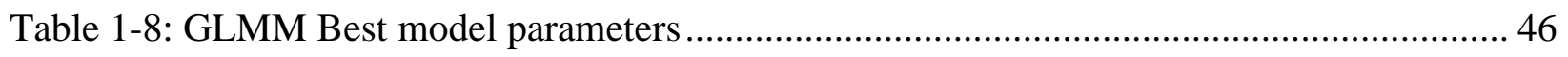

Table 1-9: Parameters of 2 best GLMM models. .................................................................. 53

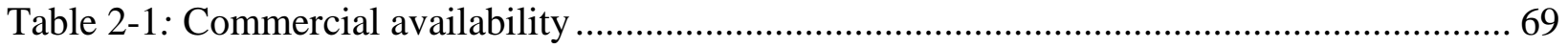




\section{Introduction}

Revegetation is a crucial step in restoration following invasive species removal, especially in urban forest remnants where the soil seed bank is often lacking for the natural regeneration of native forest species (Overdyck and Clarkson, 2014). ${ }^{1}$ However, revegetation efforts in these settings commonly focus on dominant woody species, and not on the herbaceous understory species that are also a vital component of healthy forests. Beyond an underappreciation of the ecological value of understory species, several interacting practical factors likely contribute to the practice of excluding understory species from revegetation efforts, including a lack of technical information about best practices for their implementation, budget constraints, and limited commercial availability. Commercial availability is especially limited for seeds, which may offer a more economical approach to establishing a diverse assemblage compared to other forms of plant materials (Palma, 2015).

Despite the focus on dominant woody species in revegetation efforts, herbaceous understory species also play a significant role in the structure and function of forests and contribute greatly to overall habitat and biodiversity. In forests, herbaceous species have been found to account for more than 80 percent of the total plant species richness on average, even given their relatively low stature and small contribution to overall standing biomass $(\sim 0.2 \%$ of total, Gilliam, 2007). Herbaceous litter has been found to decompose more than twice as quickly as tree litter and to contain higher concentrations of nitrogen $(\mathrm{N})$, phosphorus $(\mathrm{P})$, potassium $(\mathrm{K})$, and magnesium (Mg) than trees, in eastern deciduous forests (Muller, 2003). This indicates that the herbaceous layer plays an important role in nutrient cycling and energy flow in forest

\footnotetext{
${ }^{1}$ The term "invasive" species describes those which meet the Portland Plant List's definition: Species that spread at such a rate in which they cause harm to human health, the environment, and /or the economy. In natural areas, invasive plants are those species that displace native species and become the dominant species in that vegetation layer. (City of Portland, 2016).
} 
ecosystems. Although it was once thought that overstory species determine the composition of the understory in a one-way interaction, more recently it has been shown that understory dynamics can have strong impacts on tree regeneration (Thrippleton et al., 2016). Additionally, herbaceous species provide sustenance and refuge for many wildlife species and can be used as an indicator of overall habitat quality (Willie, 2014).

Herbaceous species are facing unprecedented challenges in the Anthropocene era, with many studies showing a trend in temperate forests toward urbanization, biotic homogenization, and a subsequent loss in native biodiversity (Wavrek et al., 2017). The loss of biodiversity within the herbaceous layer can be attributed to many interacting anthropogenic factors, including habitat fragmentation, changes in adjacent land use patterns, deer overabundance, climate change, species invasions, and degraded soils (Wavrek et al., 2017, Simmons et al., 2017). In a recent meta-analysis of species declines in relation to disturbance type, it was reported that species invasions were the only disturbance type that resulted in significant declines in species richness in the northern temperate forest biome (Murphy and Romanuk, 2014). Accordingly, natural resource managers invest a large proportion of time and resources into the control of invasive species (Hulme, 2006, Pimentel et al., 2005).

The management of invasive species, however, brings about a new suite of challenges for land managers. One primary concern is that many invasive plant control methods can promote reinvasion through the release of resources (water, light, nutrients), and reduced competitionoften resulting in reinvasion by the species of concern or a different invasive species (Kettenring and Adams, 2011). Passive recovery of herbaceous species following invasive removal may be adequate at improving native species richness in situations where the ecosystem is naturally resilient, has a sufficient native seed bank, and a lack of degradation and disturbance (Holl \& Aide, 2011). In many other settings, the degraded conditions left by the invasive species often 
impedes natural regeneration and makes active revegetation necessary (Bauer and Reynolds, 2017, Clements, 2017; Cordell et al., 2009, Schuster et al., 2018). A meta-analysis of invasive plant control methods found that many studies failed to increase native plant cover or diversity (Kettenring and Adams, 2011). The authors attributed this to the fact that only approximately one-third of the 355 research papers reviewed included a revegetation component and suggested that native plant revegetation should be included in future investigations.

While revegetation has received increasing attention in restoration projects, dominant forest species such as hardwood trees and shrubs remain the focus of forest revegetation efforts. This approach has been called a passive relay floristics approach (Clewell, 1999), in which restoration practitioners plant a host of woody species that are well adapted to colonize early in forest succession, under the assumption that these species will facilitate the establishment of understory species later in succession (McClain et al., 2011). However, an understory dominated by exotic species can result from this approach (Holl and Crone, 2004). Invasive control has been postulated to be more successful if revegetation objectives included herbaceous species as well (Simmons et al., 2016). Actively revegetating herbaceous species is especially important in fragmented landscapes with long histories of invasion, as source populations for natural regeneration are unlikely to exist (Mottl et al., 2006, Altrichter, 2016), making recovery of native species dispersal limited (Brudvig et al. 2011). The herbaceous understory species that are planted or seeded in restoration projects become established with varying degrees of success. Additionally, many desirable native understory species are not made commercially available from local sources, creating a shortage of supply, and forcing those restoration practitioners who are devoted to their use to spend many contractor hours on wild collection and cleaning of seed.

The Understory Species Increase Project (USIP) was formed in 2013 as a collaborative effort between Clean Water Services (CWS), Portland Metro, and the City of Portland's Bureau 
of Environmental Services (BES). USIP aims to fill the gap in knowledge and resources relating to the revegetation of forest herbs. Its mission is to increase the feasibility of understory herbaceous species enhancement in the Willamette Valley region by researching and developing diverse, cost-effective understory species materials for use by regional restoration practitioners to create resilient native plant communities. One step to reach this goal is to investigate whether seeding a mix of native herbaceous species is an effective method to establish a diverse native herbaceous layer. Seeding offers land managers a relatively inexpensive means to introduce herbaceous species, but it is important to understand the overall effectiveness of seeding, which species are most successful, and which environmental variables have the greatest impact on seedling establishment. These questions were addressed through the installation of in-situ trial plots, which are the focus of the first chapter of this report.

Additionally, this project seeks to increase the commercial availability of target species. Previous work has focused on amplification, wherein species are grown at designated plots for later seed collection, at facilities operated by partner agencies. While these seeds have chiefly been used at small-scale restoration sites in the past, one potential pathway to expand seed availability is to distribute seeds to commercial growers with guidance on how to best produce them at a commercial scale. However, the practicality of such a plan in the current market must first be investigated. To research the current market for understory species, regional plant material producers were surveyed to identify which species of interest are currently available as well as any challenges in production and opportunities for expansion. Survey results and recommendations to further this work are the subject of the second chapter of this document. Overall, this report hopes to clarify the current understanding and future needs to enhance forest herb restoration in the Willamette Valley. 


\section{Chapter 1: In-Situ Trial Plots}

\section{Background:}

To enhance the use of native herbaceous species in regional restoration projects, it is crucial to understand what forms of plant materials offer the best outcomes while minimizing associated costs. Because revegetation of forest herbs is not a common practice regionally, little information is publicly available on best practices for deploying native herbs endemic to the Pacific Northwest. Many shade-tolerant herbaceous species are generally regarded as having a poor performance from seed (Mottl et al., 2006); however, this is likely highly nuanced and species-specific. Given that seeding offers a cost-effective (Palma et al., 2015) and less labor extensive approach to revegetation, investigations into the germination and establishment of native herbaceous species from seed are warranted.

Likewise, understanding site-specific impacts of urbanization and invasive species on soils and their implications for seedling establishment in revegetation projects is critical for successful restoration projects. While many studies have focused on the role of nutrients in herbaceous growth, most of this work within the U.S. has occurred outside of the Pacific Northwest, primarily in eastern deciduous forests (Gilliam and Roberts, 2003, Small and McCarthy, 2005). These studies have revealed that natural herbaceous understory composition is impacted by soil nutrients $\left(\mathrm{Ca}^{2+}, \mathrm{Mg}^{2+}, \mathrm{K}^{+}, \mathrm{P}, \mathrm{N}\right)$ to varying degrees based on stand age and study location. Herbaceous understory species establishment, including in restoration work, can also be greatly influenced by urbanization, through changes in soil quality, species competition, seedling establishment, and disturbance regimes (Pavao-Zuckerman, 2008). In urbanized areas, soil compaction is common and can limit plant root development; however, little is known regarding the compaction tolerance of non-crop native species (Basset et al., 2005). In the 
Portland metro area, urbanization of riparian areas has been linked to increased establishment and dominance of invasive species (Sharp, 2002).

To help better understand how well native herbaceous forest species establish from seed, as well as to understand which target species grow well under a variety of conditions, a series of in-situ trial plots were installed by original USIP partners in fall of 2016 and 2017. Additional plots were installed by West Multnomah Soil and Water Conservation District (WM) in fall of 2018. Vegetation in the plots has been monitored annually to semi-annually since installation. Basic landscape variables including slope, aspect, elevation, canopy cover, and type were recorded at the time of plot installation. Soil characteristics of the plots were also measured as part of this study, including soil compaction, plant-available nutrients, $\mathrm{pH}$, texture, $\mathrm{C}: \mathrm{N}$ ratio, organic matter content, worm density, and soil moisture and temperature. The current study has two primary objectives: 1) to examine vegetation data collected 1-4 years following seeding to determine the success of a seeding treatment and to identify which species display the strongest establishment from seed; and 2) to characterize the environmental predictors that best explain observed patterns in herbaceous species establishment from seed in a setting where anthropogenic changes are abundant. 


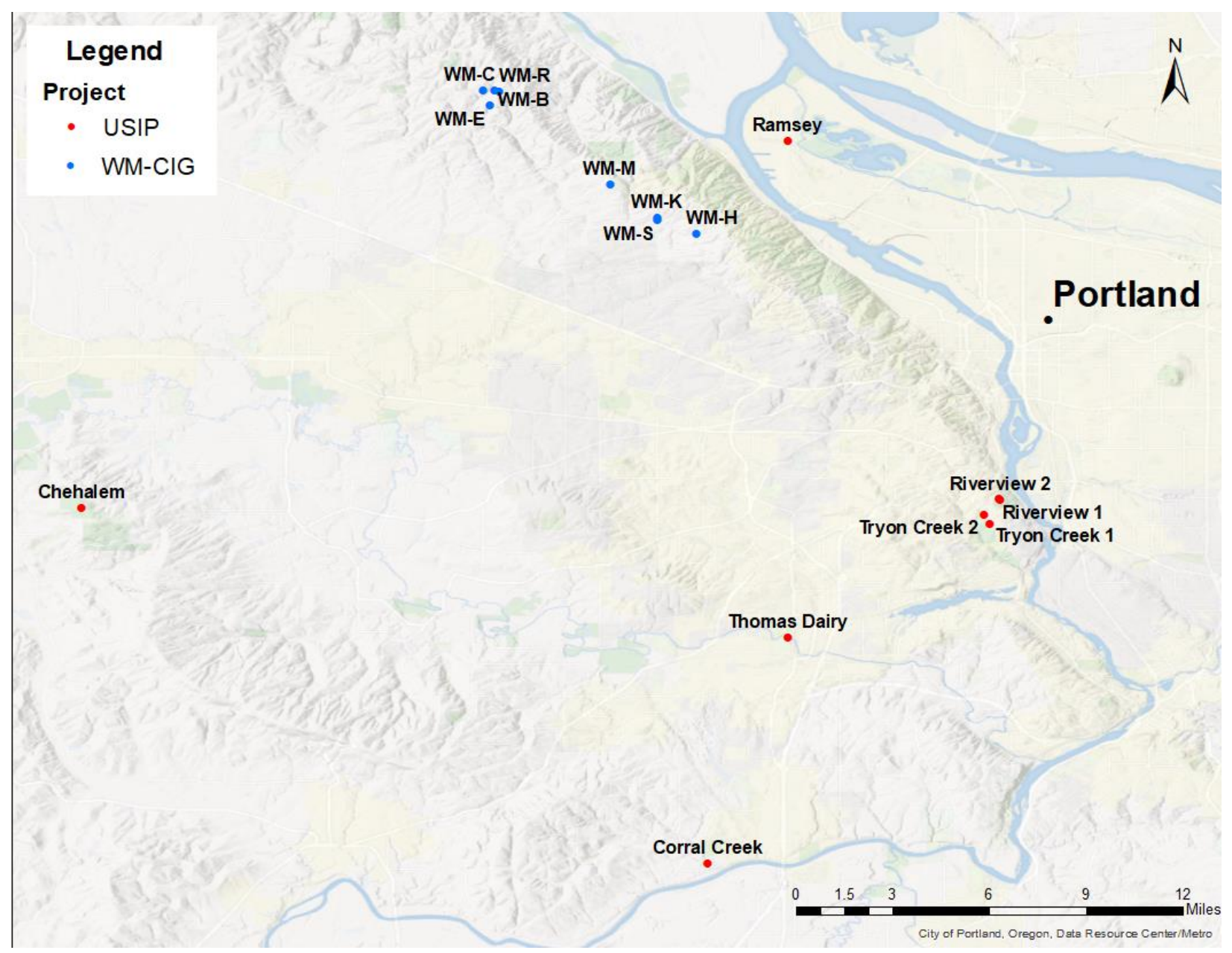

Figure 1-1: Site locations of USIP (red) and West Multnomah CWCD's (blue) plots. Several sites are in very close proximity resulting in overlapping dots (WM-K \& WM-S, River View $1 \& 2$ ).

\section{Methods:}

\section{Plot Set-up}

The USIP team installed trial plots at nine sites throughout the Portland metro area (Figure 1-1). In October 2016, 36 plots were installed in groups of five. In October 2017, an additional 18 plots were installed. Sites were selected by each partner agency, and plots were installed in groups of 6 . At two of the sites, Riverview and Tryon Creek, two groups of plots (12 total) were installed. Each group of 6 plots was divided into 3 control plots (raked but left unseeded) and 3 plots that were raked and seeded. 
Species were selected using responses to a survey sent to regional restoration practitioners in 2015 describing which species were most desired for restoration projects, along with information gained from previous trials about which species may establish from seed. Experimental plots were seeded with a mixture of 8-16 "target species", a recurring term used to describe species included in the seed mix (Table 1-1). Two distinct mixes, an upland mix and a riparian mix, were used for different plots based on their landscape position. Final seed mixes were also based on the availability of seed, causing them to vary slightly by year. The combined landscape position (upland/riparian) and year of installation will be referred to as "set" throughout this text, as this was the level at which seed mix compositions varied. Each site was assigned to only one set (Appendix A).

Seed collection was performed by each agency and/or contractors of each agency. The team aimed to create a genetically diverse representation of each species. Therefore, the seed mix included as many unique seed lots (based on unique collection location and time) as were available, with as near to equal amounts included in the seed mix as possible. A cumulative weight of approximately 7-31 grams of live seed was used for upland plots and approximately 15 grams of live seed at riparian plots (detailed description of seed mixes available in Appendix B). The target seeding rate was 50 live seeds per square foot. Information regarding the amount and location of seed collected for the seed mixes is available in Appendix C.

To aid in interpreting germination rates of target species, tetrazolium (TZ) tests were performed for 400 seeds of each species seed lot. TZ tests report the percent of seeds within a sample that are viable, meaning that they are capable of producing a plant under suitable germination conditions. These results were used to correct seeding rates to reflect the amount 
(grams) of pure live seed in seed mixes (Appendix B). Seed weights varied considerably by species (Appendix D).

Table 1-1: Target species by common and scientific name as well as 4-letter codon by which species are referred to throughout the document. All species were not seeded at all plots. For detailed information about which species were used in specific sets of plots see Appendixes A \& B.

\begin{tabular}{lll}
\hline Common Name & Scientific Name & Codon \\
\hline American trail plant & Adenocaulon bicolor & ADBI \\
Red columbine & Aquilegia formosa & AQFO \\
Columbia brome & Bromus vulgaris & BRVU \\
Dewey sedge & Carex leptopoda & CALE \\
Slough sedge & Carex obnupta & CAOB \\
Small enchanter's nightshade & Circaea alpina & CIAL \\
Miner's lettuce & Claytonia perfoliata & CLPE \\
Siberian springbeauty & Claytonia sibirica & CLSI \\
Blue wild rye & Elymus glaucus & ELGL \\
Western fescue & Festuca occidentalis & FEOC \\
Largeleaf avens & Geum macrophyllum & GEMA \\
Pacific waterleaf & Hydrophyllum tenuipes & HYTE \\
spreading rush & Juncus patens & JUPA \\
Small flower nemophila & Nemophila parviflora & NEPA \\
Sweet cicily & Osmorhiza berteroi & OSBE \\
Large-leaved penstemon & Penstemon ovatus & PEOV \\
California figwart & Scrophularia californica & SCCA \\
Coastal hedgenettle & Stachys chamissonis $v$. cooleyae & STCH \\
Fringecup & Tellima grandiflora & TEGR \\
Fender's meadowrue & Thalictrum polycarpum & THPO \\
Youth on age & Tolmiea menziesii & TOME \\
Stinging nettle & Urtica dioica & URDI \\
Inside out flower & Vancouveria hexandra & VAHE \\
\hline
\end{tabular}

Plot locations represented areas that were likely to be candidates for understory restoration; occurring in natural areas with a history of invasive species management, with low herbaceous cover and diversity, with few to no shrubs present, and on predominantly gentle slopes. For ease of monitoring and to replicate site conditions more closely, plots were installed within $50 \mathrm{~m}$ of one another. Plots were circular with the centers semi-permanently marked with either whisker flags or carbonite posts. The plot boundaries and their subplots were found and 
laid out at the time of monitoring

(Figure 1-2). USIP team

members monitored the plots at

the time of installation, and

follow-up monitoring was

conducted in spring and fall for

three years after installation.

Beyond the third-year post-

seeding, monitoring was

conducted in the summer only.

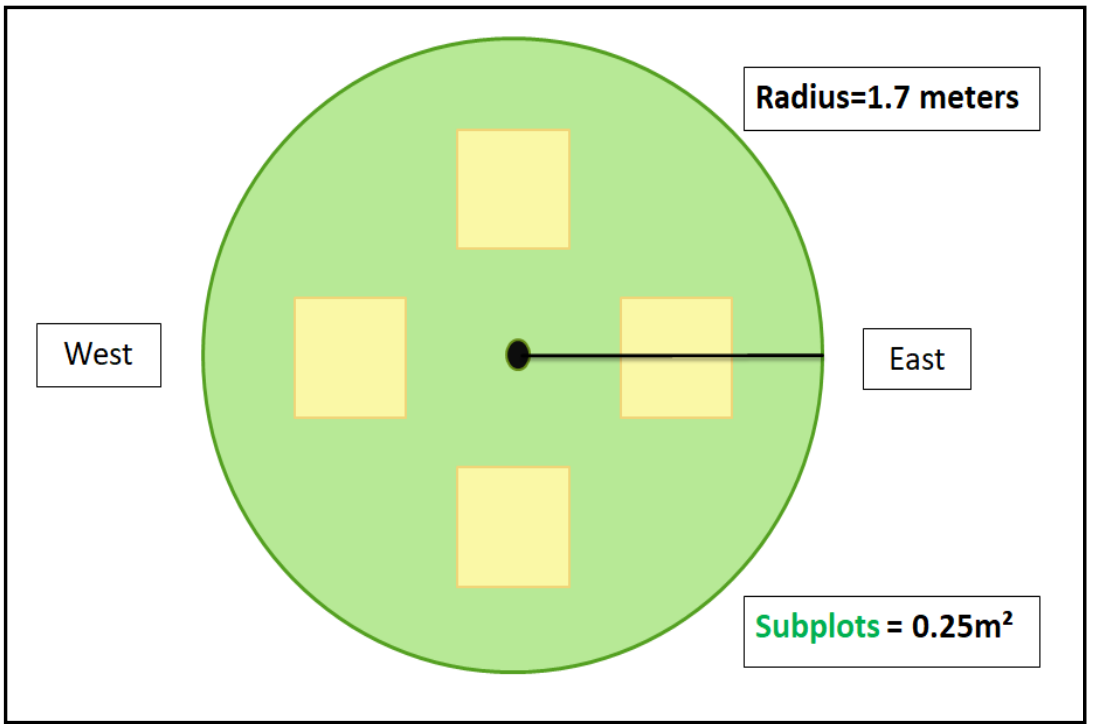

Figure 1-2: Plot Layout. Area is approximately 9 meters $^{2}$. Subplots are located half-way between center and outer perimeter in every cardinal direction.

Extenuating circumstances resulted in the inability to continue to monitor two sites over the period of this study. This includes Fanno Creek - Ash to Main, where plots were washed out during a high flow event, and Ramsey, where a homeless camp was established that created safety concerns. Ramsey was monitored up to two years following seeding and was one of only two sites using the riparian seed mix; therefore, the data for this site was included in analyses from those years (1-2 years post-seeding). Fanno Creek - Ash to Main had more limited data and was excluded from all analyses within this study. Neither site was included in analysis of sitelevel data collected during the 2020 field season.

\section{West Multnomah Trial Plots}

In fall of 2018, West Multnomah Soil and Water Conservation District (WM) installed additional understory trial-plots at 8 privately-owned sites. While the majority of plot setup and monitoring activities were consistent with USIP protocols described in this document, an additional treatment was also attempted at a subset of plots. Plots were installed in groups of 6 at 
all but one site which was smaller in size and therefore limited to 2 plots. The plots were equally divided into the following three treatments: raked and seeded, raked and control, and unraked and seeded with a less-diverse seed mix (this treatment was not included at the small site). This final treatment was unique to the WM plots; therefore, these plots have been excluded from further analyses within this document. This resulted in a total of 30 plots from WM that were included in all aspects of this study, unless explicitly stated otherwise. General locations of these sites are shown in Figure 1-1.

\section{Vegetation Monitoring}

The northern- and southern-most points of each plot were marked by measuring 1.7 meters in each direction from semi-permanently marked plot centers, using a compass to verify cardinal direction. Subplots were laid out using a PVC $0.5 \mathrm{~m}$ x $0.5 \mathrm{~m}$ square, placed halfway from the plot center and the flags marking the plot's outer perimeter. All data was recorded digitally using the Fulcrum application on an iPad. The following data were collected: percent cover of any species occurring within the plot if greater than 5\%, presence of any target species occurring directly outside the plot (in square meters), stem counts of all species within subplots, and cover of moss and wood within the plot. Photo monitoring was also conducted, consisting of 3 pictures per plot: one landscape photo of the plot standing at a specified direction, one looking down from the plot center, and one looking up at the canopy above from the plot center.

\section{Collection of Environmental Predictors}

Environmental variables were measured at different spatial scales: plot level, site level, site + treatment level (control or seeded). Analyses were sometimes performed at the set level, for which seed mix composition varied. In some cases, the methodology of data collection was not consistent between USIP and WM sites, or certain predictors were recorded only at USIP 
sites; in such instances, USIP data was prioritized over WM data. This included collection of nutrient data via Plant Root Simulator probes, as well as soil moisture and temperature data collected with in-situ soil sensors attached to data loggers. Figure 1-3 summarizes data collected at each hierarchical level within the experimental design, and Table 1-2 describes methods of data collection for each predictor. Detailed descriptions of specific data collection methods are available in Appendix E.

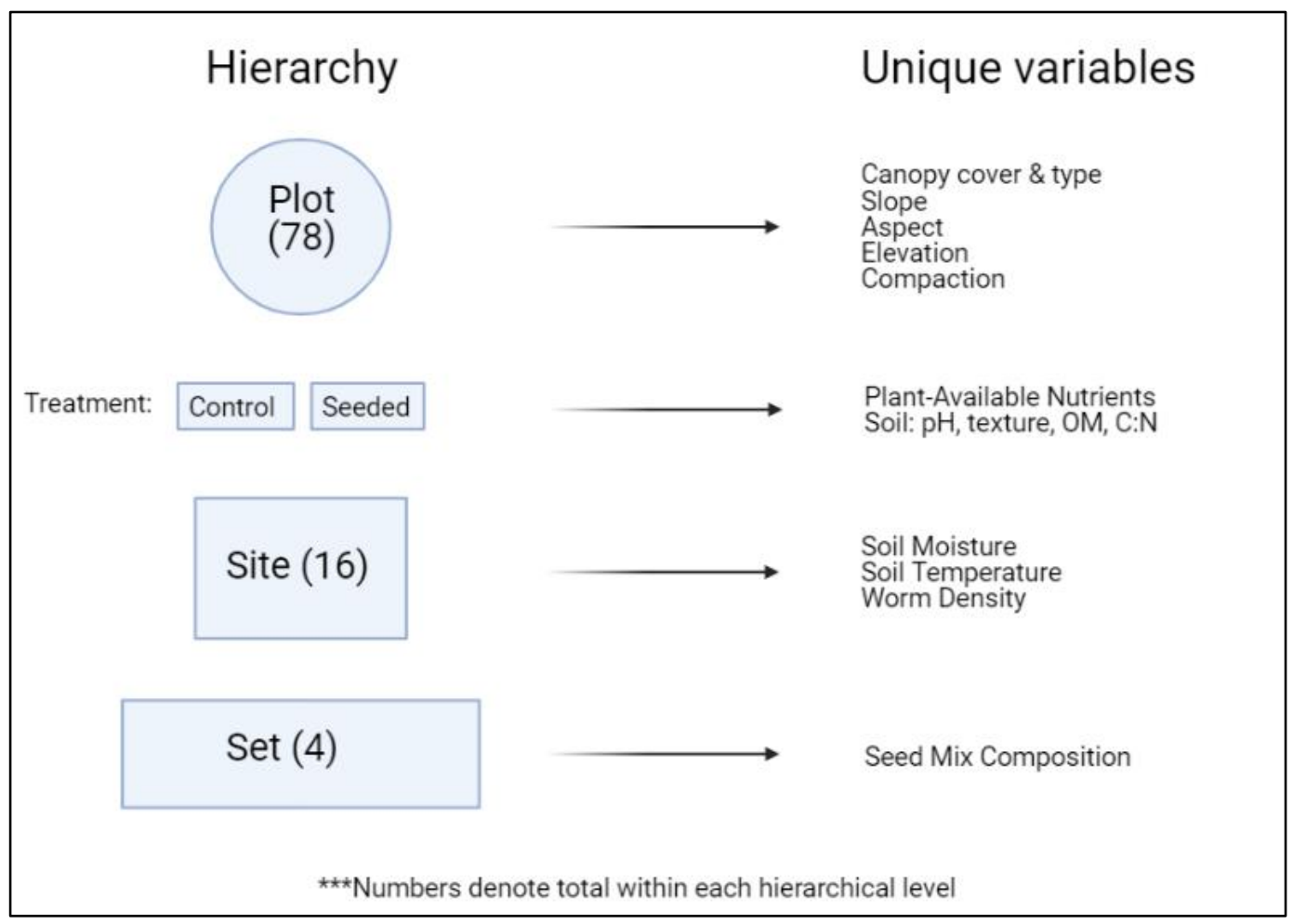

Figure 1-3: Predictor conceptual model showing experimental hierarchy and predictors collected for each level. Treatment level predictors are collected at the site + treatment level. 
Table 1-2: Collection methods and units of environmental predictors.

\begin{tabular}{|c|c|c|c|}
\hline Category & Variable & Collection Method & Units \\
\hline \multirow[t]{5}{*}{ Landscape } & Canopy Type & Visual estimate & $\begin{array}{l}\text { Categorical: } \\
\text { Coniferous (if }>80 \% \text { ) } \\
\text { Deciduous (if }>80 \% \text { ) } \\
\text { Mixed (if }<80 \% \text { either) }\end{array}$ \\
\hline & Canopy Cover & Densiometer & $\%$ \\
\hline & Slope & Clinometer & Degrees \\
\hline & Aspect & Compass & Degrees \\
\hline & Elevation & Derived using National Map & Meters \\
\hline \multirow[t]{6}{*}{ Soil Properties } & Texture & & $\%$ sand, \%silt, \%clay \\
\hline & $\mathrm{pH}$ & Composite samples ( 4 cores per plot) air dried & Unitless \\
\hline & C:N & and sent to OSU soils lab for analysis & Ratio \%C: \%N \\
\hline & $\mathrm{OM}$ & & $\%$ \\
\hline & Compaction & Penetrometer & Pounds per square inch \\
\hline & Worm density & $\begin{array}{l}\text { Modified mustard vermifuge multi-plot method } \\
\text { (McCay, 2013) }\end{array}$ & \# per 0.25 square meter \\
\hline Soil Nutrients & $\begin{array}{l}\mathrm{NO}_{3}, \mathrm{NH}_{4}, \mathrm{P}, \mathrm{K} \\
\mathrm{S}, \mathrm{Mg}, \mathrm{Ca}\end{array}$ & $\begin{array}{l}\text { Plant-root simulator (PRS) probes: } 28 \text {-day burial } \\
\text { in } 2 \text { periods: spring and fall }\end{array}$ & $\left(\mu \mathrm{g} / 10 \mathrm{~cm}^{2} / 28\right.$ days $)$ \\
\hline $\begin{array}{l}\text { Soil Moisture } \\
\& \\
\text { Temperature }\end{array}$ & $\begin{array}{l}\text { Water Content } \\
\text { Soil Temp. }\end{array}$ & $\begin{array}{l}\text { In-situ soil probes buried at } 4-\& \text { - inch depth. } \\
\text { Data logger records measurements every } 15 \\
\text { minutes from May-November }\end{array}$ & $\begin{array}{l}\mathrm{m}^{3} / \mathrm{m}^{3} \\
\text { Degrees Celsius }\end{array}$ \\
\hline
\end{tabular}

\section{Statistical Analysis}

All statistical analyses of trial plot data were performed using $\mathrm{R}$ version 4.0.4 (R Core

Team 2019). This analysis had four broad objectives: 1) Assess overall effectiveness of seeding treatment by comparing germination, cover, and native species richness between seeded and control plots throughout the years of monitoring and investigate what, if any, level of invasive suppression resulted from the seeding of native species; 2) Investigate species performance to determine which species showed strongest germination from seed; 3) investigate site factors that may have influenced germination by analyzing stem counts 1-2 years following seeding; and 4) investigate site factors that may have influenced cover, our best proxy for establishment, by analyzing data from 2020 vegetation monitoring of USIP plots 3-4 years following seeding. I 
decided not to analyze cover data from WM plots because the sites were relatively young (2 years), and we were interested in more long-term establishment of cover.

These data did not meet assumptions of normality or homoscedasticity, and therefore all analyses performed were non-parametric in nature.

\section{Treatment Performance}

Vegetation data from all spring and summer monitoring sessions were compiled and used to calculate mean annual stem counts and cover per plot, to account for uneven monitoring events that could inflate the importance of plots monitored for two sessions compared to a single session. Species were categorized based on their status as either target (native species that were part of the seed mix at a select group of plots), native, exotic, or invasive (non-natives that are known to form monocultures and crowd out native species), using information obtained from the Portland Plant List (City of Portland, 2016). During monitoring, some stems could only be identified to the genus level. If multiple species from a genus were known to occur from different categories (native/non-native), they were categorized as unknown.

It was decided to look at treatment performance metrics on a years-post seeding basis to aid in viewing temporal trends in the persistence of seeded species. In many instances it was also useful to view trends based on set (year installed + upland/riparian seed mix). To determine statistical significance of observed differences between treatments Wilcoxon Rank-based tests were utilized as a non-parametric alternative to a paired t-test.

\section{Species Performance}

To determine which species were most successful from seed, average stem counts were calculated for target species in each set of plots, as seed mix composition varied between sets. Due to the limited data available for riparian plots (only one site was monitored more than 2 
years following seeding), in addition to the poor performance of the remaining site, this set was not included in the analysis of species performance. To account for species that may be naturally occurring in the soil seed bank, mean stem counts in control plots were subtracted from their seeded counterparts to create a corrected number of mean stems per species per plot. Using the weight of each species included in the seed mix in combination with data on average seeds per pound (Appendix D), the percent of live seeds per species was also calculated. I used percent of total seeds rather than percent by weight because the weight of individual seeds is highly variable between species (between 100-15,419 seeds/lb. for upland species). A final performance metric was created by calculating the average number of corrected stems per $1 \%$ of total seeds in seed mix.

Due to difficulties in distinguishing between seedlings of certain species, some species were lumped together for this analysis. These groupings include: Claytonia perfoliata and Claytonia sibirica (CLSPP), Elymus glaucus and Bromus vulgaris (ELGL.BRVU), and Tolmiea menziesii and Tellima grandiflora (TEGR.TOME).

A second performance metric was created to assess the percentage of plots that species were present at compared to the number of plots in which they were originally sown. This analysis utilized 2020 monitoring data so that species that may have originally germinated but not persisted in their seeded environments would not be included. This metric was determined using both cover and stem count data to capture all species present. Control plots were excluded from this analysis as no species were seeded within them.

\section{Environmental Predictors}

Investigations into site factors influencing germination and cover were conducted separately but using similar techniques, including exploration of multivariate assemblage data 
with Non-metric Multidimensional Scaling (NMDS), as well as Generalized Linear MixedModels (GLMMs) to model counts of target stems and cover. These techniques were selected based on the non-parametric nature of the data, as well as a failure to meet assumptions of independence of observations and homogeneity of variance between groups.

Given the large array of environmental predictor data gathered for this analysis, a variable selection process was used to identify the strongest predictors that warranted further investigation. The first step was to divide predictors into the following categories:

1. Landscape variables: slope, aspect, elevation, canopy cover, and canopy type

2. Soil properties: C:N, OM. pH, texture, worms, and compaction

3. Nutrients: spring and fall measurements, mean, and flux of $\mathrm{N}, \mathrm{P}, \mathrm{K}, \mathrm{Ca}, \mathrm{Mg}$, and $\mathrm{S}$

4. Moisture and Temperature: mean, max, min, range, and coefficient of variation for soil moisture and temperature at 4- and 8-inch depths.

Treatment remained as a singular category, as this was the primary manipulated variable in the study. Measures of both invasive species cover and stem counts were also explored. For both cover and germination, predictors were initially reduced based on Spearman correlation coefficients to select the strongest predictors in each category to be explored in further NMDS and GLMM analyses. Because control plots represented structural zeros for target cover and stem counts (nothing was seeded, meaning the design itself likely creates zeros for target species metrics), correlation coefficients were explored for all plots (control and seeded) and all seeded plots separately. This generally produced similar results but stronger correlation coefficients for seeded plots alone. This exploration also provided evidence of a high degree of multicollinearity in predictors, necessitating further predictor selection prior to running GLMMs. Only relationships with a correlation coefficient of $>0.2$ were selected to move forward. In cases 
where variables were highly correlated to one another due to a known relationship (i.e.: \% Sand v. Silt v. Clay; OM and C:N—both derived from soil C; and various moisture and temperature covariates) the variable with the strongest relationship was selected.

\section{$\underline{\text { NMDS }}$}

Non-metric Multidimensional Scaling (NMDS) was selected to visualize differences in understory assemblages between plots based on the non-parametric and non-independent nature of the data. The NMDS plots were created for 2 dimensions using Bray-Curtis dissimilarity distances (Clark et al., 2006), using the "vegan" package in R (Oksanen et al., 2020). The best NMDS model out of 20 runs in terms of lowest stress value was selected. Significant environmental predictor variables $(\mathrm{p}<0.05)$ were fitted to the NMDS plot using the "envfit" function from the "vegan" package, run with 999 permutations.

\section{$\underline{\text { Generalized Linear Mixed Models }}$}

Generalized Linear Mixed Models (GLMMs) allow for non-independence of observational units that have a hierarchical structure by allowing the user to specify random and fixed effects (Harrison, 2017). This was the case with USIP plot data that was nested within sites, as it would be expected that plots within the same site would be more similar to each other than to plots from other sites. We then specified site as a random effect so that the GLMM would explicitly model this nonindependence (Harrison, 2018). Additionally, GLMMs offered an approach to deal with psuedoreplication that could result from using multiple years of monitoring data for stem counts, as there were repeated measurements from individual plots.

Prior to fitting GLMMs a Spearman's correlation coefficient matrix was used to investigate collinearity of predictors. As suggested by Dormann et al. (2013), predictors with a correlation of greater than \pm 0.7 were considered collinear and dealt with by dropping the 
predictors with a lower correlation to the response variable. For both cover and stem counts the data was zero-inflated and/or overdispersed, which resulted in the need to use the "glmmTMB" package which allows for a negative binomial distribution and enables zero-inflation resulting from structural zeros to be explicitly modeled. Predictor values were scaled by centering and subtracting corresponding values from center prior to running models. The best model was determined using an information theory (IT) approach comparing model Akaike Information Criterion (AIC), a measure of how well the model fits the data, through forward selection (Harrison et al., 2017). Models within an AIC score of 6 points from the best-supported model were considered equally well supported (Harrison et al., 2017). Models were validated using diagnostics from the "DHARMa" package which relies on a simulation-based approach to check model residuals versus fitted values and to check for zero-inflation and overdispersion (Hartig, 2020).

\section{$\underline{\text { Germination and Environmental Predictors }}$}

Stem count data from years 1-2 post-seeding were used for all USIP and West Multnomah plots. Due to soil data being collected in 2020, predictors such as plant-available nutrients and specific soil moisture and temperature measurements could not be analyzed with respect to germination data from 2017-2019, as such measures have high temporal variability (Morse, 2012, Groffman, 1987). Rather, variables within the landscape and soil properties categories were used. Additionally, soil temperature and moisture coefficient of variation were retained to investigate whether variability in these metrics had detectable effects on germination.

\section{NMDS:}

Species assemblage data were compiled using subplot stem counts for yearly averages of all plots 1-2 years post-seeding, excluding unknown plants and tree seedlings to focus on 
understory plant assemblages. To minimize the importance of rare taxa, species with less than 50 total stem counts were removed from the data frame, reducing the total number of species from 179 to 58 . Stem counts were manipulated by adding a small constant $(0.1)$ and square root transforming to minimize the importance of dominant taxa and reduce model stress.

\section{GLMM}

For stem counts, only a single set of predictors, worm density and altitude, were found to have a Pearson's correlation greater than 0.7 and thus were considered collinear. Due to worm density having a stronger correlation to target stem counts, altitude was not included in further GLMM analyses. Due to data from two years of monitoring being used, plot was specified as a random effect (1|plot) to avoid psuedoreplication from repeated measures.

\section{$\underline{\text { Cover and Environmental Predictors }}$}

Cover was investigated using 2020 cover data from USIP plots only, as these plots had been established for a longer period (3-4 years) and plant-available nutrient and soil moisture and temperature data were collected for these sites alone. This included data from 42 plots at 7 sites within 5 different natural areas.

\section{$N M D S$}

Assemblage data were compiled excluding unknown plants and tree seedlings to focus on understory species. There was a total of 32 species included in the data frame. Cover data was manipulated by adding a small constant $(0.1)$ and square root transforming to minimize the importance of dominant taxa and reduce model stress.

\section{GLMM}

There were several instances of target cover predictors showing collinearity using a Pearson's correlation coefficient of 0.7 as a limit. This was especially true of the soil moisture 
and temperature metrics, and thus it was decided to only keep mean water content at 8-inch depth, as it demonstrated the strongest Pearson's correlation coefficient to target cover. Plantavailable phosphorus was collinear with both $\mathrm{K}$ and $\mathrm{OM}$, so it was also dropped. Due to data only including a single year of monitoring, there were no repeated measures to account for in this portion of the analysis. 


\section{Analysis and Results:}

\section{Treatment Performance}

When compared cumulatively across years, seeded plots were significantly higher $(\mathrm{p}<$ 0.05) than control plots in three measures of performance: mean stem counts, cover of target species, and mean native species richness (see Table 1-3). There were significant differences between seeded and control plots in germination of target species and native species richness in all year-wise comparisons. For cover, statistically significant differences $(p<0.05)$ were only found in 2-year post seeding data; however, there were moderately significant $(0.05<\mathrm{p}<0.1)$ differences in 3-year post seeding data. It is important to note that sample size is much smaller in 3- and 4-year data due to the varying years of plot installation, so these differences may grow to be significant once 3- and 4- year data has been collected for all plots. Additionally, a large amount of cover of a single species (HYTE) at several sites accounts for most of the cover at control plots, as further discussed in subsequent sections (Figure 1-10).

Table 1-3: Mean stem counts and cover of target species and native species richness in control versus seeded plots. The number of plots vary by year post-seeding due to different years of plot installation. Asterisks represent statistical significance $(\mathrm{p}<0.05)$ of Wilcoxon tests.

\begin{tabular}{|c|c|c|c|c|c|c|c|c|c|c|}
\hline \multirow{2}{*}{$\begin{array}{c}\text { Year } \\
\text { post- } \\
\text { seeding }\end{array}$} & \multirow{2}{*}{$\begin{array}{c}\# \\
\text { plots }\end{array}$} & \multicolumn{3}{|c|}{ Target Cover (\%) } & \multicolumn{3}{|c|}{ Target Stem Counts $\left(\mathbf{m}^{-2}\right)$} & \multicolumn{3}{|c|}{ Native Species Richness } \\
\hline & & Control & Seeded & $p$-value & Control & Seeded & p-value & Control & Seeded & p-value \\
\hline 1 & 78 & 8.9 & 7.8 & 0.158 & 21.9 & 157.9 & $<0.001 *$ & 3.7 & 9.9 & $<0.001^{*}$ \\
\hline 2 & 78 & 10.1 & 18.3 & $<0.001 *$ & 17.2 & 111.8 & $<0.001 *$ & 4.2 & 10.9 & $<0.001 *$ \\
\hline 3 & 42 & 11.7 & 21.9 & 0.088 & 19.7 & 72.4 & $<0.001 *$ & 2.3 & 6.7 & $<0.001^{*}$ \\
\hline 4 & 24 & 9.3 & 15.8 & 0.273 & 5.8 & 26.8 & $0.006^{*}$ & 1.7 & 3.5 & $0.026^{*}$ \\
\hline Cumulative & 222 & 9.9 & 15.0 & $<0.001^{*}$ & 18.1 & 111.4 & $<0.001 *$ & 3.4 & 8.9 & $<0.001^{*}$ \\
\hline
\end{tabular}


Performance of seeded plots varied by set (landscape position + year of installation), as shown in Figure 1-4. Most notably, the riparian plots had a particularly poor performance. While there were slight variations in the seed mix utilized between all sets of plots, the riparian seed mix was the most dissimilar. In addition, the number of riparian plots was also the most limited, with 12 total plots installed and only 6 plots that were monitored for more than 2 years following seeding. Upland
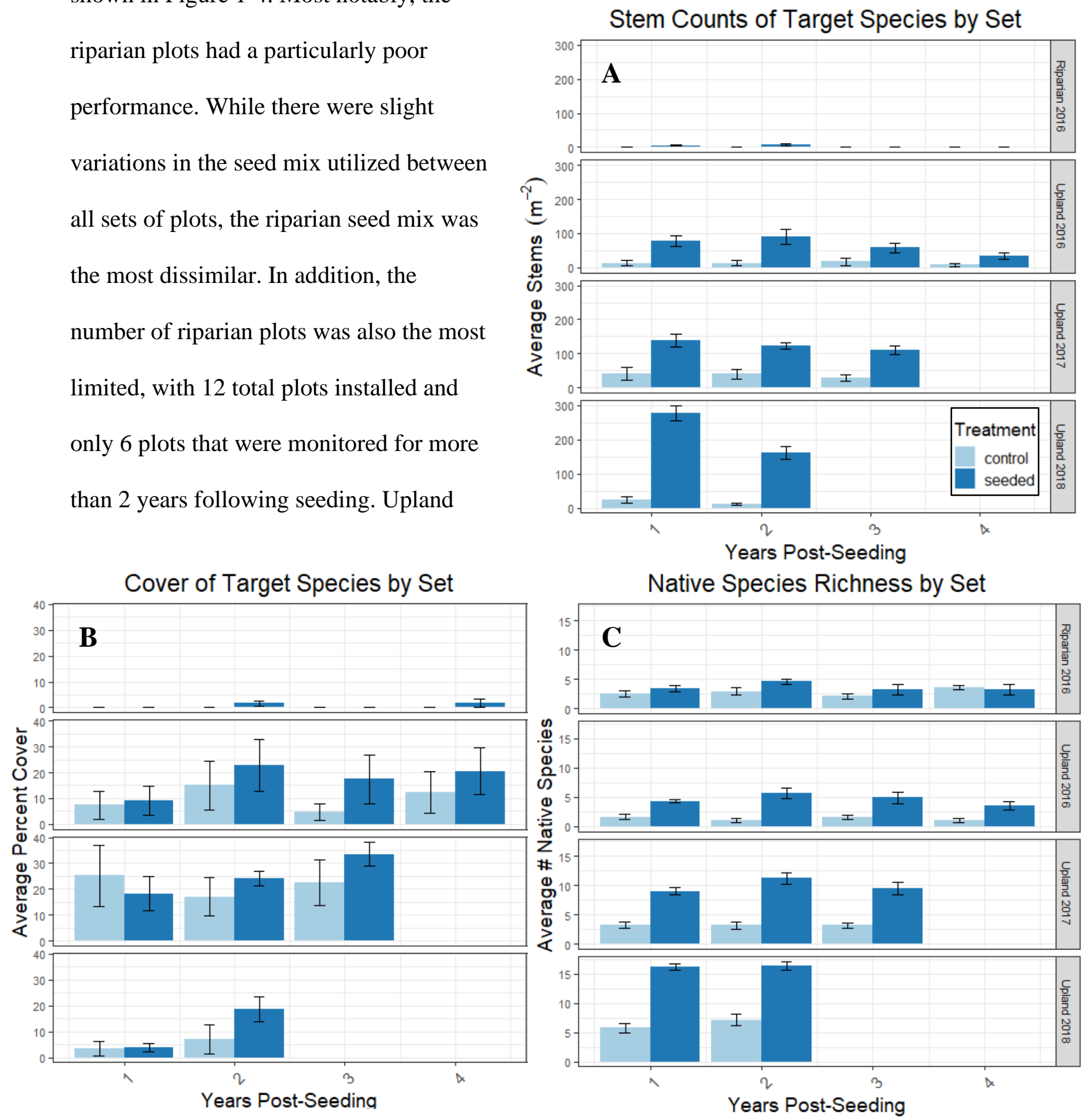

Figure 1-4: Target species metrics by set showing mean plot-level A) Stem Counts of target species, B) Cover of target species, and C) Native species richness in control versus seeded plots over yearspost seeding and arranged by set. Error bars indicate standard error. 
plots installed in 2018 outperformed upland plots installed in 2017 and 2016 in the metrics of germination and native species richness. Upland plots installed in 2017 outperformed those installed in 2016 in these same metrics. The metric of cover in 2-year post seeding data was similar between upland sets for seeded plots. However, more control plots also established target cover in 2016 and 2017 installed upland plots. Despite the varied level of performance by set, seeded plots continued to outperform control plots in these three metrics.

To investigate whether revegetating the herbaceous layer prevented reinvasion from occurring, invasive species stem counts and cover were compared between seeded and control plots. Both metrics were highly variable between sets (Table 1-4). Despite a generally lower presence and cover of invasive in seeded plots (mean cover: $4.36 \% \pm 9.85$ control and $2.57 \% \pm$ 6.70 seeded; mean stem counts: $34.89 \pm 70.45$ control, $19.55 \pm 43.07$ seeded), no statistically significant differences were determined.

Table 1-4: Mean cover and stem counts of invasive species shown by sets of plots and year post-seeding.

\begin{tabular}{|c|c|c|c|c|c|c|}
\hline \multirow{2}{*}{$\begin{array}{c}\text { Years } \\
\text { post-seeding }\end{array}$} & \multirow{2}{*}{ Set } & \multirow{2}{*}{ \# plots } & \multicolumn{2}{|c|}{ Cover $(\%)$} & \multicolumn{2}{|c|}{ Stem Counts $\left(\mathrm{m}^{-2}\right)$} \\
\hline & & & Control & Seeded & Control & Seeded \\
\hline \multirow{4}{*}{1} & Riparian 2016 & 6 & 5 & 1 & 63 & 27 \\
\hline & Upland 2016 & 9 & 6 & 1 & 37 & 5 \\
\hline & Upland 2017 & 9 & 0 & 0 & 1 & 2 \\
\hline & Upland 2018 & 15 & 1 & 1 & 40 & 14 \\
\hline \multirow{4}{*}{2} & Riparian 2016 & 6 & 14 & 6 & 70 & 39 \\
\hline & Upland 2016 & 9 & 4 & 0 & 41 & 16 \\
\hline & Upland 2017 & 9 & 0 & 1 & 2 & 1 \\
\hline & Upland 2018 & 15 & 8 & 5 & 28 & 13 \\
\hline \multirow{3}{*}{3} & Riparian 2016 & 3 & 12 & 11 & 184 & 177 \\
\hline & Upland 2016 & 9 & 3 & 2 & 39 & 28 \\
\hline & Upland 2017 & 9 & 0 & 0 & 1 & 1 \\
\hline \multirow{2}{*}{4} & Riparian 2016 & 3 & 15 & 8 & 83 & 48 \\
\hline & Upland 2016 & 9 & 2 & 7 & 18 & 24 \\
\hline
\end{tabular}

While no statistically significant benefits of seeding for invasive suppression were found, there was evidence of an inverse relationship between target cover and invasive species stems 
(Figure 1-5). Despite several exceptions, there are generally fewer seeded plots with high levels of invasive stems and more seeded plots with established target cover while the opposite is true for control plots.

Breaking down this relationship by set (Figure 1-6) further highlights the variability in performance at this level. Again, the riparian set suffers from poor performance, with limited target cover and relatively high invasive species stems. The upland sets have more similarities except that plots installed in 2017 have virtually no invasive stems present. All upland sites have at least one control plot with high target cover; but generally, follow trends of more seeded plots than control plots attaining target cover.

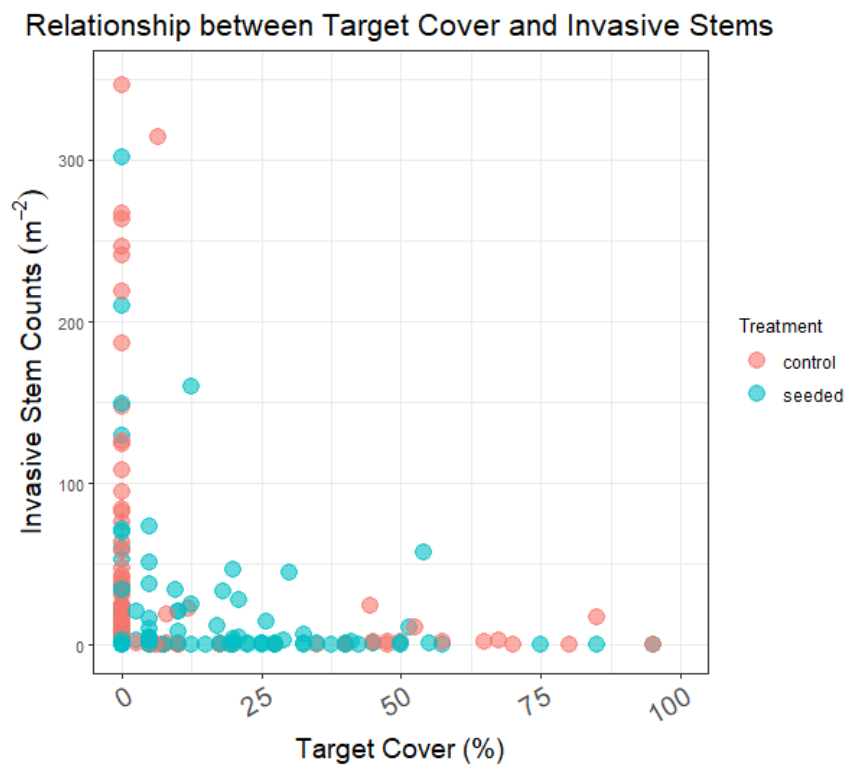

Figure 1-5:Target cover and invasive species stem counts relationship using yearly average data.

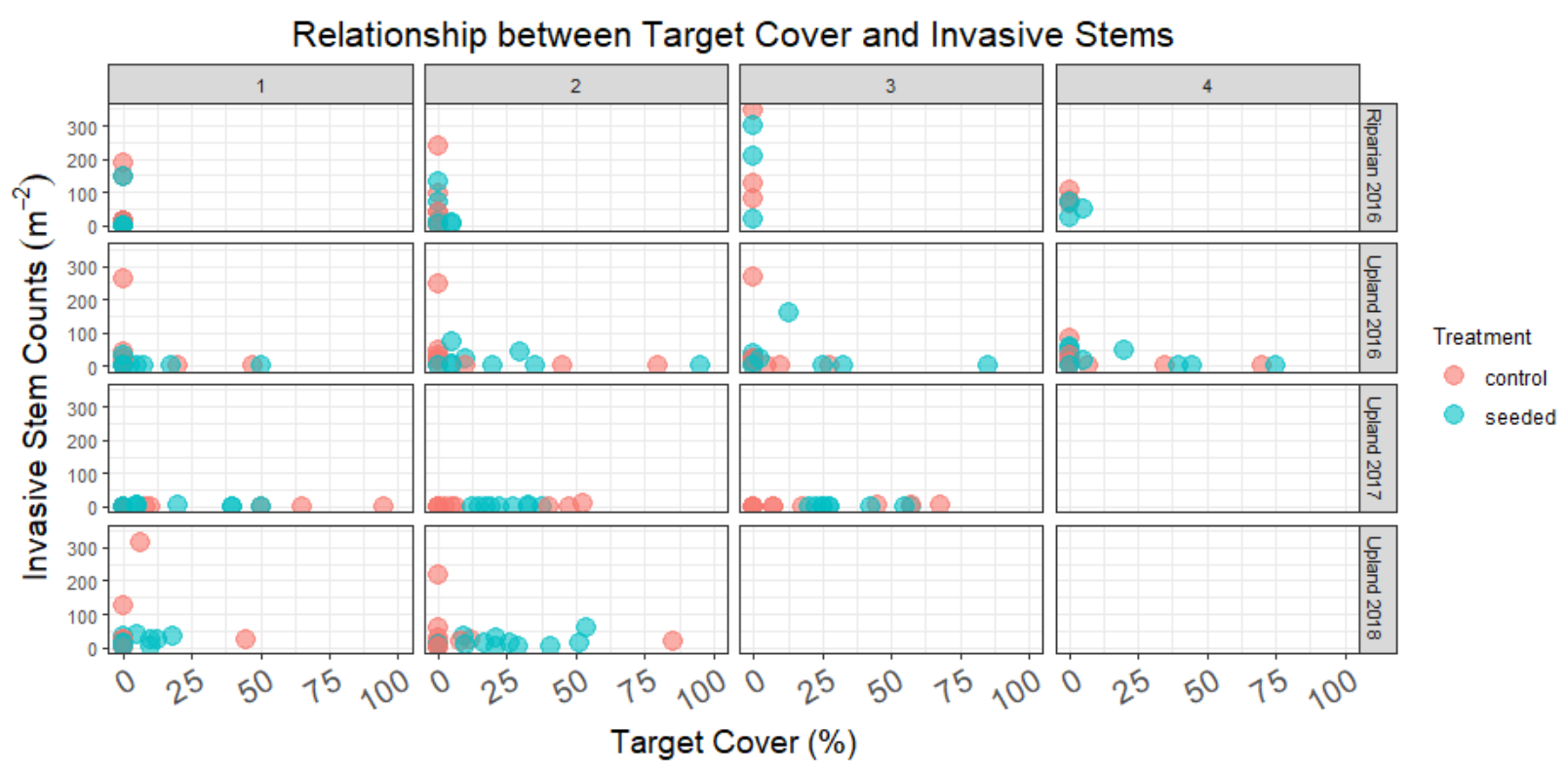

Figure 1-6: Target cover and invasive species stem counts relationship by set shown by years postseeding horizontally. 
Species Performance

Performance of

species from the upland seed

mixes varied greatly by

species (Figure 1-7), with

the top performer reaching

nearly 4 stems $/ \mathrm{m}^{2} / 1 \%$ of

seed mix (Osmorhiza

berteroi) and lowest

performers having only

negligible stem counts
Species Stems per $1 \%$ of Seed Mix

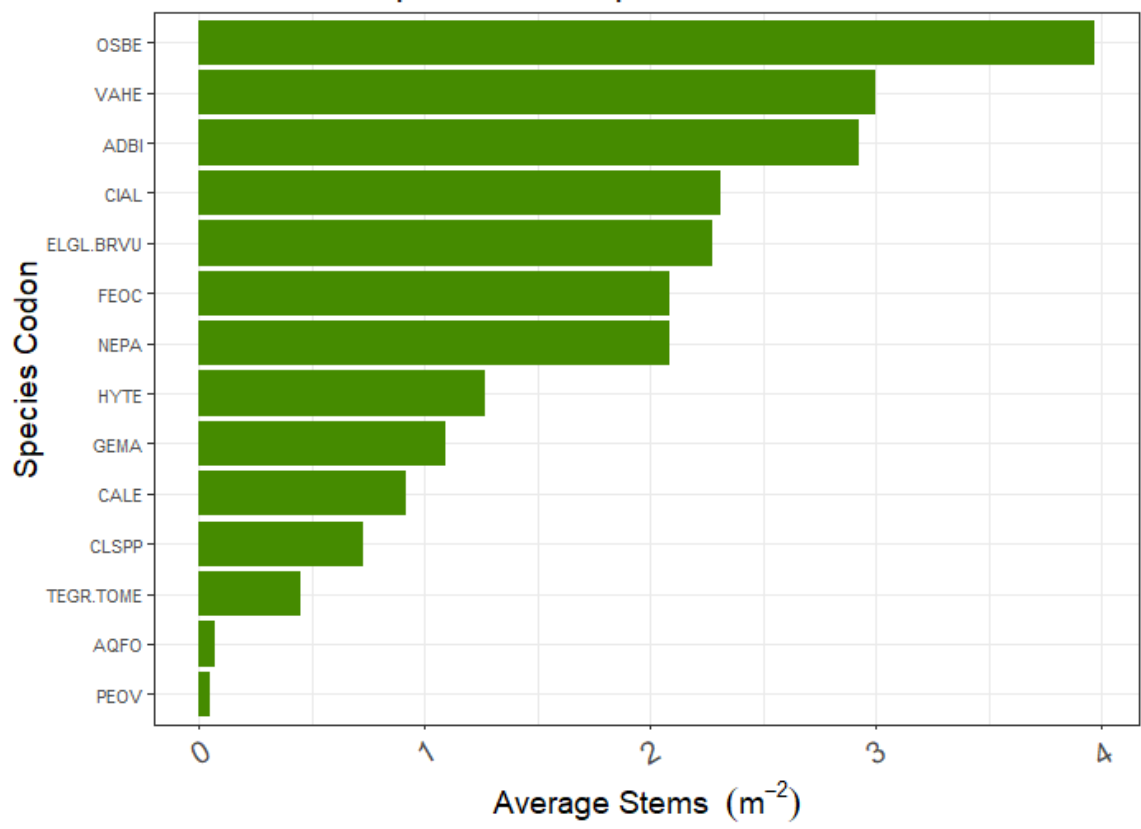

Figure 1-7: Species performance metric showing average stems per $\mathrm{m}^{2}$ per $1 \%$ of the total number of seeds in the seed mix.

$(<0.10)$. After removing the bottom two performers (Aquilegia formosa and Penstemon ovatus),

as they did not show much promise from seed, the group average was approximately 2

stems $/ \mathrm{m}^{2} / 1 \%$ seed mix. The top $50 \%$ of performers included 3 grass and 5 forb species.

Correcting for seeds naturally occurring in the soil seed bank by subtracting control stem counts was a necessary step given the high occurrence of certain species, primarily Hydrophyllum tenuipes (HYTE) and to a lesser degree Claytonia sibirica (CLSPP here), in control plots. There is, however, a chance that this correction turned into an overcorrection, bringing down the scores of these species. This is especially likely for HYTE, which had the highest non-corrected mean stem count before this correction was made.

Additionally, while grouping was necessary due to difficulties distinguishing between seedlings, this undoubtedly resulted in a loss of information about the performance of these individual species. Future trials should focus on testing species that are not easily distinguished 
in separate plots to aid interpretation of such data. For the ELGL.BRVU grouping, the species still scored relatively high in performance, but for Claytonia species (CLSPP) and TEGR.TOME, the low score could be due to a single species having poor performance, potentially bringing down the overall average.

Similar to previous analyses, investigating trends between sets of upland plots revealed interesting contrasts in species performance (Figure 1-8). This was especially evident for ELGL.BRVU which showed strong responses in plots installed in 2017 and 2018 but were completely absent in 2016 plots. It also highlights that VAHE and CIAL, two of the four top performers, were not included in 2016 and 2017 plots. This, in combination with the overall stronger response of species in the 2018 seed mix (keeping in mind the varying scale bars on the $\mathrm{x}$-axis), indicates there may be inflation of their performance scores. FEOC also showed much stronger establishment in 2018 plots, and NEPA had stronger performance in 2018 and 2016 plots than 2017 plots. Considering that the TZ test scores were already taken into account when calculating the proportion of live seeds, there is no clear explanation for these varying performances, but it could relate to seed sources, site conditions, or even diverging weather patterns in the years of installation.

Stems per $1 \%$ of seed mix reflect only average stem counts, and do not paint a picture of which species will effectively establish populations that persist in their seeded environments. Rather, this information will be useful in determining rates of seeding and indicating which species warrant further investigation in seeding trials. This metric also does not consider temporal trends, but rather looks at overall stem counts through the years. A similar analysis was done using only 1-2 years post-seeding data (Appendix G). This resulted in what were generally small shifts in species performance, with three species showing more considerable shifts. NEPA 


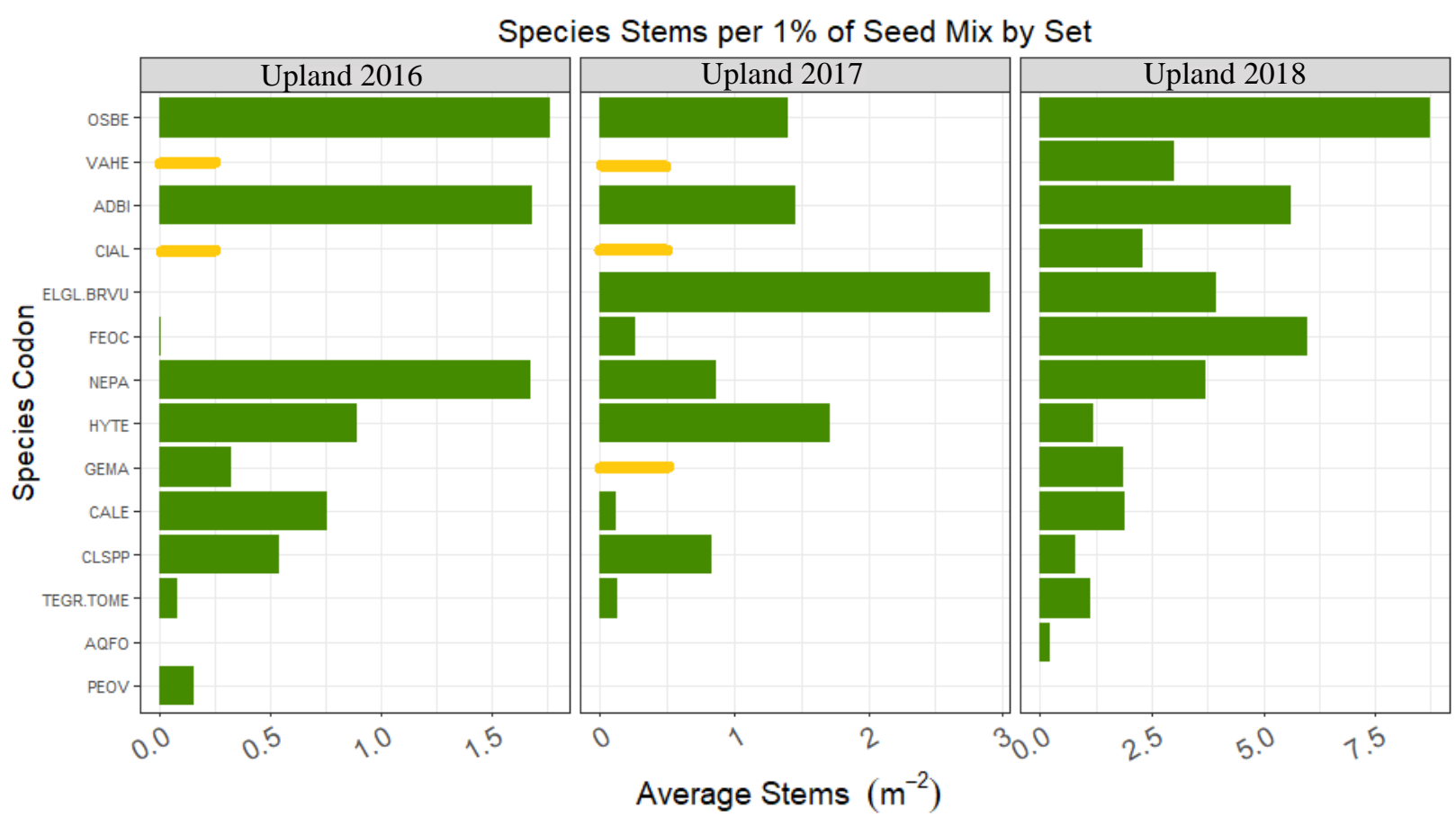

Figure 1-8: Species performance metric by set ((average seeded stems - average control stems) / percent of seeds). Yellow lines indicate species that were not included in respective seed mix.

showed a stronger performance in early years, and BRVU.ELGL showed a stronger performance in later years. It is possible that BRVU and ELGL take longer to establish from seed, but it is perhaps more likely that these scores are inflated in later years because the smaller sample size increases the importance of 2017 plots, for which these species performed very well. The change in NEPA's performance through time is likely a reflection of the changes in primary monitoring sessions from spring to summer after two years post-seeding, because it was observed that NEPA often had senesced to some degree by the time of summer monitoring. Despite these small shifts, the top and bottom $50 \%$ of species according to this performance metric were unchanged.

The presence of target upland species in 2020 monitoring was also used to evaluate the relative success of species. Figure 1-9 describes the number of seeded plots in which a species was present compared to the number of plots in which it was sown. A success rate was then calculated. This metric covers 2-4-year data depending on year of plot installation, giving some 
indication of persistence of seeds within the soil seed bank. In some instances, the success rate is greater than 100 due to the species being present in seeded plots for which it was not included in the seed mix. This metric also does not take into account the abundance of target species, but rather is useful in assessing how successful the species was in establishing in diverse locations. Again, this suggests that species installed at only the upland 2018 set had the strongest performance (CIAL, VAHE). There are several other consistencies with the previously presented performance metrics, with both ADBI and OSBE still showing a relatively strong performance, while $\mathrm{AQFO}$ and PEOV have poor performance. Other species that did not rank very high in the earlier performance metric, including HYTE, CALE, and the TOME.TEGR grouping, also performed better in this metric. This supports earlier assumptions that HYTE's low score in the previous metric of seeded stems $/ 1 \%$ of seed mix may have been an over correction due to its high presence at several control plots. Additionally, while grass species (ELGL.BRVU and FEOC) showed a high number of stems per $1 \%$ seed mix, their ability to establish at many sites was diminished, particularly for FEOC. Most target species (13 of 17) were able to establish to

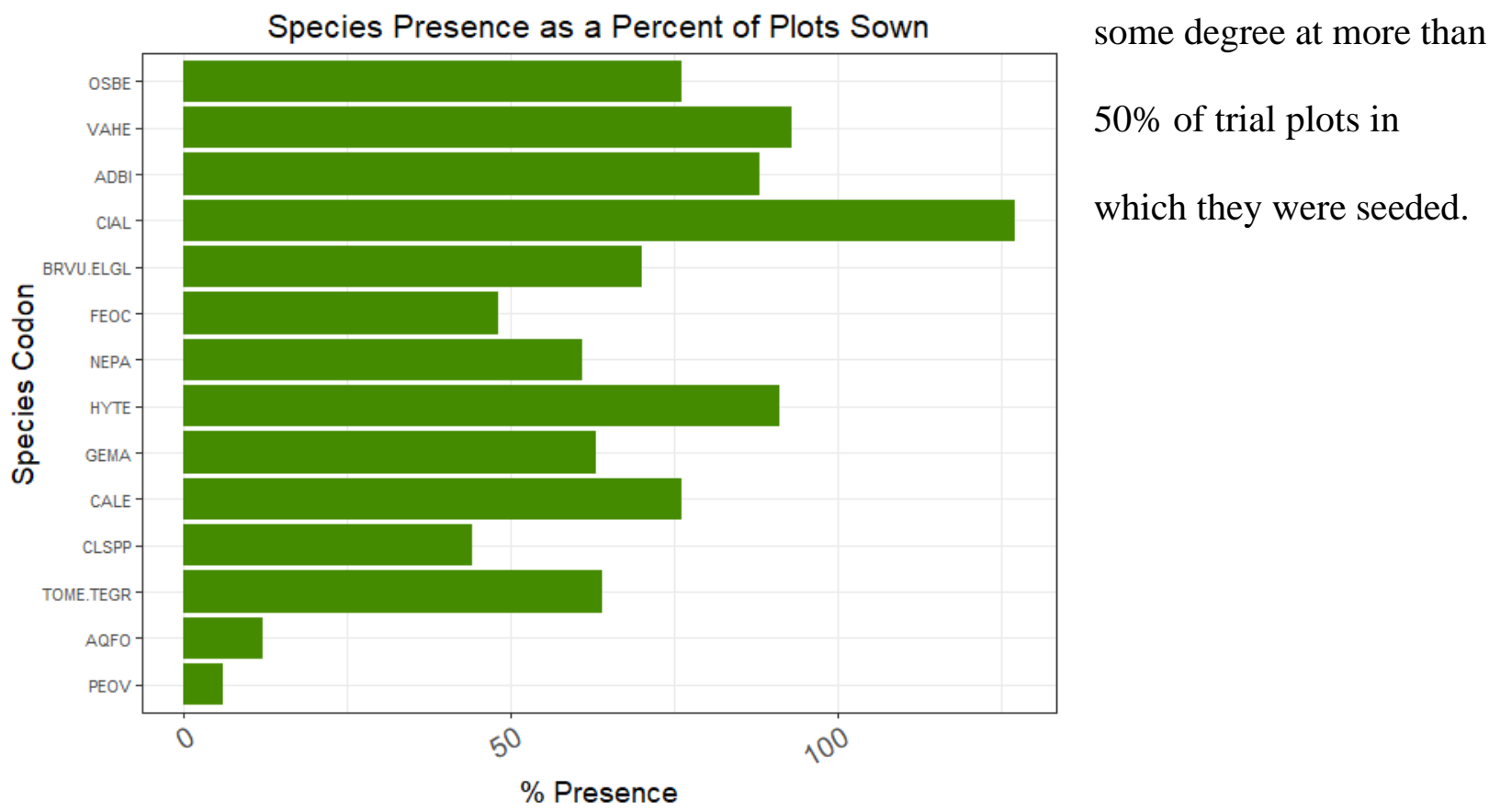

Figure 1-9 Species performance metric showing percent presence of target species during 2020 monitoring out of the total number of upland plots for which a species was seeded. 


\section{Performance by Site}

Initial analysis of trial plot data revealed substantial differences in the performance of the seeding treatments across sites. These differences were apparent in metrics of germination and cover to varying degrees (Figure 1-10). While all but three sites responded strongly to seeding with more than 50 target stems per square meter, only approximately half of the sites successfully established an average plot cover of $>20 \%$ target species by 2020 . Figure $1-10$ also highlights the dominance of Hydrophyllum tenuipes (HYTE) at several sites regardless of seeding treatment, which accounts for the control plot outliers in target cover (Figure 1-5). These differences in seeding outcomes by site prompted investigations into potentially influential site conditions. Plot level predictors are summarized in Table 1-5. While variables such as altitude and compaction have a wide range of values (7-312 ft and 62-262 psi), canopy cover has much less variation (81-97\%). Site-level soil predictors collected for USIP and West Multnomah are summarized in Table 1-6. Most of these variables have a wide range of values, while $\mathrm{pH}$ values are narrower (5.57-6.42). Site-level variables collected for only USIP plots are summarized in Table 1-7. Values were also highly varied across sites for most nutrients, apart from ammonium $\left(\mathrm{NH}_{4}{ }^{+}\right)$, for which values were low $\left(\leq 10 \mu \mathrm{g} / 10 \mathrm{~cm}^{2} / 28\right.$ days $)$ at all sites. 


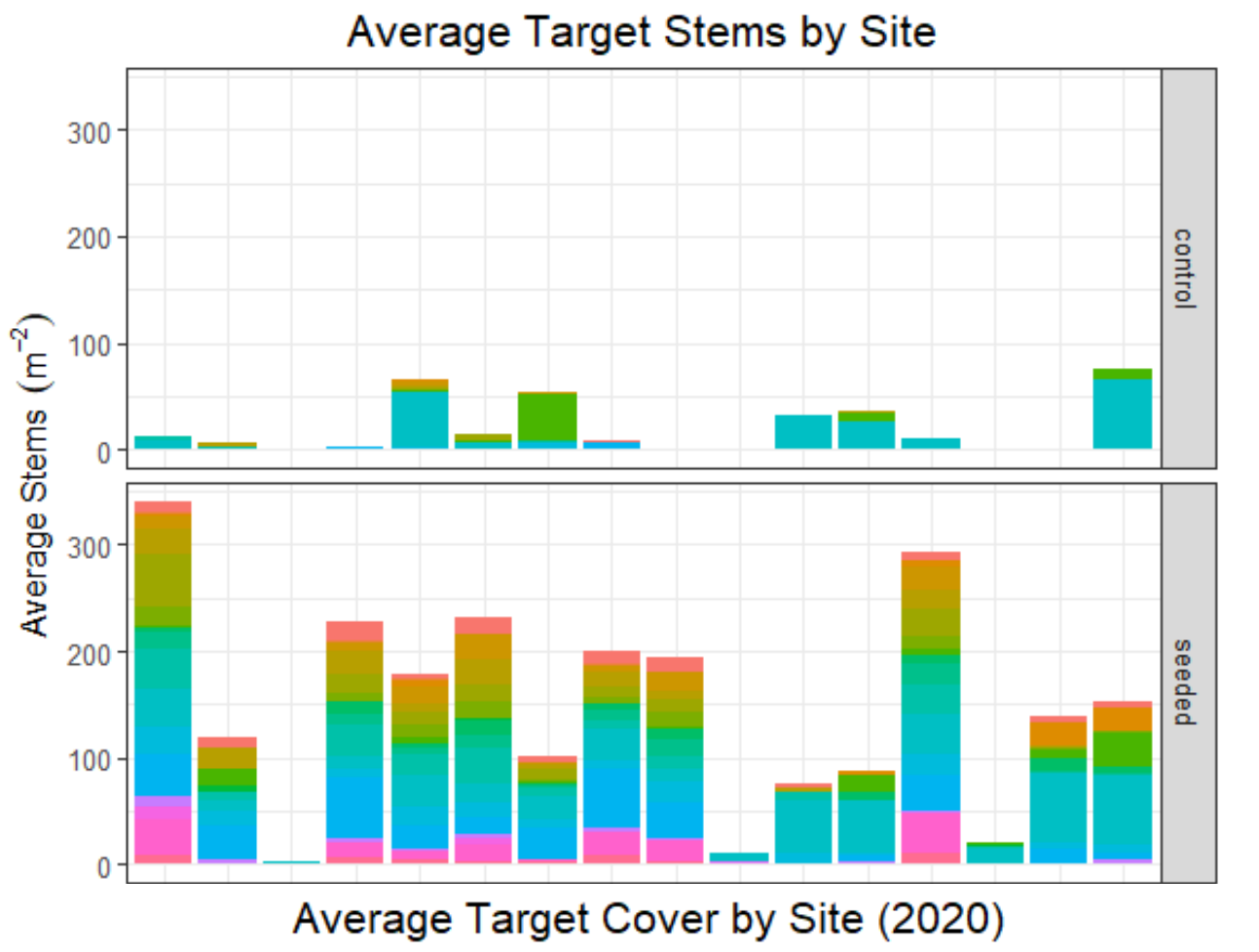

\begin{tabular}{l|l|l|}
\multicolumn{2}{l|}{ Species } \\
\hline ADBI & HYTE \\
\hline AQFO & NEPA \\
\hline BRVU & OSBE \\
\hline BRVU.ELGL & PEOV \\
\hline CALE & SCCA \\
\hline CIAL & STCO \\
\hline CLPE & TEGR \\
\hline CLSI & THPO \\
\hline CLSP. & TOME \\
\hline ELGL & TOME.TEGR \\
\hline FEOC & URDI \\
\hline GEMA & VAHE \\
\hline
\end{tabular}

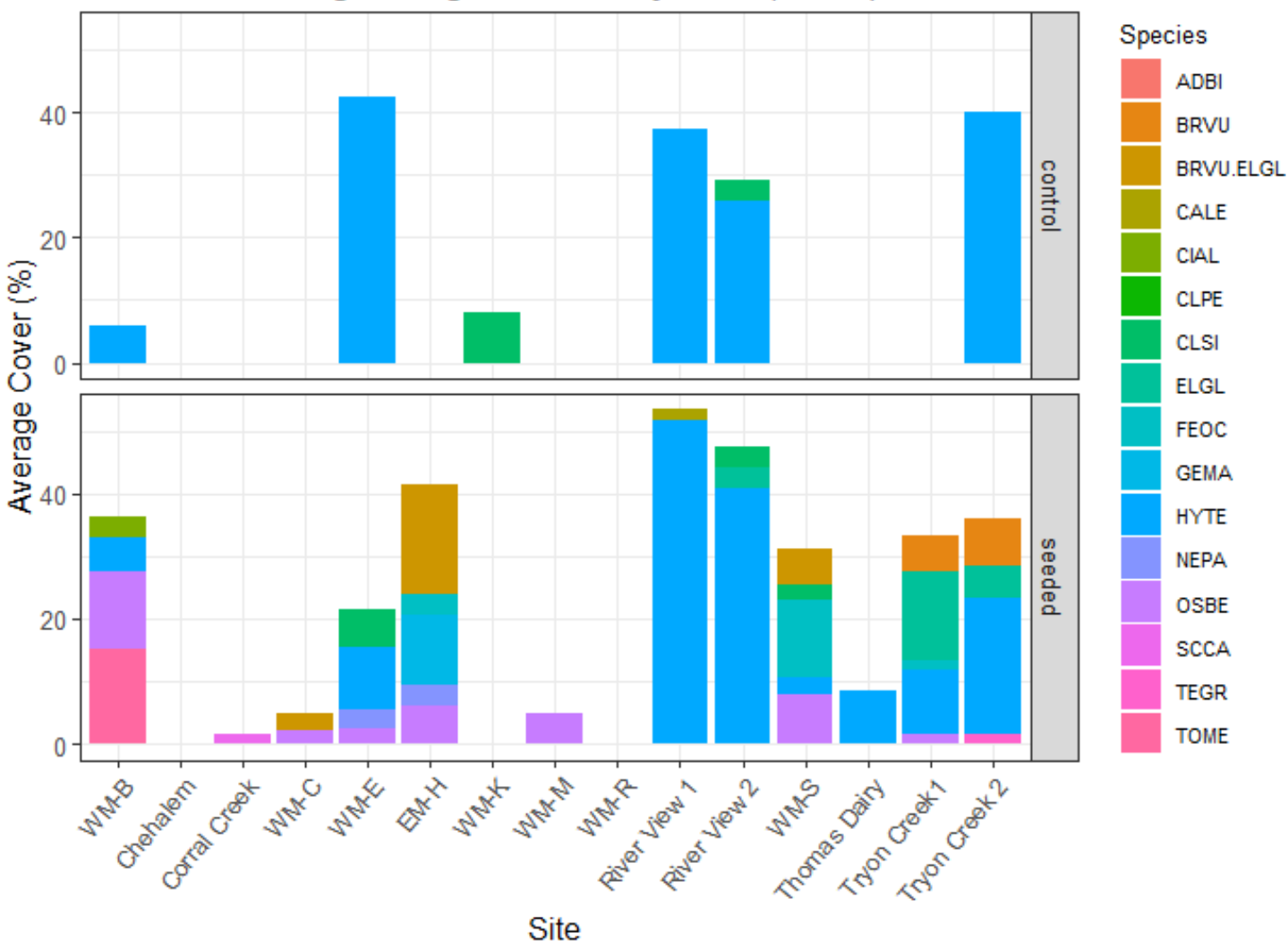

Figure 1-10: Site-specific target species metrics showing plot level averages of A) target species stem counts and B) target species cover in control versus seeded plots using most recent cover data and average stem counts from 1-2 years post-seeding. 
Table 1-5:Site-wide averages of plot-level predictors.

\begin{tabular}{lcccccc}
\hline Site Name & Slope & Aspect & $\begin{array}{l}\text { Altitude } \\
(\mathrm{ft})\end{array}$ & $\begin{array}{l}\text { Canopy Cover } \\
(\%)\end{array}$ & $\begin{array}{l}\text { Canopy } \\
\text { Type }\end{array}$ & $\begin{array}{l}\text { Compaction } \\
(\mathrm{psi})\end{array}$ \\
\hline WM-B & 16 & 263 & 280 & 82 & Mixed & 132 \\
Chehalem & 6 & 135 & 282 & 89 & Coniferous & 253 \\
Corral Creek & 3 & 71 & 26 & 78 & Mixed & 249 \\
WM-C & 4 & 272 & 274 & 84 & Coniferous & 255 \\
WM-E & 20 & 143 & 266 & 85 & Deciduous & 99 \\
WM-H & 10 & 210 & 176 & 87 & Deciduous & 149 \\
WM-K & 4 & 196 & 131 & 97 & Mixed & 63 \\
WM-M & 8 & 172 & 215 & 89 & Coniferous & 262 \\
WM-R & 5 & 289 & 312 & 81 & Coniferous & 203 \\
Ramsey & 4 & 291 & 7 & 94 & Deciduous & NA \\
River View 1 & 9 & 300 & 121 & 94 & Mixed & 104 \\
River View 2 & 7 & 187 & 118 & 96 & Mixed & 155 \\
WM-S & 4 & 176 & 110 & 91 & Mixed & 105 \\
Thomas Dairy & 1 & 177 & 37 & 97 & Coniferous & 204 \\
Tryon Creek 1 & 10 & 216 & 96 & 92 & Mixed & 206 \\
Tryon Creek 2 & 5 & 244 & 101 & 95 & Mixed & 114 \\
\hline
\end{tabular}

Table 1-6: Site level soil characteristics for USIP and WM sites.

\begin{tabular}{lcccrrrr}
\hline Site & $\mathbf{p H}$ & $\mathbf{C : N}$ & $\begin{array}{c}\text { Organic } \\
\text { Matter } \\
(\boldsymbol{\%})\end{array}$ & $\begin{array}{c}\text { Sand } \\
(\boldsymbol{\%})\end{array}$ & $\begin{array}{c}\text { Silt } \\
(\boldsymbol{\%})\end{array}$ & $\begin{array}{c}\text { Clay } \\
(\boldsymbol{\%})\end{array}$ & $\begin{array}{c}\text { Worm } \\
\text { Density } \\
\left(\mathbf{p e r} \mathbf{0 . 2 5} \mathbf{2}^{\mathbf{2}}\right)\end{array}$ \\
\hline WM-B & 6.18 & 18 & 5.8 & 55.5 & 35.5 & 9 & 0 \\
Chehalem & 6.40 & 16 & 4.5 & 22.5 & 54.5 & 23 & 12 \\
Corral Creek & 5.97 & 13 & 5.4 & 12.25 & 60.75 & 27 & 42.6 \\
WM-C & 5.64 & 17 & 5.4 & 28.5 & 49.5 & 22 & 7 \\
WM-E & 5.69 & 16 & 5.2 & 34.5 & 49.5 & 16 & 2.3 \\
WM-H & 6.22 & 18 & 4.7 & 58 & 37 & 5 & 0.7 \\
WM-K & 5.89 & 19 & 5.8 & 59.5 & 32.5 & 8 & 4 \\
WM-M & 5.79 & 19 & 3.5 & 47 & 43 & 10 & 0.7 \\
WM-R & 5.57 & 18 & 5.3 & 45.5 & 42.5 & 12 & 1 \\
River View 1 & 6.28 & 17 & 6.7 & 23 & 57 & 20 & 28.7 \\
River View 2 & 6.34 & 18 & 5.6 & 24.5 & 56 & 19.5 & 41.7 \\
WM-S & 6.01 & 17 & 5.5 & 50 & 41 & 9 & 1.7 \\
Thomas Dairy & 5.75 & 12 & 3.8 & 53 & 30.5 & 16.5 & 31.5 \\
Tryon Creek 1 & 5.89 & 18 & 6.4 & 20.5 & 60.5 & 19 & 11.1 \\
Tryon Creek 2 & 6.42 & 17 & 5.8 & 22.5 & 57.5 & 20 & 33.3 \\
\hline
\end{tabular}


Table 1-7: Site-level averages for predictors collected at USIP sites only.

\begin{tabular}{|c|c|c|c|c|c|c|c|c|c|c|c|}
\hline \multirow[t]{2}{*}{ Site } & \multicolumn{7}{|c|}{$\begin{array}{l}\text { Nutrient Supply Rate } \\
\left(\mu \mathrm{g} / 10 \mathrm{~cm}^{2} / 28 \text { days }\right)\end{array}$} & \multicolumn{2}{|c|}{$\begin{array}{c}\text { Temperature } \\
\left({ }^{\circ} \mathbf{C}\right)\end{array}$} & \multicolumn{2}{|c|}{$\begin{array}{l}\text { Volumetric Water Content } \\
\qquad\left(\mathbf{m}^{3} / \mathbf{m}^{3}\right)\end{array}$} \\
\hline & NO3.N & NH4.N & Ca & $\mathrm{Mg}$ & $\mathbf{K}$ & $\mathbf{P}$ & $\mathbf{S}$ & 4-inch depth & 8-inch depth & 4-inch depth & 8-inch depth \\
\hline Chehalem & 2.0 & 0.8 & 652.5 & 154.0 & 211.3 & 6.4 & 5.7 & 14.7 & 14.4 & 0.27 & 0.27 \\
\hline Corral Creek & 156.8 & 0.3 & 1963.0 & 355.0 & 83.3 & 3.4 & 20.1 & 15.2 & 14.9 & 0.30 & 0.31 \\
\hline River View 1 & 181.0 & 2.5 & 1656.3 & 234.8 & 395.3 & 17.0 & 23.0 & 14.0 & 14.0 & 0.32 & 0.39 \\
\hline River View 2 & 179.3 & 2.0 & 1659.0 & 197.3 & 371.3 & 15.4 & 23.9 & 15.0 & 14.2 & 0.31 & 0.32 \\
\hline Thomas Dairy & 176.0 & 2.5 & 1786.3 & 330.8 & 124.0 & 7.9 & 19.1 & 14.2 & 14.0 & 0.24 & 0.31 \\
\hline Tryon Creek 1 & 85.5 & 10.0 & 1022.0 & 257.0 & 215.8 & 15.7 & 35.8 & 14.9 & 15.0 & 0.30 & 0.31 \\
\hline Tryon Creek 2 & 49.8 & 5.3 & 1717.8 & 236.5 & 335.8 & 14.4 & 15.0 & 14.8 & 14.8 & 0.33 & 0.32 \\
\hline
\end{tabular}




\section{Germination}

Pearson correlation coefficient

selection for stem count data resulted in

the selection of 3 landscape predictors:

slope (degrees), altitude (meters), and

canopy cover (\%); 4 soil property

predictors: C:N, worm density, \% clay,

and compaction, and coefficient of

variation for soil temperature at 4-inch

depth and for soil moisture at 8-inch depth

(Figure 1-11). Invasive stems had

correlation to many of the same predictors

as target stems, but in the opposite

direction.

$N M D S$

NMDS ordination resulted in a

stress value of 0.17 (stress plots available

in Appendix F). NMDS results showed

clear separation of plots by treatment;

however, separation by site and years 1 and

2 post-seeding was not as apparent (Figure
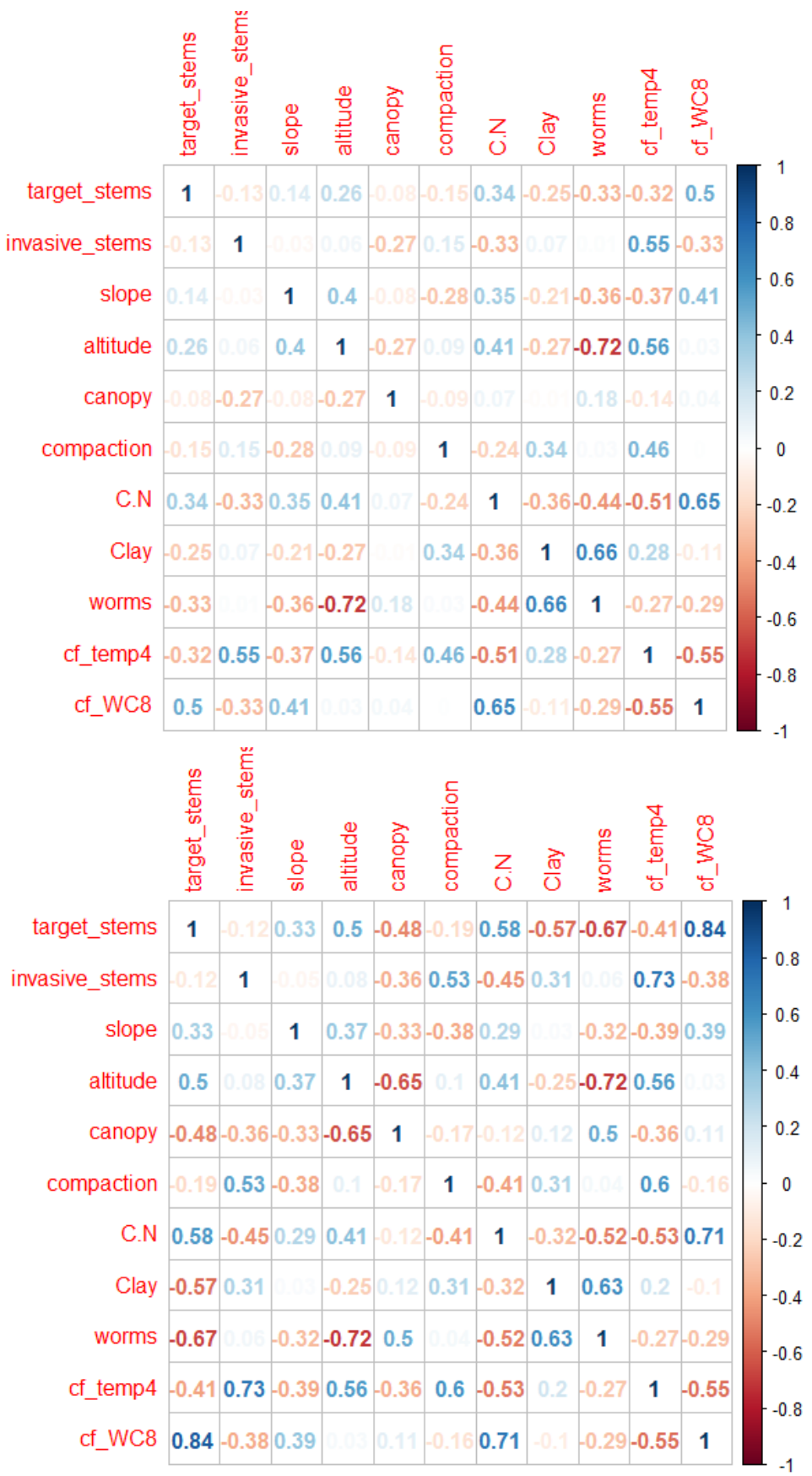

Figure 1-11: Pearson's correlation coefficients of target species stem counts from A) all plots and B) seeded plots only, using data from 1-2 years post seeding and selected predictors.

1-12). Target stems were imposed on the NMDS plot, which supported a higher number of target stem counts at seeded plots, as well as highlighting that a greater proportion of target stems 


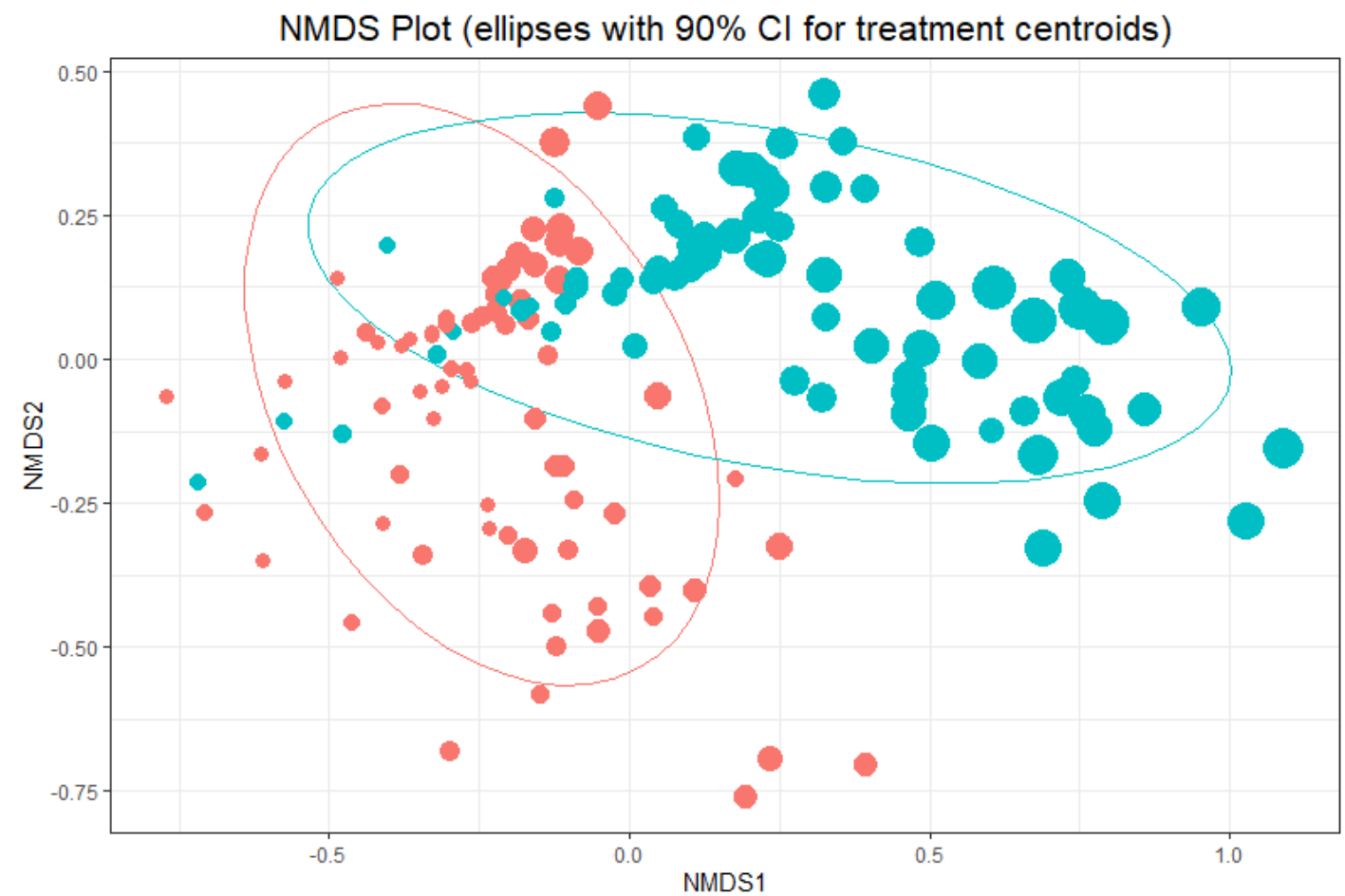

Treatment

$\rightarrow$ control

$\rightarrow$ seeded

Target Stems

- 0

C 100

200

C 300

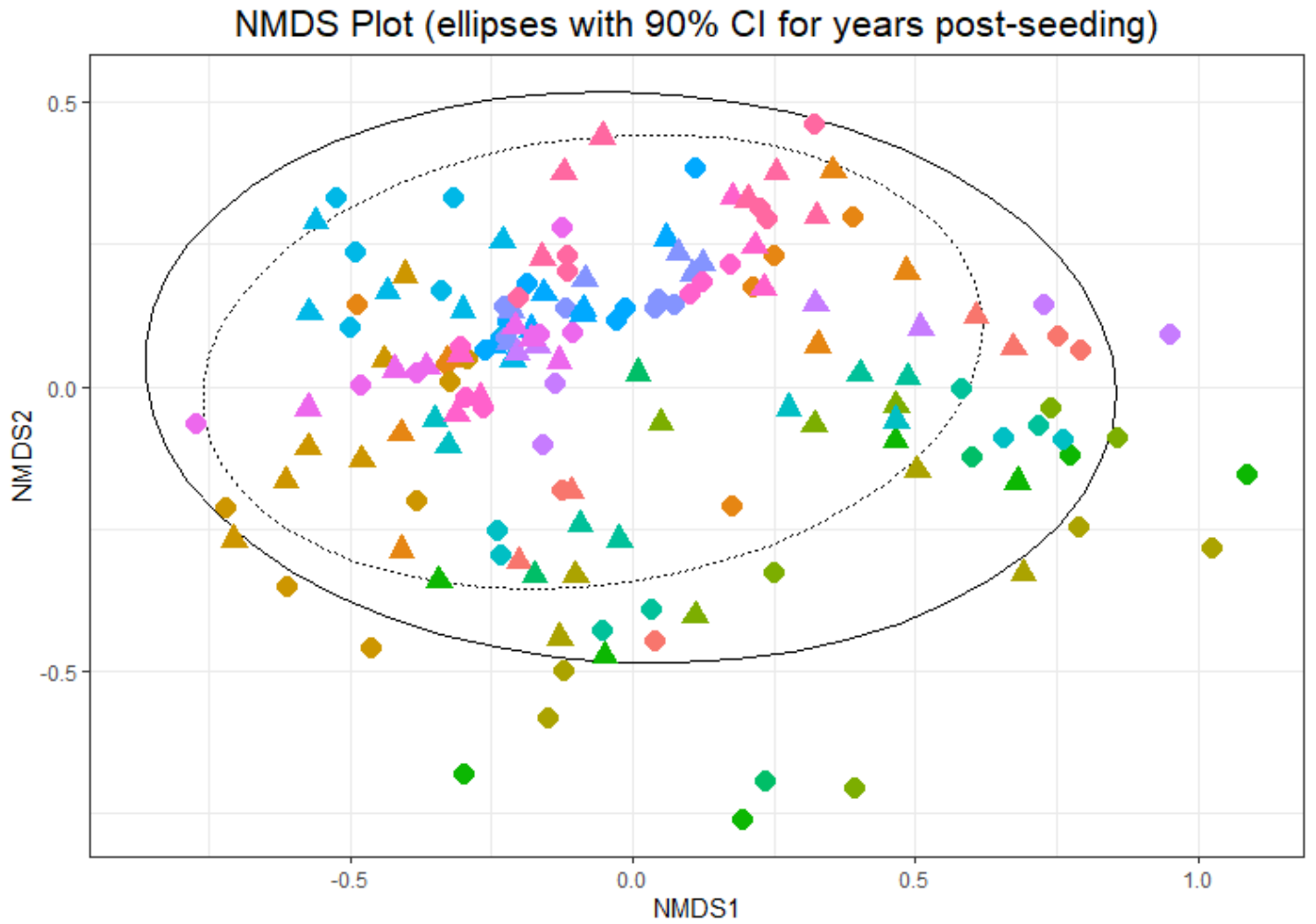

Years Post-Seeding

- 1

A 2

Site

Bunch

- Chehalem

- Corral Creek

- Crockett

- Eroh

- Hockensmith

- Karp

- Mecklem

- Rader

- Ramsey

- River View 1

- River View 2

Selby

- Thomas Dairy

- Tryon Creek 1

- Tryon Creek 2

Figure 1-12: NMDS plots of stem count data for all plots showing separation by A) Treatment, with number of target stems portrayed by point size, and B) Years post-seeding by shape and ellipses (solid line $=1$ year and dashed line $=2$ years ) and site by color. 
occurred at seeded plots, as well as highlighting that a greater proportion of target stems occurred at plots on the upper right side of the NMDS plot. It was also apparent that several seeded plots exist on the left side of the NMDS graph as outliers with low target stem counts. When viewed by site, there was no clear separation, but rather several sites clustered together in different portions of the graph. Based on years post-seeding, the data were not clearly separated but rather there was a slight shift inward, indicating that assemblages were more similar in year 2 .

The fitting of significant environmental predictors using "envfit" identified 8/9 predictors as significant at the $\mathrm{p}<0.05$ level, omitting only slope as non-significant. However, the strength of interactions varied, as seen in Figure 1-13, with longer vectors indicating a greater effect. Predictor vectors agreed with relationships described in the earlier correlation matrix; Specifically, that $\mathrm{C}: \mathrm{N}$, altitude, and coefficient of variation of water content at 8-inch depth all had a positive interaction with target species stem counts, while compaction, \% clay, worm density, and coefficient of variation for soil temperature at 4-inch depth had a negative interaction. Percent canopy cover, while identified as significant, was largely influenced by a single outlier with low canopy cover $(<20 \%)$, while the remainder of plots have very high cover (median 92\%). NMDS graphs were explored to view patterns by significant predictors, and canopy cover did not appear to exert any visible influence on understory assemblages. Among the strongest predictors (C.N, compaction, and altitude, all $\mathrm{p}=0.001), \mathrm{C}: \mathrm{N}$ had the strongest separation in supplemental NMDS graphs exploring predictor interactions ( Figure 1-14). This figure shows that most seeded plots with very low $\mathrm{C}: \mathrm{N}$ ratio also had low germination of target species cover, and account for many of the outlier seeded plots identified earlier. 


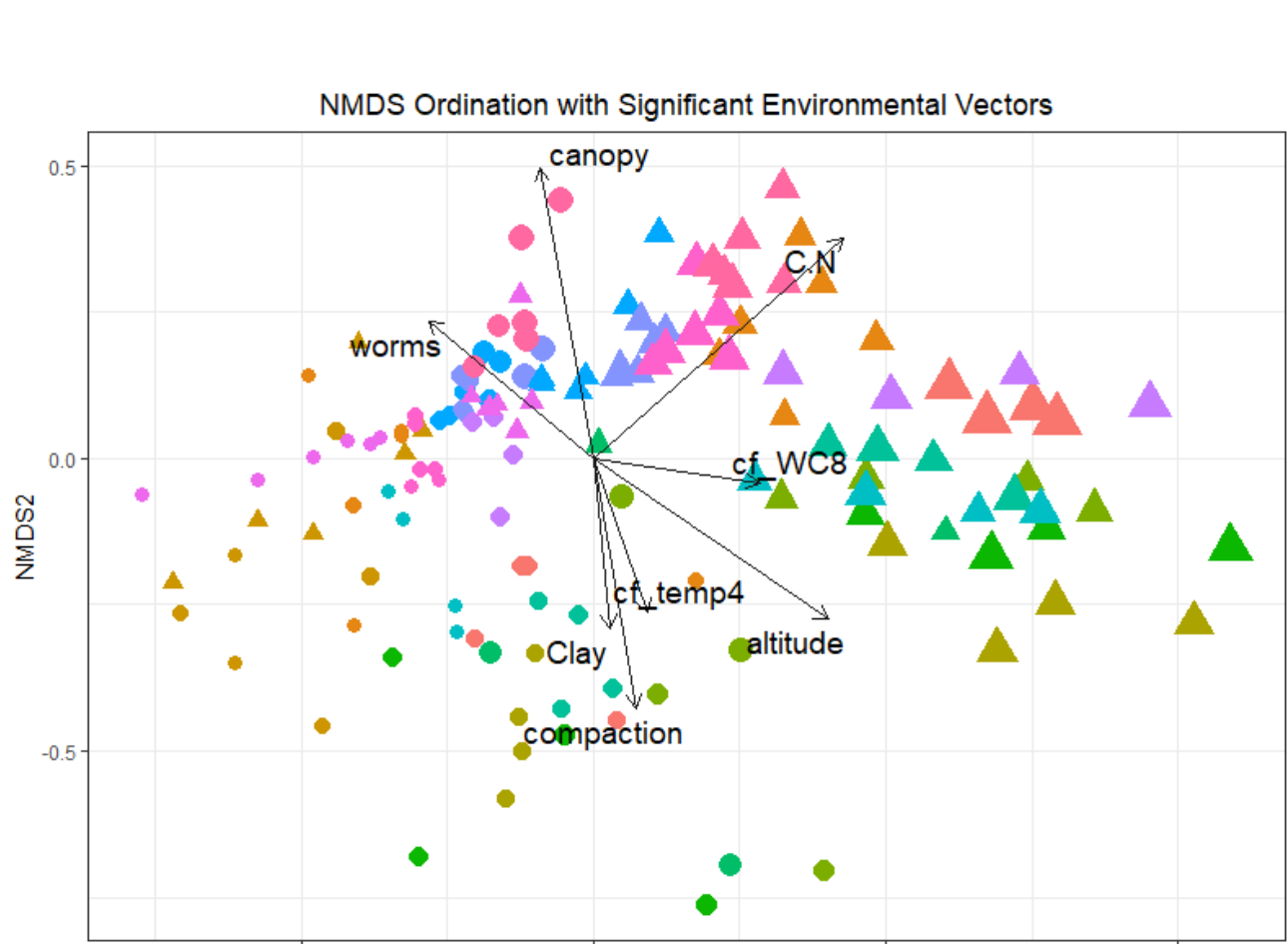

Figure 1-14: NMDS plot with significant $(\mathrm{p}<0.05)$ environmental predictors imposed as vectors. Length of vector indicates relative magnitude of the relationship.
Treatment

- control

- seeded

Target Stems

$-0$

- 100

200

C 300

Site

- Bunch

- Chehalem

- Corral Creek

- Crockett

- Eroh

- Hockensmith

- Karp

- Mecklem

- Rader

- Ramsey

- River View 1

- River View 2

- Selby

- Thomas Dairy

- Tryon Creek 1

- Tryon Creek 2

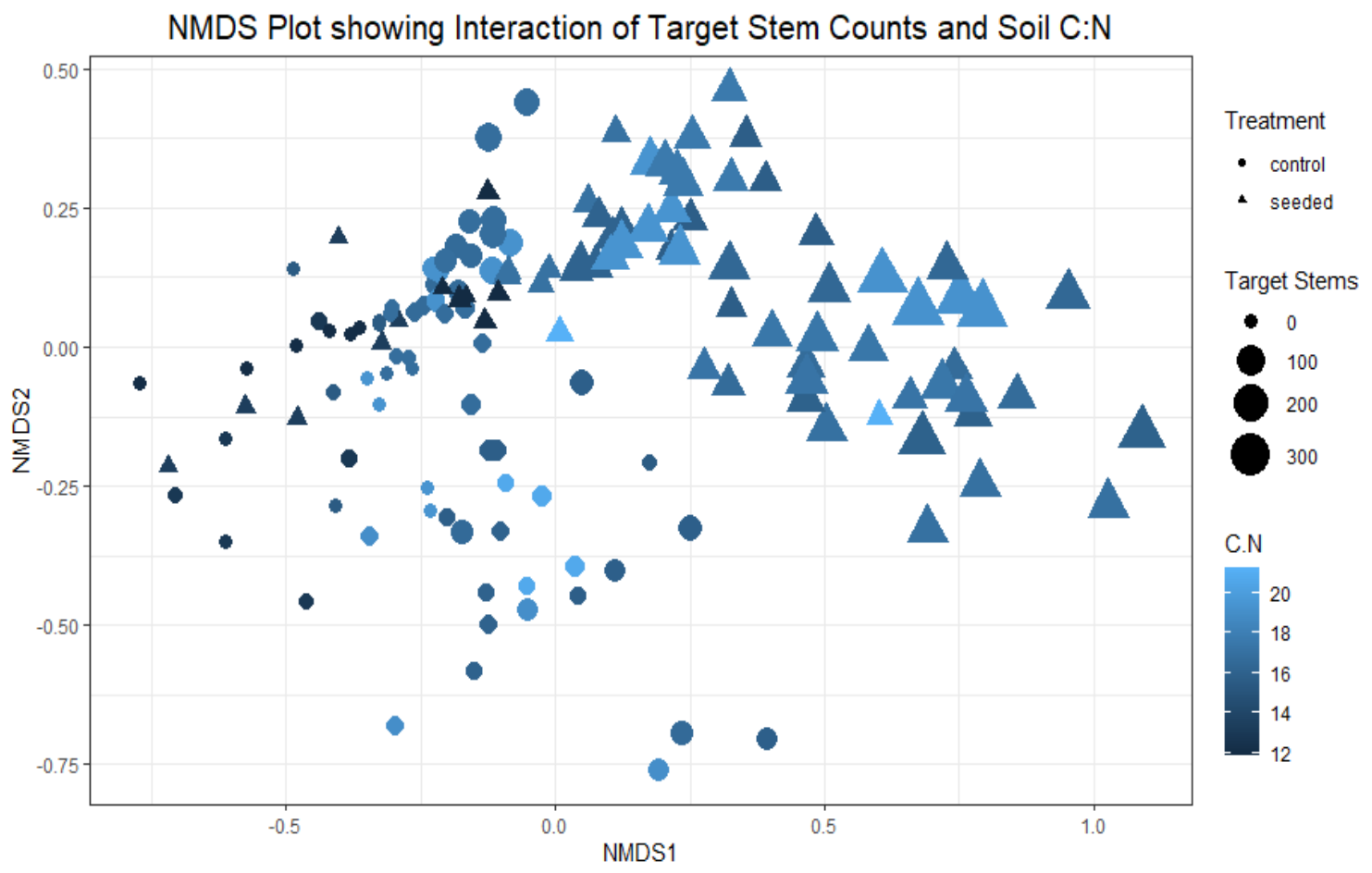

Figure 1-13:NMDS plot of the relationship between soil C:N and target stem counts , specifically in seeded plots (triangles). 


\section{GLMM}

Germination of target species was explained by treatment $(\mathrm{p}<0.001)$, compaction $(\mathrm{p}=0.002)$, and worm density $(\mathrm{p}=0.0075)$ as variables retained in the best model. Percent of clay and altitude covaried with worm density, meaning they could also be drivers of target species germination success, but models that included clay in lieu of worm density had slighly higher AIC values. The best model was selected based on lowest AIC and meeting diagnostic checks available within the "DHARMa" package in R, and is summarized in Table 1-8. Effect plots (from package "effects," Fox, 2003) can be seen in Figure 1-15 and additional graphs of relationships between target species stem counts and significant predictors are available in Appendix H. Treatment was the strongest predictor of target germination. Both worm density and compaction had a similarly negative impact on target species germination, with compaction having a stronger overall effect.

Table 1-8: GLMM Best model parameters. AIC: 1291.1

\begin{tabular}{lcccc}
\hline Model: & \multicolumn{4}{c}{ Target Stems (1|site) $+(1 \mid$ plot $)+$ treatment + compaction + worm density } \\
\hline Fixed Effects & Estimate & Standard Error & z-value & p-value \\
\hline (Intercept) & 2.4303 & 0.2305 & 10.542 & $<2 \mathrm{e}-16^{* * *}$ \\
Treatment: seeded & 2.2514 & 0.2044 & 11.013 & $<2 \mathrm{e}-16^{* * *}$ \\
Compaction & -0.4427 & 0.1443 & -3.067 & $0.00216^{* *}$ \\
Worm Density & -0.4377 & 0.1636 & -2.675 & $0.00747^{* *}$ \\
\hline
\end{tabular}

Unlike predictors in the soil properties category, no landscape predictors were retained as having significant impacts on target species. According to AIC values, including coefficient of variation for soil moisture (8-inch depth) and temperature (4-inch depth) did strengthen model fit; however, no models including these variables were able to meet residual checks. Inclusion of 
soil $\mathrm{C}: \mathrm{N}$ in the models only resulted in a slight AIC improvement $(<0.5)$, and C:N

was not identified as a significant predictor $(\mathrm{p}=0.12)$, despite the apparent relationship seen in NMDS graphs. When added to models using percent clay in lieu of worms, $\mathrm{C}: \mathrm{N}$ was identified as moderately significant $(\mathrm{p}=0.076)$, but again AIC improvement was not adequate to justify its addition ( 1 point improvement).

Appendix $\mathrm{J}$ describes models used in the forward selection process. Model checks from the "DHARMa" package included tests for dispersion, outliers, and deviations from the expected distribution (KS), as well as a plot of residuals against predicted values. The package was also used to check for zero inflation. No significant issues of model fit were identified with the best model (dignostics available in Appendix I).

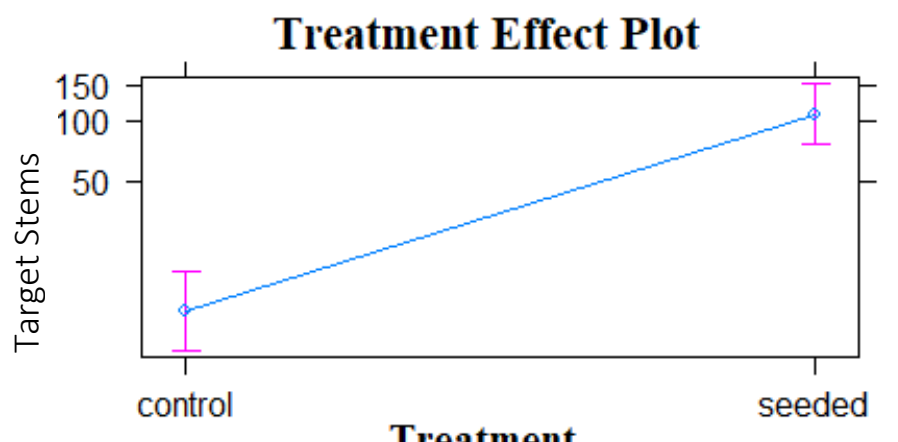

Treatment

Compaction Effect Plot

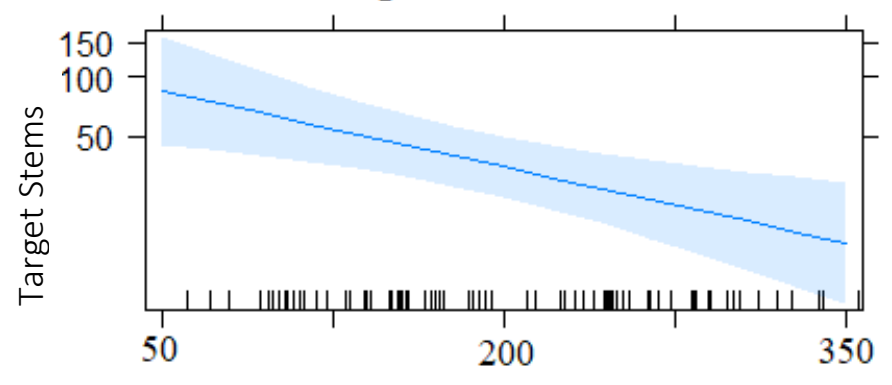

Compaction (psi)

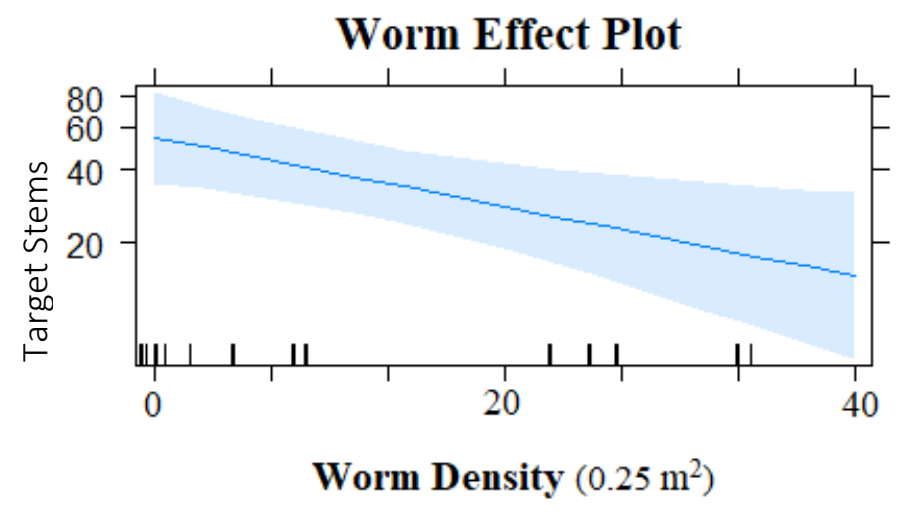

Figure 1-15: Germination predictor effect plots showing role of significant predictors in best GLMM, including treatment, compaction, and worm density. Dashes along $\mathrm{X}$-axis show distribution of data points. $\mathrm{Y}$-axis shows predicted target cover in response to predictor variable with other predictors held constant and light blue shading represents $0.95 \%$ confidence intervals. 


\section{Cover}

Pearson correlation coefficients

selection with target cover from USIP

plots resulted in the selection of 3

landscape predictors: aspect, canopy

cover, and canopy type (determined with

Spearman correlation due to not being a

continuous variable); 3 soil property

predictors: compaction, $\mathrm{OM}$, and $\mathrm{pH} ; 3$

nutrients: $\mathrm{P}, \mathrm{K}$, and spring $\mathrm{NO}_{3}$; and 4

temperature and moisture variables:

maximum and coefficient of variation

for soil temperature at 4-inch depth, and

mean soil moisture at 4-inch and 8-inch

depth (Figure 1-16). Invasive stems were

strongly negatively correlated to target

cover. The only of these predictors that

were consistent in relationship to both

germination and cover were canopy

cover, compaction, and coefficient of

variation for soil temperature at 4-inch

depth. Even with the first round of predictor

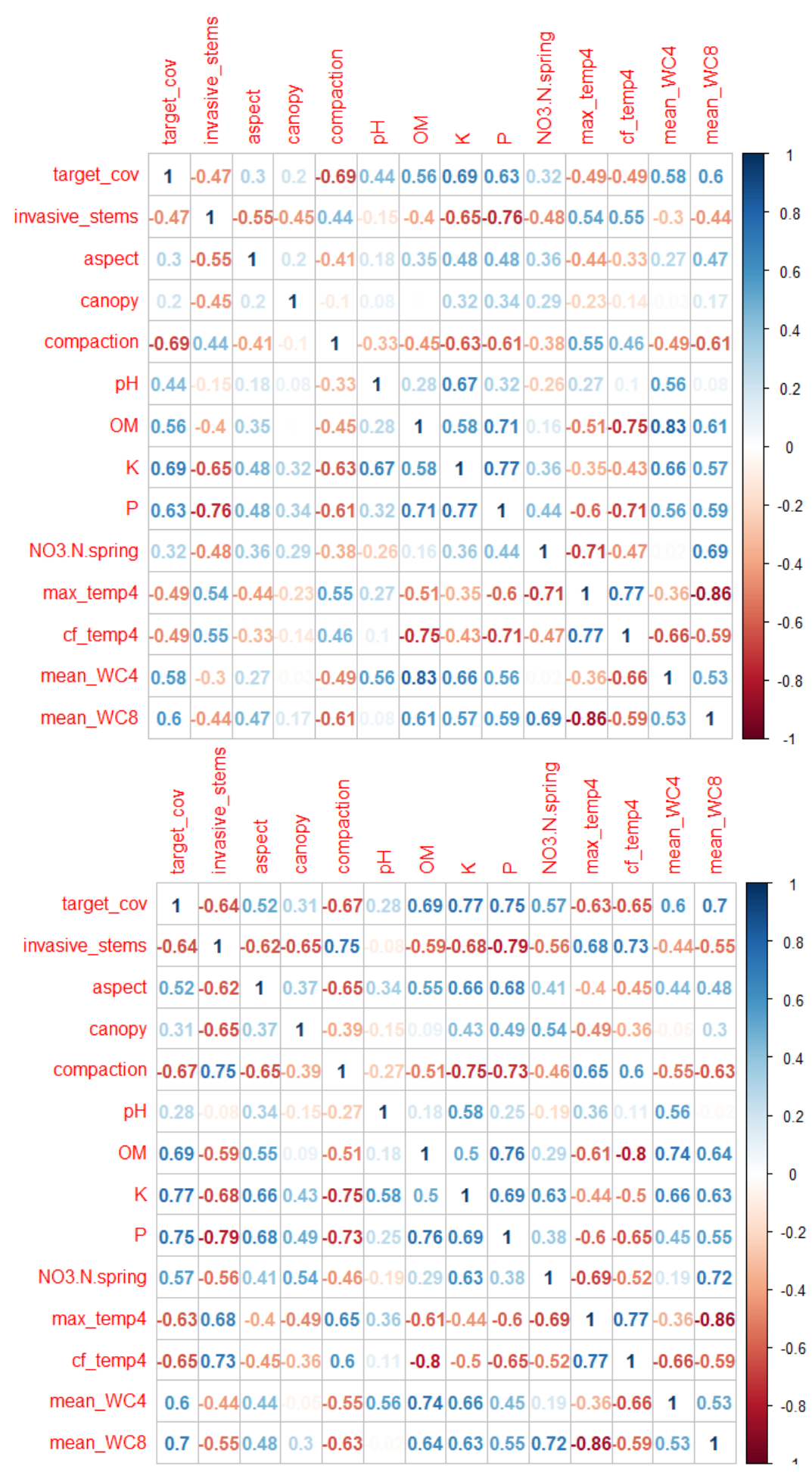

Figure 1-16: Pearson's correlation coefficients of target species cover from A) all plots and B) seeded plots only, using USIP data from 2020 monitoring and select predictors.

selection, many of the remaining variables were collinear (Figure 1-16). 
NMDS ordination resulted in a stress value of 0.144 (stress plots in Appendix F). NMDS results for cover data did not support the long-term benefits of a seeding treatment, as separation by treatment was negligible (Figure 1-17), and differences in target species cover between treatments were not clear. Rather, plots clustered primarily by site (Figure 1-18). Once grouped by site, it was possible to see some separation by treatment, particularly at Tryon Creek 1 where both separation and a marked increase in target cover were apparent. Other sites with higher target cover had both control and seeded plots highly clustered together in NMDS space, likely driven by HYTE, which, as previously discussed, was very prevalent at both River View sites as well as Tryon Creek 2. Both Thomas Dairy and Corral Creek showed very little establishment of target species cover in seeded plots, while Chehalem shows none.

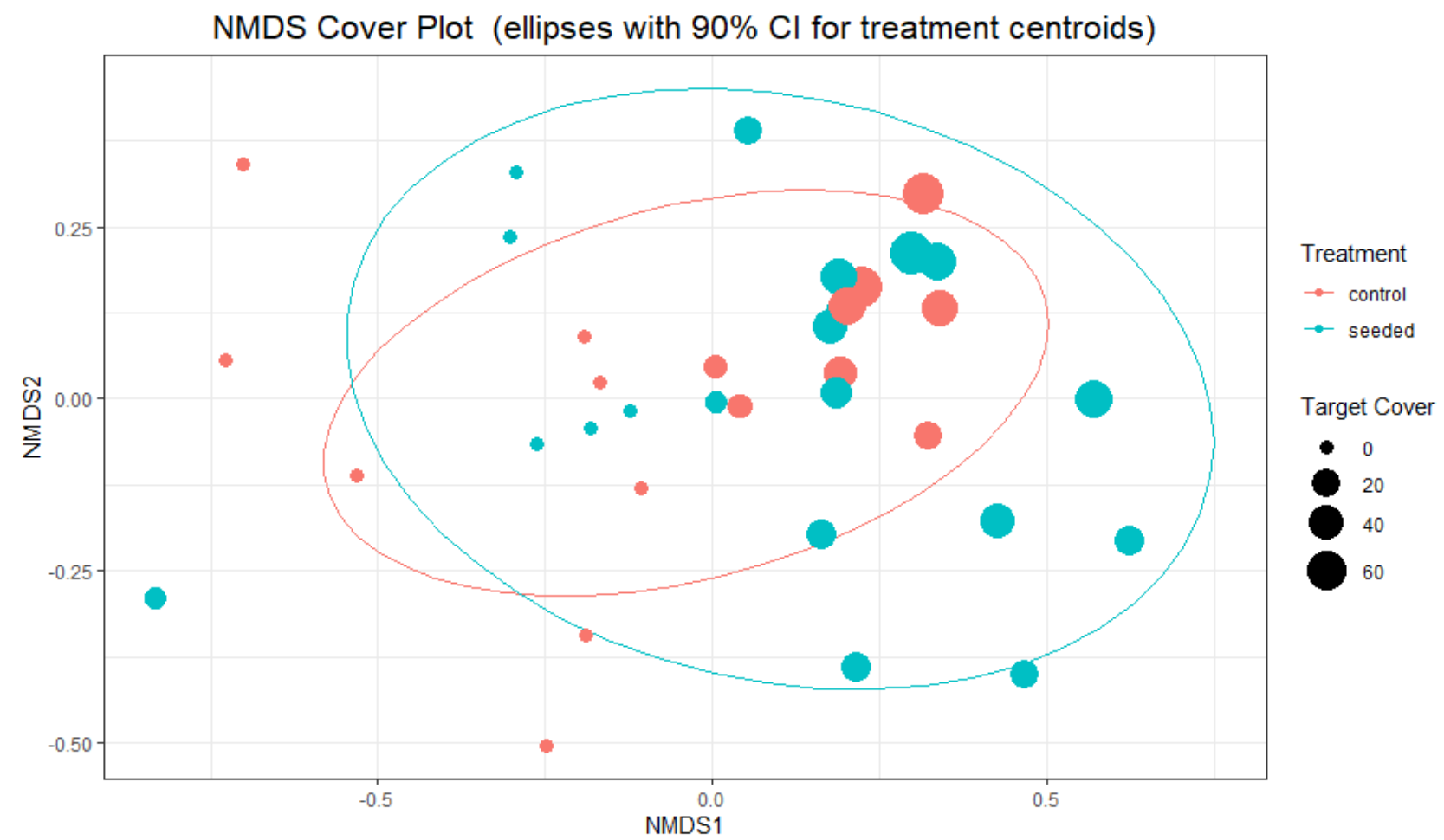

Figure 1-17: Cover NMDS plot showing separation by treatment, with amount of target cover (\%) highlighted by point size and ellipses showing $90 \%$ confidence intervals of treatment centroids. 


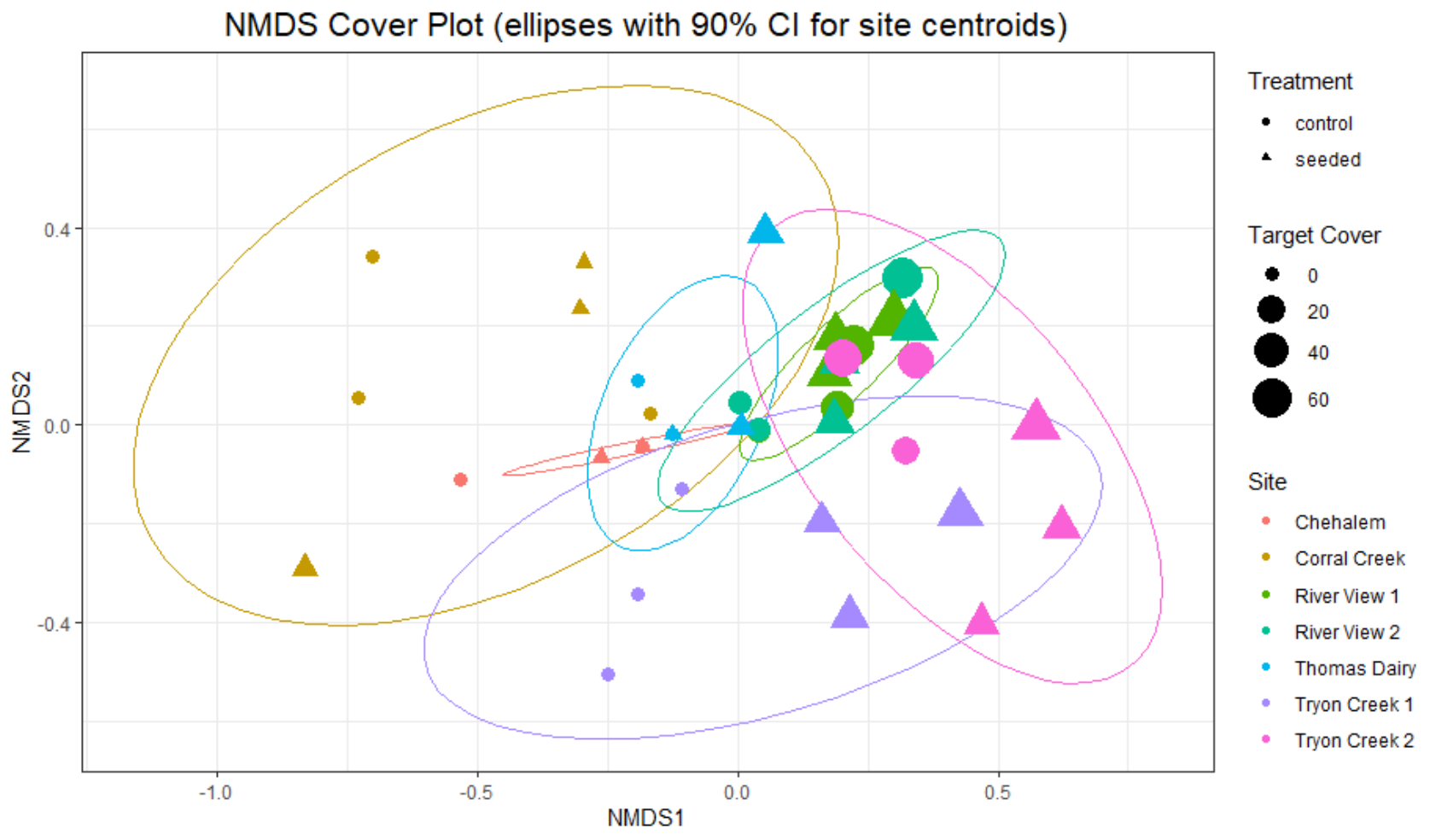

Figure 1-19: Cover NMDS plot showing separation by site, with amount of target cover (\%) highlighted by point size and treatment by shape. Length of vector indicates relative magnitude of the relationship.

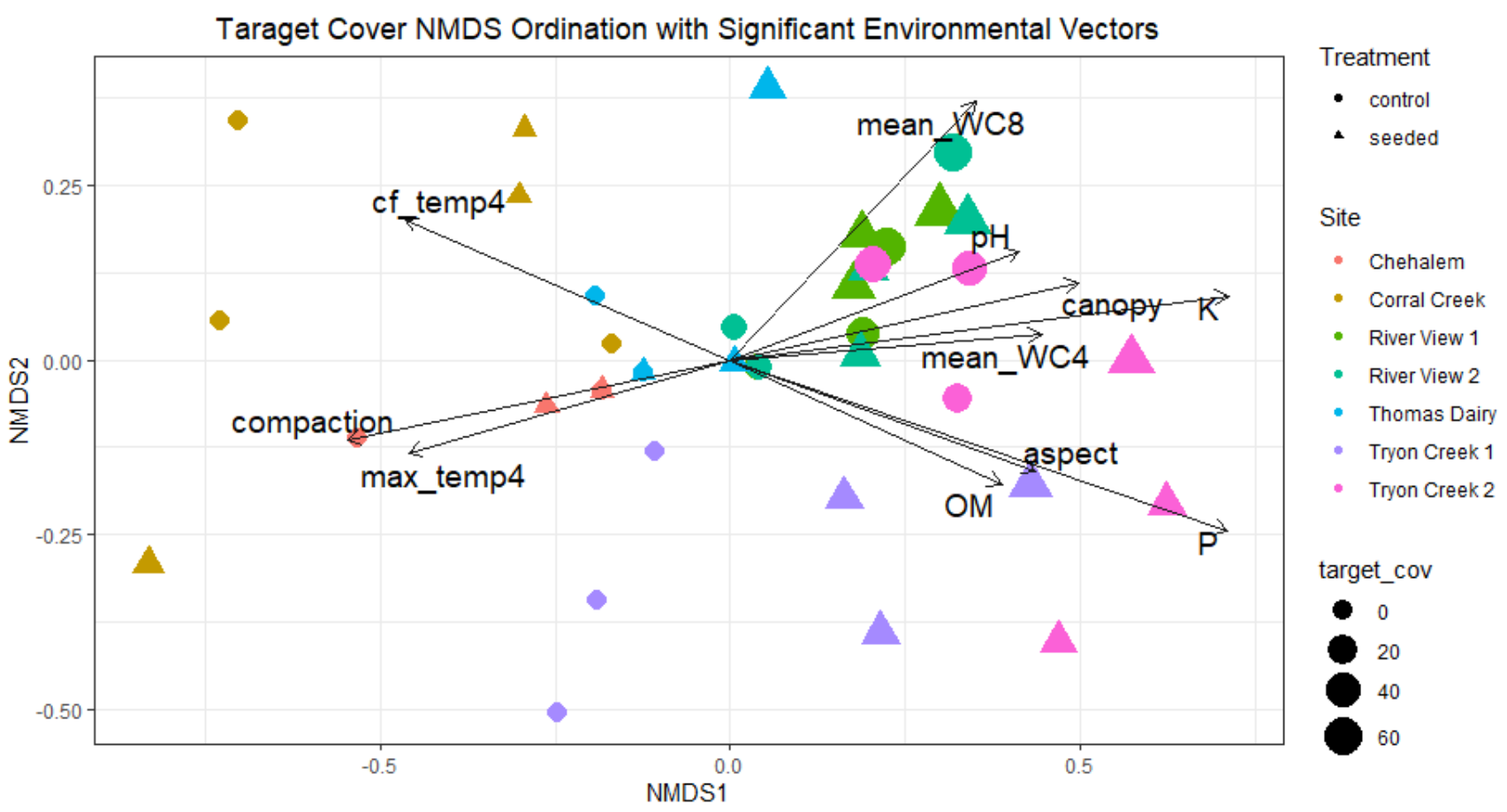

Figure 1-19: Cover NMDS plot with significant $(\mathrm{p}<0.05)$ environmental predictors imposed as vectors. Length of vector indicates relative magnitude of the relationship. 
Fitting environmental predictors using envfit resulted in 11/12 variables being identified as significant at the $\mathrm{p}<0.05$ level, with spring $\mathrm{NO}_{3}{ }^{-}$being the only non-significant predictor $(p=0.06)$. Again, the vector direction in association with target cover seem to support the same relationships identified in previous correlation matrices for germination (Figure 1-19). Specifically, compaction, maximum temperature and coefficient of variation of temperature at four inches have a negative interaction and appear to be elevated at Corral Creek, Thomas Dairy and Chehalem. Conversely, many soil parameters $(\mathrm{P}, \mathrm{K}, \mathrm{OM}, \mathrm{pH}$, mean water content at 4 \& 8inch depths) had positive interactions of varying magnitudes with target cover, and all appeared to be higher at Tryon Creek and River View sites. Three landscape variables were also significant: canopy type, canopy cover (\%), and aspect, although exploratory graphing of NMDS patterns did not support strong interactions with canopy cover and aspect. The strongest predictors included $\mathrm{P}, \mathrm{K}$, compaction, and mean water content at 8 -inch depth $(\mathrm{p}<0.002)$.

All strong predictors had noticable patterns in NMDS space as well as likely interactions with one another. For instance, it was common for sites with high compaction to also exhibit low $\mathrm{P}$ and $\mathrm{K}$ availability and lower soil moisture. (Figure 1-20) There were, however, instances of somewhat high compaction in sites with moderate levels of $\mathrm{P}$ and $\mathrm{K}$, and these sites generally had higher target cover. Due to nutrient and soil moisture data being collected at the site or site+treatment level, more noticable patterns would be expected than for plot level data, such as compaction. Another interesting pattern from exploratory graphing was the relationship between certain predictors and invasive stem counts, which were found to be highly negatively correlated to target cover. Both invasive stem counts and target cover had especially noticeable responses 
to soil $\mathrm{K}$ and $\mathrm{P}$ supply rates, which displayed a high degree of collinearity. These graphs indicate that plots with $\mathrm{P}$ and $\mathrm{K}$ limitations were more conducive to invasive species establishment, which may then outcompete target species. This competitive advantage for invasive species may also have been driven by degraded soil conditions that are common in urban soils, such as increased compaction and temperature and lower water availability. Overall results suggest that seeding was at least somewhat dependent on soil factors, whereas landscape features were less influential.

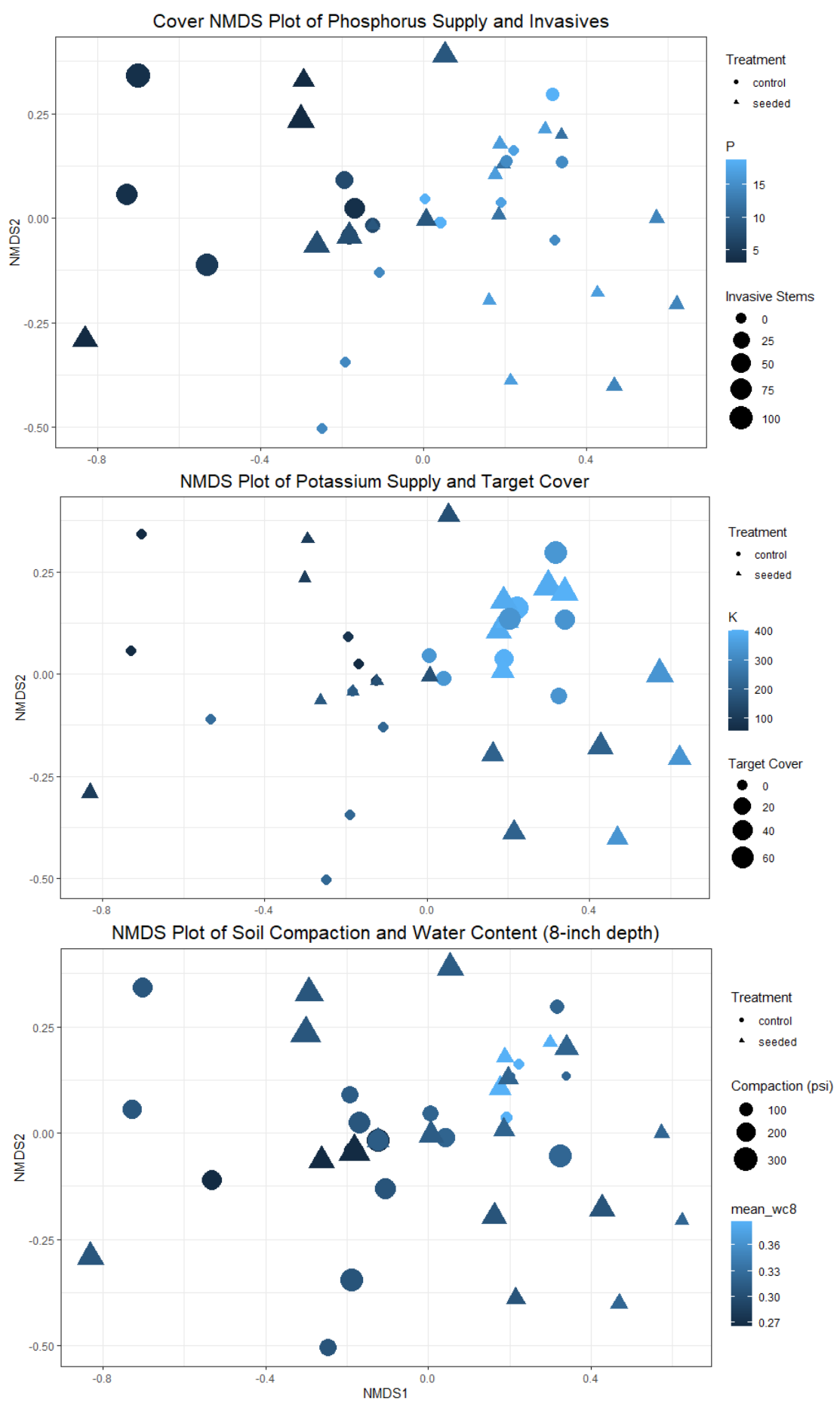

Figure 1-20: Cover NMDS plots highlighting relationships GLMM between strongest predictors, A) Phosphorus supply rate and invasive stems, B) Potassium supply rate and target cover, and The two best models C) soil compaction and mean water content at 8-inch depth. identified for target cover included organic matter (\%) and plant-available potassium as 
significant predictors, but these variables were collinear, making it necessary to assess their impacts separately. While plant-available K offered a slightly ( 3) improved AIC value, because organic matter estimates are easier to collect, they offer a more practical approach for land managers to determine the feasibility of seeding herbaceous species. Canopy type was also found to be a significant predictor in the $\mathrm{K}$ model and when modeled alone. Both $\mathrm{K}$ and $\mathrm{OM}$ showed significant positive relationships to target cover ( $\mathrm{p}<0.001$ and $\sim \mathrm{p}=0.002$, respectively) as did a deciduous canopy type $(\mathrm{p}=0.006)$. A mixed canopy type was marginally significant $(\mathrm{p}=0.052)$ and had a more positive outcome for target cover compared to coniferous canopy types. Effect plots from both models are available in Figure 1-21, and Table 1-9 shows details of the two best models. Additional graphs showing the relationships between significant predictors and target cover data are available in Appendix K.

Table 1-9: Parameters of 2 best GLMM models.

\begin{tabular}{lcccc}
\hline Model: & \multicolumn{3}{c}{ Target Cover $\sim(1 \mid$ site $)+$ K+ canopy type } & AIC: 249.3 \\
\hline Fixed Effects & Estimate & Standard Error & z-value & p-value \\
\hline (Intercept) & 0.7468 & 0.7423 & 1.006 & 0.31455 \\
K & 1.0768 & 0.2178 & 4.944 & $7.65 \mathrm{e}-07^{*}$ \\
Canopy type: Deciduous & 2.2055 & 0.8093 & 2.725 & $0.00642^{*}$ \\
Canopy type: Mixed & 1.5504 & 0.7979 & 1.943 & 0.05200 \\
\hline Model: & \multicolumn{5}{c}{ Target Cover $\sim(1 \mid$ site) + OM } & AIC: 258.4 \\
\hline Fixed Effects & Estimate & Standard Error & z-value & p-value \\
\hline (Intercept) & 1.9296 & 0.5465 & 3.531 & $0.00041^{*}$ \\
Organic Matter $(\%)$ & 1.6092 & 0.5178 & 3.108 & $0.00188^{*}$ \\
\hline
\end{tabular}

No landscape variables were retained as having significant impacts on target cover besides canopy type. When included in the $\mathrm{K}$ and canopy type model, compaction was also a significant predictor $(\mathrm{p}=0.02)$; however, it was only moderately significant $(\mathrm{p}=0.08)$ in the $\mathrm{OM}$ model and only resulted in a slight improvement to AIC for both $(\sim 3)$. While compaction was not retained in the final models, there is evidence that compaction was having some deleterious 
impacts on target species cover, similar to its impacts on target species germination. The addition of treatment into these separate models also offered a slight AIC improvement, but did not meet the threshold of $\triangle \mathrm{AIC}>6$ and resulted in residuals not meeting diagnostic checks. There was also no evidence that a control treatment was responsible for substantial zero-inflation of target cover data, despite $2 / 3$ of the plots with no target cover being control plots, while only $1 / 3$ were seeded plots. This supports findings from NMDS ordination of cover data that showed treatment did not create substantial differences in understory assemblages 3-4 years post seeding. While there are certainly sites for which this is not the Organic Matter Effect Plot case (Tryon Creek 1, specifically), from a broad view the seeding treatment was not responsible for significant improvements in target cover. Appendix J further details the forward model selection process and Appendix L shows model diagnostics for best models.
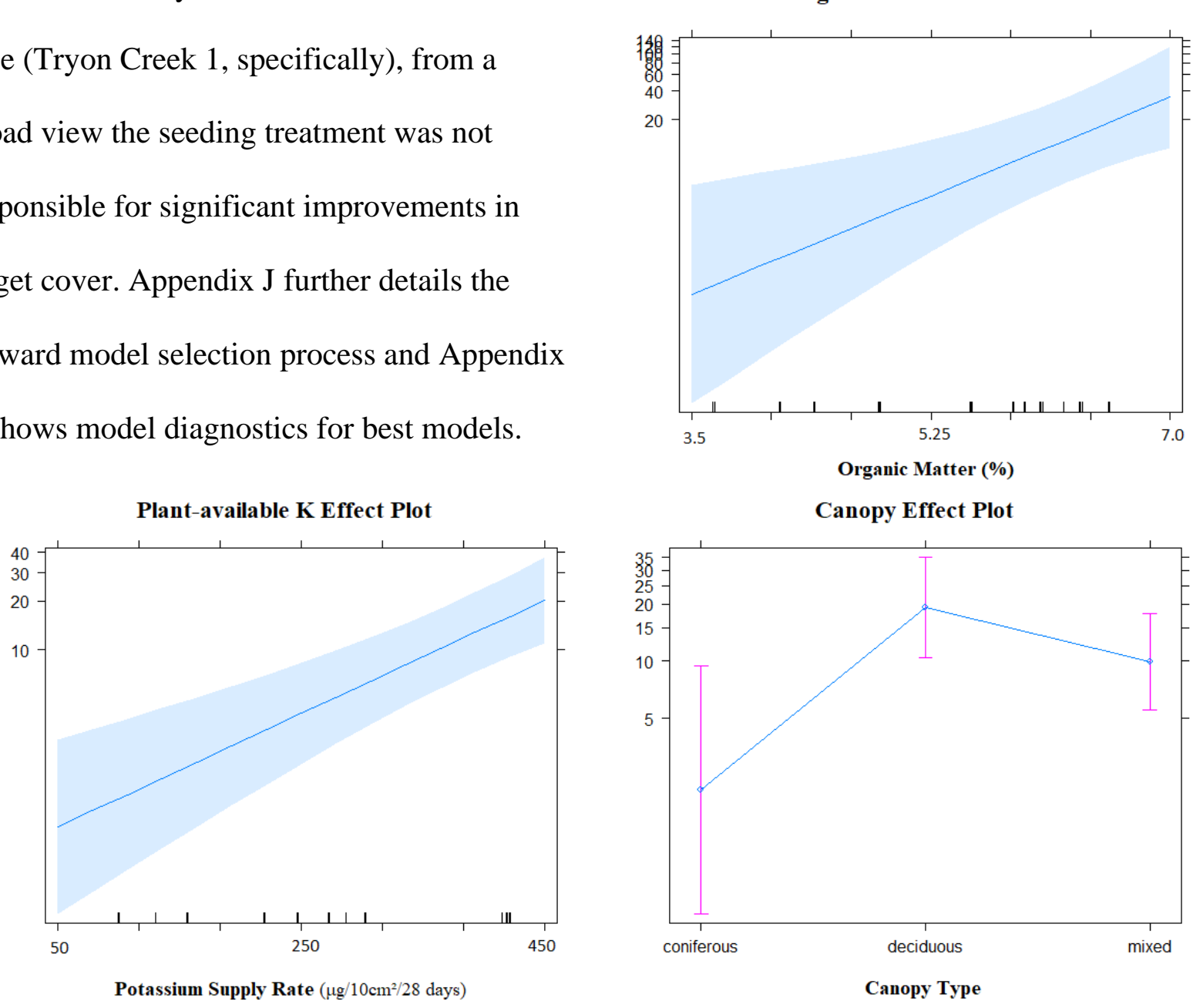

Figure 1-21: Cover predictor effect plots showing role of significant predictors in best GLMMs, A) organic matter model, and B) potassium and canopy type model. Dashes along X-axis show distribution of data points. Y-axis shows predicted target cover in response to predictor variable with other predictors held constant and light blue shading represents $0.95 \%$ confidence intervals. 


\section{Discussion:}

\section{Species Success}

Recruitment of plant species in restoration projects can be hindered by dispersal limitation (failure to reach a site), or establishment limitation (failure to germinate and survive at a site, Brudvig et al., 2011). Dispersal limitation can be overcome by seed additions. However, it is often thought that perennial herbaceous species suffer from establishment limitation due to life history traits including low seed production (Mabry, 2004), low viability and specific germination requirements (Cullina, 2000), and long periods to reach seed producing maturity (Bierzychudek, 1982). The results of this study indicate that many of the target species utilized in our upland seed mix can successfully germinate from seed and can successfully establish when environmental conditions are suitable. Notable exceptions include Aquilegia formosa (AQFO) and Penstemon ovatus (PEOV) which both had poor performance from seed. Interestingly, the top four species are all forbs, indicating assumptions that shade-tolerant forbs do not establish well from seed may be mistaken.

Species that ranked within the top $50 \%$ of both performance metrics include OSBE, ADBI, VAHE, CIAL, HYTE and the BRVU.ELGL grouping. A common trait for $6 / 7$ of these species (all but CIAL) is that they had the six highest seed weights compared to other species in our mixes (Appendix 4). This agrees with findings from Jakobsson and Eriksson (2002), wherein species with larger seeds were found to have improved recruitment in $2 / 3$ forests in their study. Numerous other studies have indicated an evolutionary advantage of larger seeds for overcoming challenges such as competition with established vegetation and other seedlings, and surviving drought, nutrient limitations, deep shade, and depth under soil litter during seedling establishment (Westoby et al., 2002). However, dispersal limitation has been found to affect 
species with larger seeds more acutely (Mabry, 2004), indicating the need to introduce seeds in highly fragmented landscapes such as urban natural areas to overcome this barrier. These species should therefore be considered in regional seed mixes for forest understory revegetation projects.

Other species that performed within the top $50 \%$ of at least one performance metric include NEPA, FEOC, CALE, and the TOME.TEGR grouping. These species, and others, require further investigations to determine whether they may be more successful if deployed only at sites with more desirable environmental conditions (see next section) or whether introduction of different forms of plant materials (i.e., transplants or root fragments) would have stronger outcomes (Mottl et al., 2007). However, it is important to also consider the varying economics of different forms of plant materials in such studies, as the relative cost of different plant materials is of high practical interest to land managers.

The species investigated within this trial demonstrated varying responses to seed introductions, but most species were present at a majority of seeded plots. Despite this presence, many species were not able to establish strongly enough to constitute 5\% cover. Continued monitoring of trial plots will help determine whether the small individuals that have persisted will eventually mature to produce seeds and further bolster their populations. However, this is not necessarily expected for all species at all sites, as our modeling results indicated establishment limitation in addition to dispersal limitations. This establishment limitation appears to result primarily from abiotic factors for many of the herbaceous species in this study, as further detailed in the subsequent section.

The study was limited in time, with only 24 of 72 plots being monitored for more than 3 years. More long-term data would be useful in determining species persistence after introduction from seed and in capturing success of species that may be slower growing, as the short period of 
monitoring likely biased results towards faster growing species. Additionally, future research should consider climate change impacts when evaluating species for use in restoration. Climate projections for the Pacific Northwest predict warming temperatures (mean $1.5^{\circ} \mathrm{C}$ ) with increasing precipitation in the winter and decreasing precipitation in the summer (Franczyk \&Chang, 2009). Choosing species that are adapted for these expected conditions is crucial for ensuring their long-term persistence and success.

\section{Considerations of Environmental Conditions}

This research demonstrates that it is prudent for land managers to consider soil conditions prior to implementing revegetation of forest herbs from seed, as numerous soil factors were found to contribute to the successful germination and cover of target species. Many of the soil factors measured in this study also displayed a high degree of collinearity, demonstrating that degradation of soil health can be seen in many forms. This included a general tendency of sites with higher compaction to also demonstrate reduced organic matter and soil $\mathrm{C}: \mathrm{N}$ ratios, lower volumetric water content and higher variation in soil temperatures and, when measured, reduced potassium and phosphorus availability. Such degraded soil quality was found to have negative associations with the presence and cover of target species to varying degrees, while invasive species showed a positive association, indicating they are better able to cope with these degraded conditions.

Modeling revealed that treatment had a significant and positive impact on germination of target species, indicating that many of the target species were viable from seed. However, both compaction and the density of worms were found to have a negative impact on target species germination. Compaction has previously been found to have negative impacts on the growth of forest herbs, which was attributed to anaerobic root environments, reduced water availability, 
and decreased root penetration (Small and McCarthy, 2002). The higher bulk density associated with compacted soils in urban environments has also been found to negatively affect soil organic matter (Pouyat et al., 2002), which has also been identified as an important predictor to target species cover in this study. Compaction measurements are easily taken in the field which can offer managers a quick and inexpensive means to determine seeding feasibility.

As ecosystem engineers, introduced earthworms are capable of drastically altering soil structure, nutrient dynamics, and seed bank compositions and subsequently, entire plant communities (Eisenhauer et al., 2009, Nuzzo et al., 2015, Szlavecz, et al. 2006). In this study we were unable to distinguish between native and introduced earthworms counted in surveys. However, in previous work within the Willamette Valley, Bailey et al. (2002), reported more than $97 \%$ of earthworms surveyed in remnant forests were introduced lumbricid species, while native earthworms were uncommon in these environments. Bailey et al. (2002) found these introduced species to have a positive correlation to organic matter content and soil moisture, but other studies have pointed to introduced earthworms as decreasing organic matter and C:N ratios while increasing bulk density in forest soils (Frelich et al., 2004, Szlavecz et al., 2006). The data in this study did not show a strong correlation between worm density and OM or compaction, but worm density had a negative relationship to soil C:N (Figure 1-11). Presence of introduced earthworms has also been found to result in the loss of herbaceous species diversity and a favoring of graminoids (Nuzzo et al, 2015), but a favoring of grass species was not observed in the current study. It has been described that introduced earthworms will likely elicit varied responses depending on plant functional traits (Thouvenot et al., 2021), including a tendency to promote species with larger seeds (Eisenhauer et al., 2008). This may help explain the relatively greater germination success of larger seeded species in this trial. While eradication of introduced 
earthworms is not a feasible endeavor for land managers, other methods of counteracting their negative impacts may exist. Seed coating with various protectants to reduce predation is a common practice for many agricultural species; however, such technologies have only recently been considered for seeds of native species intended for restoration (Pedrini et al. 2020). These technologies can help overcome other challenges to germination including limited soil moisture and nutrients (Pedrini et al., 2020) and therefore warrant further investigation to determine whether they may enhance restoration outcomes.

Soil OM and plant-available K were found to promote target species cover in separate models. The K model also included an effect of canopy type, with coniferous canopies exhibiting lower target cover than deciduous and mixed canopies. Plant-available K was highly collinear with plant-available $\mathrm{P}$ and soil OM, which likely explains why they were not included in the same model. Interestingly, plant-available nitrate and ammonium were not found to have any significant interaction with target species cover, either separately or combined, despite N's usual role as the primary limiting nutrient for plant growth in temperate forest ecosystems. However, recent work has acknowledged a switch from $\mathrm{N}$ limitation to $\mathrm{N}$ saturation in certain forest ecosystems due to increased atmospheric $\mathrm{N}$ deposition from anthropogenic sources, although much of this work has been centered around forests in the eastern United States where excess $\mathrm{N}$ deposition is especially problematic (Gilliam 2006, Small and McCarthy, 2005, Gonzales and Yanai, 2019). N saturation in Douglas fir forests of the Oregon Cascade Range has also been suggested (Perakis et al., 2006). There has been much debate whether excess $\mathrm{N}$ deposition results in subsequent P-limitation. Several studies have documented a switch to P limitation in the presence of excess N levels (Vitousek et al., 2010, Gress et al., 2007, Elser, 2007, Li et al, 2016, Gonzales and Yanai, 2019), while another study suggested evidence of $\mathrm{N}$ and P co-limitation in 
forest understories (Hedwall et al., 2017). However, many other studies have failed to recognize such a shift, with a metanalysis by Chen et al. (2020), finding that P limitation due to excess $\mathrm{N}$ deposition does not affect soil $\mathrm{P}$ in the long term as elevated $\mathrm{N}$ simultaneously acts to increase soil phosphatase activity. Again, most of this research has focused on effects of nutrient availability on tree foliar nutrients or overall biomass production. Since this study is concerned specifically with how nutrient availability affects restoration outcomes for temperate forest herbs, there is little research available for comparison. This, in combination with the use of Plan Root Simulator Probes - a relatively novel approach for which there is little comparable data in this field — and the limited number of samples $(n=14)$, makes it difficult to draw strong conclusions. However, the finding that plant available $\mathrm{P}$ and $\mathrm{K}$ limitation had stronger impacts on herbaceous species cover from seed as compared to $\mathrm{N}$, and that invasive species had a much stronger presence in $\mathrm{P}$ and $\mathrm{K}$ limited sites, provides an interesting avenue for future research.

Organic matter (OM) was also identified as a significant predictor for target species cover. Given the similar performance of the two models for target species cover and the fact that soil $\mathrm{OM}$ is more easily estimated than nutrient levels, this provides a more practical measurement when considering the feasibility of revegetating herbaceous species from seed. Soil organic carbon, from which OM estimates were derived, is a crucial component in terrestrial ecosystems, regulating ecosystem functioning by serving as the primary source of energy for microorganisms as well as controlling soil structure, soil moisture, and the availability of organically bound nutrients (Billings et al., 2021). Previous work has demonstrated the importance of OM in determining forest herbaceous layer composition (Weigel et al. 2019, Small and McCarthy, 2005), and it has long been recognized that soil OM is crucial to productivity in both forests and agriculture (Henderson, 1995). It has also been recognized that 
amending soils with OM can improve restoration outcomes, although such work has largely focused on arid regions and/or agricultural systems (Li et al., 2019, Tejada et al., 2006, Van Der Valk et al., 1999). In addition to soil OM being a strong indicator of whether seeding herbaceous species will be effective, our results indicate a potential pathway to improve restoration outcomes via addition of organic matter to soil. Deepening our understanding of soil organic carbon storage is also a critical factor in better understanding its role in climate change mitigation (Billings et al., 2021), highlighting the importance of continued research in this area.

Although not deemed statistically significant in GLMMs, soil C:N has been found to be important to herbaceous community composition in numerous studies (Hrivnák et al., 2015, Small and McCarthy, 2005, Weigel et al., 2019) and is therefore deserving of some discussion. NMDS plots of stem count data identified soil C:N as a strong driver of observed patters in understory assemblages in NMDS space (Figure 1-14), as there appeared to be a threshold in $\mathrm{C}: \mathrm{N}$ ratio $(\sim 15)$ below which plots did not perform well (Appendix H). Additionally, when looking at cover data from years 3-4 post-seeding, it was observed that the three sites with an average cover of target species per plot below $10 \%$ also exhibited the lowest $\mathrm{C}: \mathrm{N}$ ratios (mean 13.7) compared to more successful sites, while the best performing site, Tryon Creek 1 , had the highest C:N ratio (19). Similar trends were apparent for soil OM, plant-available P, and temperature variability, as the three worst performing sites also had the lowest levels of soil OM and plant-available $\mathrm{P}$ while having the highest degree of soil temperature variability. This again highlights that multiple soil properties can display degraded conditions that appear to make restoration sites resistant to revegetation of native herbaceous species from seed and more susceptible to reinvasion. 
This study demonstrates that multiple factors constrain the successful restoration of forest herbs from seed, with soil factors exhibiting the greatest impact in urban forest fragments. The physical, chemical, biological, and functional characteristics of soil quality of a site can be indicators about the overall health and resilience of an ecosystem (Pavao-Zuckerman, 2008). It can also greatly determine the ability of native species to thrive on a particular site following removal of invasive species, as native species may not be competitive in novel soil environments. In such instances, long-term success is contingent not only on the management of the invasive species, but also on an integrative approach that addresses soil conditions promoting invasion (Pavao-Zuckerman, 2008). Understanding a site's history and the causes of degradation will enable land-managers to make informed decisions when planning revegetation activities. Additionally, novel approaches to alleviate plant stress in degraded urban soil conditions, including soil amendments and seed treatments, are worth further investigation.

This study did not include any investigations into soil microbiota, which have been increasingly recognized as strong predictors of plant establishment (Van Der Heijden et al., 2008). Future studies addressing soil biota in addition to the soil properties analyzed in the current study would help to further understand soil related challenges in urban forest restoration. Additionally, while canopy cover and soil $\mathrm{pH}$ were not identified as strong predictors of either germination or cover of target species, this is likely due to the narrow ranges of values for both of these variables in our data set.

\section{Seeding Effectiveness and Feasibility}

The results of this study indicate that seeding herbaceous forest species following invasive removal does have short-term benefits of improving seedling presence and native diversity. Seeding also showed a modest suppression of invasive species present within trial 
plots. However, it remains difficult to assess whether a single seeding treatment will result in sustainable improvements. Long term outcomes are uncertain due to limited data in years 3 and 4 post seeding, and beyond. While there are many factors influencing the persistence of target species, the history of invasion is particularly important to consider. A recent study by Clements and Bierzychudek (2017) taking place in Portland, OR, found that invasive removal alone did not significantly improve the soil seed bank. Rather, sites with a longer period of invasion had seed banks dominated by invasive species, while a recently invaded site had a higher richness and abundance of native species. Additionally, many shade-tolerant species in temperate deciduous forests have been found to take many years to reach seed producing maturity (Bierzychudek, 1992). With these traits in mind, it may be advisable for land managers aiming to enhance herbaceous communities to perform supplemental seed additions. Such efforts warrant further investigation.

Other important considerations for land managers involve both the method of invasive removal and the timing of seed additions. While these traits were not explicitly explored within the present study, previous research has demonstrated the importance of both. In a study comparing the effects of two methods of English ivy (Hedera helix) removal and subsequent seeding on the regeneration of natural vegetation, Biggerstaff and Beck (2007) found that both method of removal and seed addition had significant effects on the density and diversity of seedlings to emerge. Hand-pulling resulted in a 5-fold increase in the number of species to emerge as well as a consistently higher density and diversity of seedlings. Seed addition also significantly increased density, diversity, and species richness of seedlings as well as increasing the proportion of natives over exotics; however, this trend was only true for the hand-pulled plots (Biggerstaff and Beck, 2007). In the current study, two sites within the Tryon Creek State 
Natural Area were also treated for English ivy using these distinct methods. However, seeded sites showed a similar response to one another regardless of ivy removal method (Figure 1-10) while control plots at the sprayed site (Tryon Creek 2) outperformed the hand-pulled site (Tryon Creek 1). Given the limited sample size of this trial, further investigations are necessary to determine whether observed differences are significant. Another interesting finding of the Biggerstaff and Beck (2007) study was that soil K levels decreased in the pulled plots over time. The authors postulated this to be evidence of leaching induced by the soil disturbance of handpulling, which could explain the observed mortality of seedlings in their pulled plots over time. Indeed, the hand-pulled site, Tryon Creek 1, also had reduced plant-available potassium compared to the sprayed site (Table 1-7). Again, such observations are very limited in sample size but provide another direction for future research.

The timing of seed additions is important to consider in several regards, including time elapsed since revegetation of woody species as well as time elapsed since treatment for invasive species. McClain et al. (2009) suggest that herbaceous revegetation in forests may be most successful using an active-relay floristics approach in which species are introduced over time as the site conditions become appropriate for later successional species. For shade-tolerant herbaceous species, this would require the presence of established woody species. Such an approach would likely be most successful in combination with continued human intervention to manage invasive species (Simmons et al., 2016). Herbicide application is the most commonly used and most effective method of invasive control (Kettering and Adams, 2011). However, herbicide application has also proven detrimental to native species even at the seed stage (Wagner and Nelson, 2014). McManamen et al. (2018) investigated the optimal time between herbicide application and reseeding to promote native seed germination and reduce chances of 
reinvasion. Greenhouse experiments yielded mixed results following herbicide application and reseeding: certain species increased gemination from 0-11 months, but other species had decreased germination over the entire 11-month study. Field results were also unclear, leading the authors to conclude that while there is evidence of herbicide application having adverse effects for seed germination, the actual degree to which this is true will vary by species and depend on the environmental conditions present at the site. Specifically, soil texture and organic matter affected herbicide mobility and residual time in the soil, with more organic matter and finer texture leading to a reduced residency (McManamen et al., 2018).

The current study also highlights the importance of environmental conditions on determining the success of seeding herbaceous species. While an evident germination response to the seeding treatment was apparent at nearly all sites (with the exception of riparian sites, Corral Creek and Ramsey, Figure 1-10), cover of target species was inconsistent across sites. This indicates that difficulties establishing target cover may not be primarily related to a poor performance of herbaceous seed, but rather related to site conditions regulating the persistence and cover of these species. 


\section{Chapter 2: Commercial Availability \& Production Survey}

\section{Background:}

A recent analysis by White et al. (2018) found that approximately $74 \%$ of vascular plants native to the U.S. are not currently available commercially, with herbs and forbs having the lowest availability compared to other growth forms. This either results in a lack of these species in restoration projects or forces project managers to source seed from wild collection or contract growing (i.e., advance purchase agreements), both of which can be cost-prohibitive. Part of USIP's mission is to promote the production of diverse understory plant materials so that they may be more widely utilized in regional restoration projects in the Willamette Valley ecoregion. This has been accomplished at a small scale through agency-level production via "amplification beds," wherein partner agencies grow target species for the explicit purpose of harvesting their seeds. However, such small-scale operations are not likely to produce sufficient quantities of seed for their widespread use in the region. As such, it became a priority of this project to conduct a survey of regional plant-material producers to answer the following research questions:

1. What is the current commercial market availability of target species?

2. What are the major challenges to increasing production of target species?

3. What opportunities exist for expanding production of target species?

4. What requirements exist for expanding production via contract growing, specifically? Results from this survey have been used to inform recommendations for future directions that the USIP team can pursue to further their goal of increasing the feasibility of using these species in restoration projects across the region. 


\section{Methods:}

Due to the nature of this survey involving human participants, the survey was subject to the Institutional Review Board (IRB) process through Portland State University's Human Research Protection Program (HRPP). The survey was granted an exemption due to the determined low risk to participants. The survey (Appendix M) was developed in consultation with the USIP team and has three main sections: current availability, challenges, and opportunities for expansion. The first section asks businesses to identify which species they currently offer from an expanded list of target species. This list encompassed both species that were used for riparian and upland seed mixes, as well as a handful of other species that the team was interested in working with but were not available for those mixes. The second section asks for agree/disagree responses relating to various challenges in the production of herbaceous species. The third section includes one Yes/No question regarding willingness to contract grow along with three open-ended questions about requirements for contract growing. The final openended question asks for any other feedback concerning challenges or opportunities for the production of target species. The survey was formatted so that non-open-ended questions could be answered either broadly or for specific species using a matrix of questions numbers and species names.

A list of native plant material producers was compiled through consultation with the USIP team to include plant material providers they currently or have previously purchased from. To expand the pool, additional plant material providers were identified through PlantNative.org and Google searches, limited to the Willamette Valley ecoregion. This resulted in the identification of 35 vendors who were invited to participate. Initial outreach included an introductory email to explain the purpose of the survey and to ask those interested in 
participating to respond, so that they could be sent a copy of the survey in either paper or electronic form. The survey window was opened from the time of initial outreach in early October to its closing in mid-December. For the initial two months of the survey, reminder emails were sent at three-week intervals until the last two weeks of the survey, when reminders were sent weekly to businesses that had not yet participated. Select businesses, who were of special interest to my project team due to their production of species of interest and/or seeds specifically, were contacted directly via phone and/or personalized emails.

Of the 35 potential businesses, 19 responded to my requests. Several (3) businesses replied that they were not interested in participating, but two of these businesses did offer feedback relevant to our research questions, and their responses are therefore included in the results of the survey. A copy of the survey was sent to a total of 16 respondents and a completed version of the survey was received back from 11 participants. This included feedback from one business who deals entirely in the collection of seeds rather than production, for whom the survey was modified. These modifications resulted in this survey being summarized separately from other surveys for all questions besides that dealing with demand of target species.

The survey included both multiple choice and open-ended questions, and as such Microsoft Excel offered the most flexibility for summarizing results. Multiple choice answers were tabulated and summarized graphically using Excel. Open-ended questions were summarized qualitatively. 


\section{Results:}

\section{Commercial Availability}

The first question of the survey asked business owners to identify target species that are currently produced in any growth form. Several businesses (5) who did not return a formal survey were included in the response to this section, because they had online catalogs available, enabling me to answer the question. Due to this, the total participant pool for this question was 16 production businesses, plus one collection business. The collection business was able to collect any species on our list, but because collection is typically done in a contracted manner, this result was not included in the final tally. Of the 16 production businesses, all but one produced at least one target species. That business currently only works in the production of trees and shrubs, and therefore was also not included in the final tally. With these exclusions, the total counts are out of a possible 15 businesses. Table 2-1 summarizes the number of vendors who currently produce each species.

Table 2-1: Commercial availability of herbaceous species of interest in the Willamette Valley.

\begin{tabular}{lcc|lcc}
\hline Species & Codon & $\begin{array}{c}\text { \# Vendors } \\
\text { Offering }\end{array}$ & Species & Codon & $\begin{array}{c}\text { \# Vendors } \\
\text { Offering }\end{array}$ \\
\hline Adenocaulon bicolor & ADBI & 1 & Juncus patens & JUPA & 10 \\
Aquilegia Formosa & AQFO & 11 & Melica subulate & MESU & 0 \\
Bromus vulgaris & BRVU & 3 & Nemophila parviflora & NEPA & 0 \\
Carex leptopoda & CALE & 6 & Osmorhiza berteroi & OSBE & 1 \\
Carex obnupta & CAOB & 12 & Penstemon ovatus & PEOV & 2 \\
Circaea alpine & CIAL & 2 & Scrophularia californica & SCCA & 4 \\
Claytonia perfoliata & CLPE & 2 & Stachys chamissonis v. cooleyae & STCH & 2 \\
Claytonia sibirica & CLSI & 3 & Tellima grandiflora & TEGR & 13 \\
Dicentra Formosa & DIFO & 9 & Thalictrum polycarpum & THPO & 2 \\
Elymus glaucus & ELGL & 8 & Tolmiea menziesii & TOME & 8 \\
Festuca occidentalis & FEOC & 4 & Urtica dioica & URDI & 0 \\
Geum macrophyllum & GEMA & 9 & Vancouveria hexandra & VIGL & 7 \\
Hydrophyllum tenuipes & HYTE & 5 & Viola glabella & 6 \\
\hline \multicolumn{7}{l}{}
\end{tabular}


The commercial availability varied greatly by species, with the number of businesses currently producing each species ranging from 0 to 13 . Three species were offered by no vendors in this survey, while an additional six species were only offered by 1 or 2 . This, unfortunately, was the case for 4 out of 8 of the most successful species from seed in trial plots (OSBE, ADBI, CIAL, and NEPA).

\section{Challenges in Production}

The second portion of the survey aimed to identify major challenges in producing herbaceous species with the hopes that understanding these challenges may enable the USIP to help expand production, particularly of species that have demonstrated strong performance from seed. One unintended consequence of the survey design was a limited sample size for many of the questions within this portion. This arose due to the survey allowing participants to answer questions broadly (i.e., stating their answer was applicable to all species) or in a species-specific manner (see Appendix M for survey design). Due to the number of participants already being limited, this choice resulted in a further division of answers, since a portion of respondents answered broadly, while others answered specifically or using a combination of the two. These results are still valuable, but it is important to keep this limitation in mind.

The first question asked whether producing additional target species was challenging. This garnered a mixed response from the 10 respondents: 3 disagreed, 2 were neutral, 4 agreed, and 1 strongly agreed. While this indicates a slight lean towards agreement, from looking at the species-specific answers, it likely varies by business and by species (Figure 2-1). The sample sizes for species-specific answers are extremely limited for this question, so little else can be 
deduced from this information

besides a slight consensus that

TEGR and FEOC may be

challenging to produce.

The next questions asked

participants to agree or disagree

with various factors that make

production of herbaceous species

challenging, including lack of

demand, lack of seed supply,

lack of propagation knowledge,

lack of time and personnel

resources, lack of shade

infrastructure needed to grow

herbaceous species, and

difficulties using machinery to

harvest herbaceous seed. The

broad answers for this question

can be viewed in Figure 2-2.

For many of these
Overall

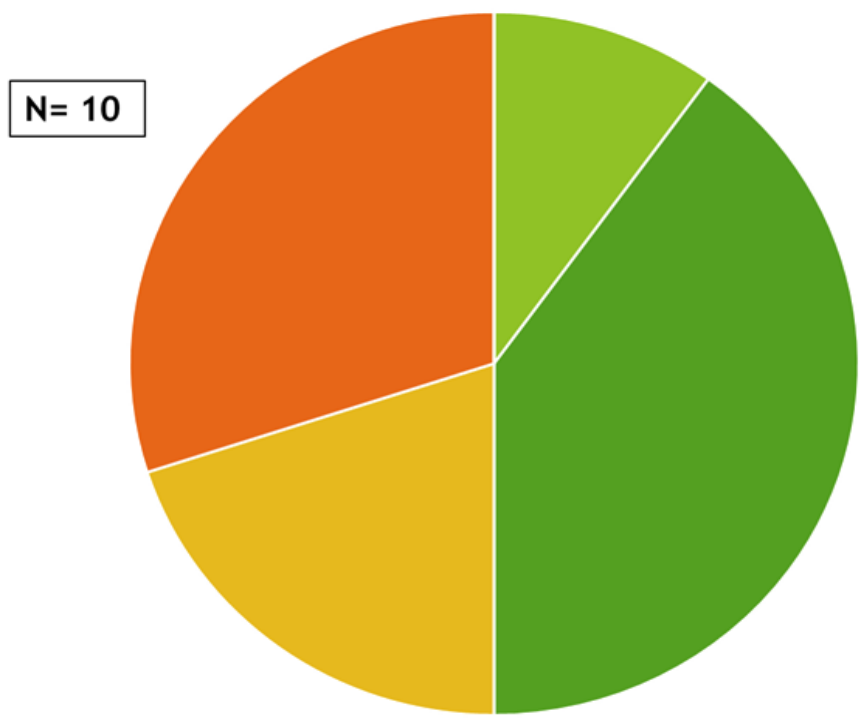

Species-specific

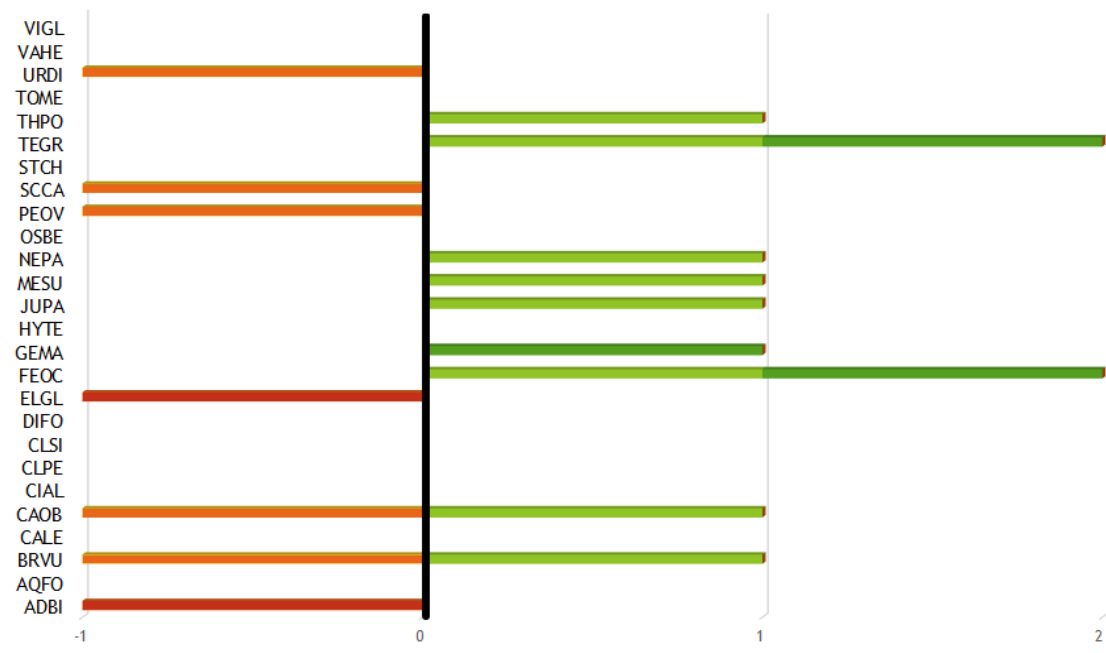

$\approx$ Strongly Agree $\backsim$ Agree $\backsim$ Neutral $\backsim$ Disagree $\backsim$ Strongly Disagree

Figure 2-1:Survey responses to question 2 asking participants to agree or disagree with the statement: "The production of additional target species is challenging." Answers were provided at two scales: overall, and speciesspecific.

proposed challenges, there was a high degree of disagreement from the various participants. This was especially true for the challenges regarding seed supply, time and personnel resources, and shade infrastructure. Unsurprisingly, infrastructure, time, and personnel resources received 
highly varied responses, as such challenges are business specific. Lack of propagation knowledge was only listed as a challenge by $1 / 5$ participants, indicating it is a relatively minor challenge. Difficulties using machinery also do not seem to hinder production.

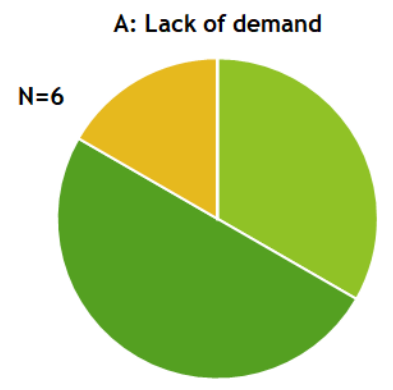

D: Lack of time \& personnel resources

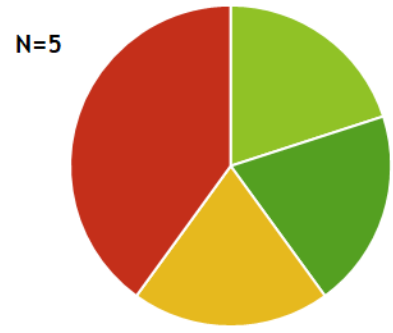

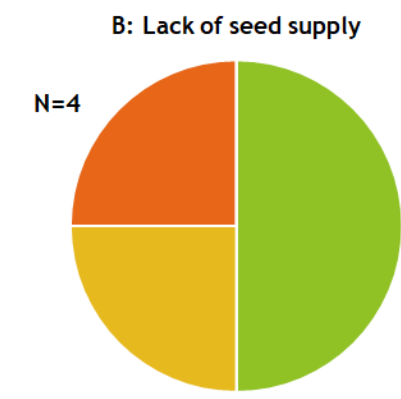

E: Lack of shade infrastructure

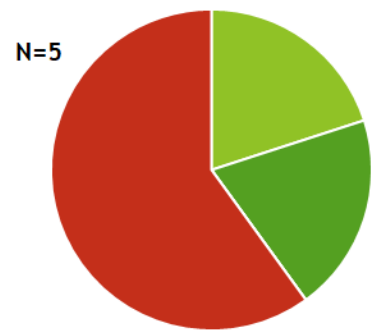

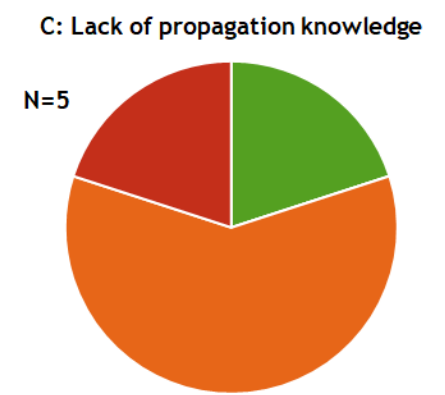

F: Difficulties using machinery to harvest

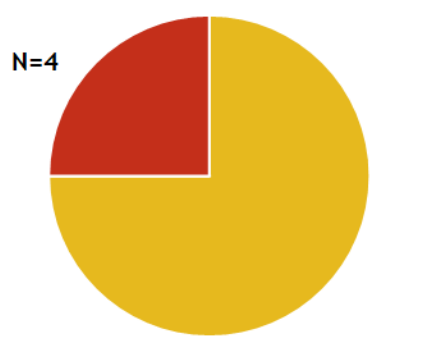

= Strongly Agree

- Agree

- Neutral

- Disagree

- Strongly Disagree

Figure 2-2: Overall survey responses identifying challenges in producing target herbaceous species.

Lack of demand was identified as a challenge by 5/6 participants, with half (3) stating that they strongly agree. One participant gave a neutral response and proceeded to describe that it varied by species, with some species having an adequate demand and others not (Figure 2-3). Lack of demand was by far the most agreed-upon challenge and was also mentioned in several of the open-ended questions, which specifically referred to a lack of stability in demand.

Several respondents answered questions relating to challenges in production on a speciesto-species basis, usually only for the species that they currently produced (Figure 2-3). This information is some of the most limited in sample size as a result, but largely mirrors the responses from the broadly answered questions when taken as a whole. While there is a high 

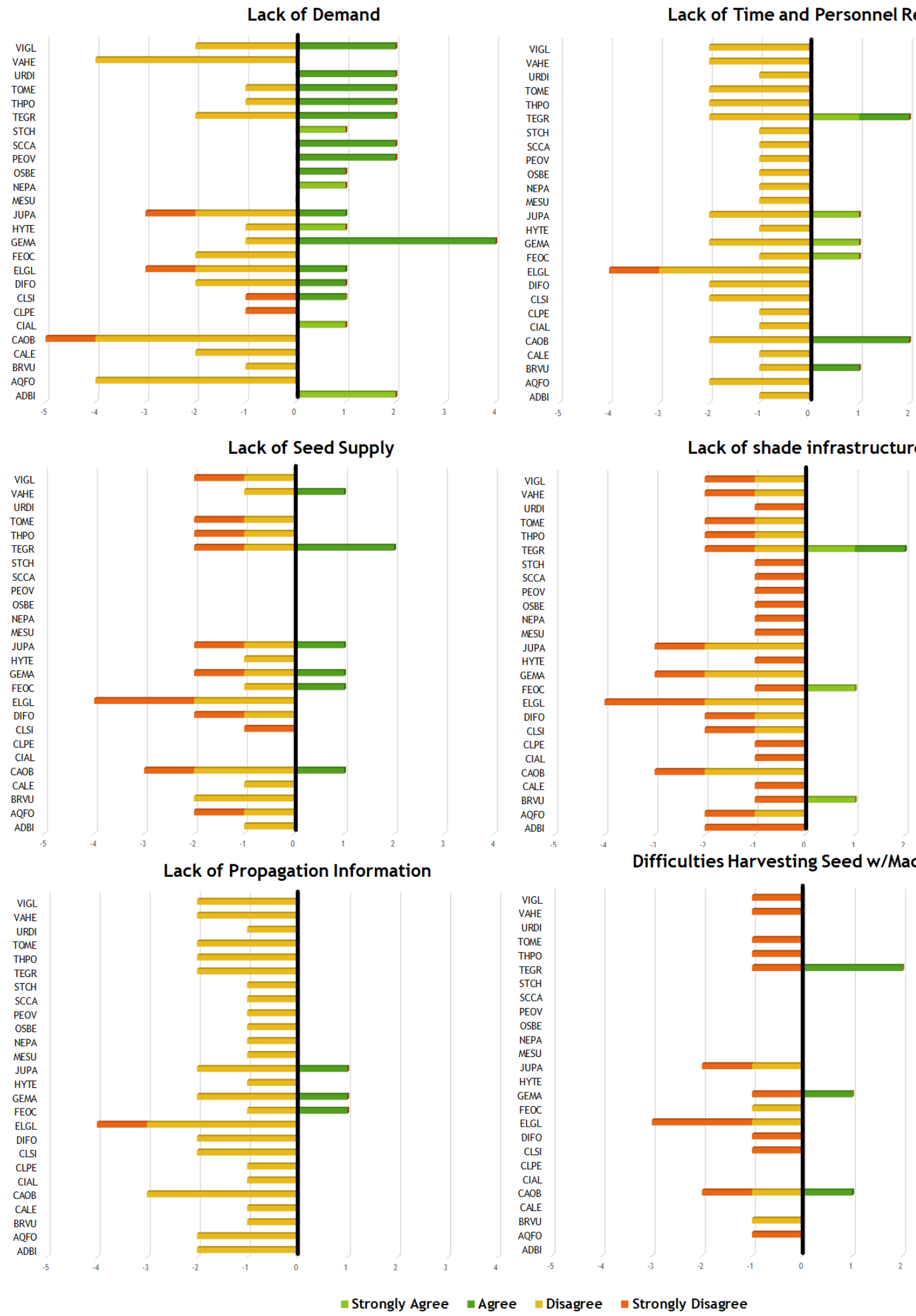

Figure 2-3: Species-specific responses identifying challenges in producing target herbaceous species 
degree of disagreement for many individual species in the various proposed challenges, there are several trends to be seen. These graphs further solidify that demand is the most agreed-upon challenge, while other challenges have varied responses that overwhelmingly lean towards disagreement.

One interesting finding from these responses comes from comparing the demand to current production of target species. Many of the most limited species in terms of commercially availability are also described as suffering from a lack of demand (ADBI, NEPA, OSBE). The inverse is also true where species that are the most commercially available (AQFO, CAOB, JUPA) have strong disagreement that there is a lack of demand. There are also two prominent cases where these trends do not hold-TEGR is one of the most commercially available species but the demand response is mixed, and GEMA is also widely available, but responses indicate a lack of demand.

The last question of the survey was an open-ended question asking for businesses to describe additional challenges, needs, or opportunities in expanding production of target herbaceous species. There were 8 businesses that used this opportunity to elaborate on specific challenges. This included two businesses that described specific reasons (climatic and limited resources) for not wanting to expand species production via contract growing. Demand was again the most frequent challenge described by remaining participants, as it was mentioned in open-ended questions by all 6 of the remaining participants. Three businesses described that an increase in demand for these species would drive production, whether via contract orders or inclusion on needs lists. Two other participants described that fluctuations in demand for these species make their production inherently risky and not a worthwhile investment. This was further reinforced by one business that stated they had previously produced several of these species, but 
there were not adequate purchases to make continued production a viable option. The amount of time associated with producing herbaceous species was also a frequently (4/6) described challenge. Several businesses (3) noted that it could take a year between contracts being placed and species production starting, with additional years (2-3) before species reached seedproducing maturity. The combination of unstable demand and lengthy production periods was described as creating a volatile market for these businesses.

Other challenges described by respondents include issues with seed provenance, viability, and yield, as well as the matter of scale. Native seed production for restoration requires locally sourced and genetically diverse source populations, described as "almost impossible to accommodate beyond small scale production." Additionally, specific challenges of herbaceous seeds such as low yields and relatively short periods they remain viable were also described as being major challenges that could ultimately make the investment of time, effort, and financial resources required for their production uneconomical. To overcome the costs and risks, two participants suggested that demand and/or contracts needed to be of adequate size that operating costs could be reduced by larger scale production.

\section{Opportunities for Expansion}

The final portion of this survey asked commercial vendors to identify whether they were interested in expanding production via contract growing. Despite the aforementioned challenges in producing these species, $7 / 10$ businesses were willing to produce additional target species and only one specified that contract size would have to be sufficiently large to do so. Three follow-up questions were posed only to participants who were willing to contract grow. When asked explicitly if there was a minimum land area requirement for contract growing, 4/7 vendors said 
no, 1 said yes (5-10+ acres), and 2 said it depends on factors including the demand, size, and seed availability for each species.

The survey then asked participants what quantity of seed would be desirable to ramp up commercial production and what level of propagation information they would prefer to receive for new species. Due to the open-ended format of these questions, there were a variety of responses. Regarding seed volumes, the most frequent response (4) included that it "depends" on specific factors, including the species in question, viability of seed, and desired quantity to be ordered. One participant went on to describe, "Quantities of hundreds to thousands require ounce type rather than pound type quantities." Another participant stated the more seed the better, and finally, one respondent gave a specific quantity of 8-10 pounds per acre. General information about successful propagation protocols was described as desirable by 3 participants, while 2 participants said such information was not needed. In one case, this was due to the business having previously worked with these species. Finally, one respondent identified several key points of information that would be helpful, including whether seed or transplants were the desired material, what dormancy requirement exists, what response the seed of a certain species would have to scarification, and finally what the timetable would be to maximum seed yield.

\section{Discussion \& Recommendations:}

The current market availability of herbaceous species included in this survey was highly varied; however, all but 3 of 26 species were available from at least one business in our sample. This represents a much lower number than the national average of $74 \%$ of native species being commercially unavailable (White et al., 2018). Unfortunately, several of the best performing species from seed (including OSBE, ADBI, and NEPA), had very limited availability, only being 
offered by $0-7 \%$ of vendors. This represents a major challenge to expanding their use in restoration. This occurrence is not only a regional problem, as the limited number of species produced commercially has been described as a biodiversity filter in ecological restoration in many regions of the world (Ladouceur et al., 2018, White et al., 2018, Vidal et al., 2020).

One limitation of this survey is there was not a chance for participants to describe whether they offered individual species as transplants or seed. Such a distinction would have undoubtedly been useful; however, it would have further complicated the already complex survey design. While a survey intended only for seed producers would have alleviated this issue, businesses offering seeds would have further limited the pool of respondents, as only $\sim 50 \%$ of respondents produce seed of herbaceous species. Taking this into account, the actual availability of seed is likely more limited than the overall availability of these species.

There are many factors that make the production of native plant materials challenging. Many of the issues that were touched upon by survey respondents are related to seed quality, which has been the focus of much research. It is widely accepted that plant material for restoration should be locally adapted and sourced to maintain genetic diversity to promote favorable restoration outcomes (Altricher, 2016, Bucharova et al., 2019, White et al., 2018, Basey et al., 2015). These requirements, along with challenges of low seed yield, short periods of viability, and the need to obtain seeds in a manner so as not to harm source populations, complicate the initial collection of wild seed (Broadhurst et al., 2015, Ladouceur et al., 2018). Additionally, while it is recognized that proper seed storage is crucial in maintaining seed viability (De Vitis et al., 2020), there is little information available about specific storage requirements and subsequent periods of viability for many native species (Shaw et al., 2005). Information regarding germination requirements and dormancy breaking treatments are also 
generally lacking (White et al., 2018), even though species with published germination data are more likely to be offered commercially (Ladouceur et al., 2018). As such, species specific research into these various topic areas is recommended to help alleviate challenges to herbaceous species production.

Despite the many technical challenges of wild seed procurement, storage, and subsequent propagation of herbaceous species, these challenges alone did not appear to significantly impede their production. Rather, the instability of demand for species was the major challenge described by survey participants. Because many native plant producing operations are small scale with finite resources, a fluctuating market severely limits the economic feasibility of production. This challenge is not unique to the Willamette Valley, with various similar research efforts also identifying unstable demand as a significant challenge to increasing the available species pool for restoration (Shaw et al., 2005, Gerken Golay, 2013, White et al., 2018).

Contract growing offers an opportunity for businesses to overcome the obstacle of an unpredictable market and has been utilized both regionally and elsewhere (Shaw et al., 2005). However, as survey respondents highlighted, such contracts often must be put in place years in advance of planned restoration activities. Additionally, this approach can be resource intensive, requiring knowledge of source populations and propagation protocols, which often means there are high costs associated with these contracts (Shaw et al., 2005). The barriers of time and monetary resources restrict the number of potential consumers utilizing this option, and results in many projects relying on a less diverse pool of already available species (Shaw et al., 2005). Nevertheless, contract growing is an important tool for agencies who can afford it, as it reduces the economic risks for production businesses. 
A more sustainable and long-term solution to the shortage in production of native herbaceous species is to facilitate an increase in their demand. While this is undoubtedly a challenging task, the following recommendations are proposed:

\section{Continued research and development of guidance documents on the use of} herbaceous species in forest restoration projects: Research conducted in this project has made large strides in better understanding the feasibility of restoring native herbaceous species from seed in urban forest fragments in the Pacific Northwest. However, there are many questions left unanswered. Continued research to address questions regarding optimal timing and rates of seeding, as well as investigations into options to accommodate specific environmental conditions found to constrain restoration outcomes (including compaction, lack of organic matter, and presence of invasive earthworms) are still needed. Additionally, research into storage and germination requirements of individual species would help reduce uncertainty for native plant producers. To make this information most accessible, the creation of guidance documents designed for restoration professionals interested in working with these species is suggested. An example of such a product designed for riparian tree and shrub planting in the Willamette Valley was created by Withrow-Robinson et al. (2011) from the Oregon State University Extension Service. Sharing of such knowledge can be key to expanding demand and production of native seeds (Ladouceur et al., 2018).

\section{Education and outreach to inform diverse regional restoration practitioners of} benefits and best practices in revegetation of native forest herbaceous species: Education and outreach to various potential consumers is one key mechanism to drive 
increased demand for native species (White et al. 2018). With information from this study, recommendations can be made on which species work well from seed and specific site factors that need to be addressed for successful restoration outcomes. Free sharing of this information is encouraged. It is also advisable to create a central repository for various resources relating to restoration of forest herbaceous species in this region. Educational products available in such a repository should reflect not only results from the current study, but perspectives from diverse groups, including seed production and nursery professionals and, if possible, tribal members with traditional ecological knowledge. Outreach will be needed to draw attention to such resources and should also focus on diverse groups working in the field of restoration.

\section{Forming partnerships to create broader interest and scale up demand: While USIP} already represents a strong partnership between several organizations, effecting greater change in the market for and use of herbaceous forest species in restoration will require a larger and more diverse coalition. Partnerships with federal and local agencies, universities, production professionals, and various community organizations will help bring unique perspectives to the table, while also increasing the volume and stability of demand. Collaboration at a regional scale has proven successful in Midwest tallgrass prairies by increasing the number of available species for restoration (White et al., 2018), and can expand funding and research opportunities. 


\section{Concluding Remarks:}

A native herbaceous layer provides many important ecological services in forested environments, as well as accounting for most of their overall biodiversity (Gilliam, 2007). With threats of biotic homogenization resulting from species invasions in urban forests, and evidence that herbaceous species cannot overcome dispersal limitations in these highly fragmented landscapes, it is increasingly important that these species are included in revegetation efforts. The Understory Species Increase Project has initiated efforts to evaluate the feasibility of introducing native forest herbs from seed by conducting two separate but complementary investigations: assessing practical implementation of seeding herbaceous species at trial plots in candidate restoration sites; and evaluating the current market for regionally produced species and challenges associated with their production through a survey of plant material producers.

Results from trial plots indicate overall success of seeding in terms of increasing germination and cover of seeded species, as well as improving overall biodiversity. However, performance of the seeding treatment was not consistent across sites. One thing that has become increasingly clear from this study is the need to consider the soil substrate in which we expect plants to grow during restoration activities. Sites with evidence of degraded soil conditions (i.e., highly compacted, high presence of earthworm, low organic matter, and low nutrient levels) generally showed a diminished performance of target species and an increased presence of invasive species. While such conditions are not ideal for a one-time seeding treatment, it may be possible to overcome soil-health barriers through seed treatments, cover cropping, or soil amendments. Additionally, continued maintenance to control invasive species or supplemental seed additions may be required to strengthen revegetation outcomes from seed. The effectiveness 
and feasibility of such practices should be assessed in future studies, which should be based on a prior understanding of a site's soil health, when possible.

In situations where sites do not display signs of degraded soil health, seeding a diverse mix of herbaceous species has proven beneficial in increasing the presence and diversity of native herbaceous species. We have identified species which demonstrate strong establishment from seed (especially: OSBE, ADBI, VAHE, CIAL, HYTE, BRVU, and ELGL), which should be prioritized for use in restoration. Unfortunately, the commercial availability of several of these species is extremely limited, especially from seed. While contract growing may offer a relatively short-term solution to this problem, it may not be a feasible solution for all organizations, and still requires 1-2 years advanced notice, depending on the production businesses and species. To increase commercial availability in a more sustainable and accessible manner, it will be necessary to create a stable demand for these species. Recommendations have been made for accomplishing this task, including continued research and creation of guidance documents, education and outreach to share information and garner interest in these species, and continued formation of diverse partnerships to help expand and stabilize demand. With this continued work, revegetation of forest herbaceous species may become a more common practice in the Willamette Valley, helping land managers to enhance biodiversity, ecosystem resilience, and to recover associated ecosystem services. 


\section{References:}

Altrichter, Emily Anne. (2016). Restoration of the forest herbaceous layer: genetic differentiation, phenotypic plasticity, and opportunities for conservation and nursery professionals. Graduate Theses and Dissertations. 15105. https://lib.dr.iastate.edu/etd/15105 Bailey, D.E., Rosenberg, D.K., Fender, W., McKey-Fender, D., Jacobs J. (2002). Patterns of abundance and habitat associations of earthworms in remnant forests of the Willamette Valley, Oregon, Northwest Sci., 76, pp. 26-34

Basey, A. C., Fant, J. B., \& Kramer, A. T. (2015). Producing native plant materials for restoration: 10 rules to collect and maintain genetic diversity. Native Plants Journal, 16(1), 3753. https://doi.org/10.3368/npj.16.1.37

Bassett, I.E., Simcock, R.C. and Mitchell, N.D. (2005). Consequences of soil compaction for seedling establishment: Implications for natural regeneration and restoration. Austral Ecology, 30: 827-833.

Bauer, J.T. and Reynolds, H.L. (2016). Restoring native understory to a woodland invaded by Euonymus fortunei: multiple factors affect success. Restoration Ecology, 24: 45-52.

doi:10.1111/rec.12285

Bierzychudek, P. (1982). Life histories and demography of shade-tolerant temperate forest herbs: a review. New Phytologist 90:757-776.

Biggerstaff, Matthew S., \& Beck, Christopher W. (2007). Effects of Method of English Ivy Removal and Seed Addition on Regeneration of Vegetation in a Southeastern Piedmont Forest. The American Midland Naturalist, 158(1), 206-220.

Billings SA, Lajtha K, Malhotra A, Berhe AA, de Graaff MA, Earl S, Fraterrigo J, Georgiou K, Grandy S, Hobbie SE, Moore JAM, Nadelhoffer K, Pierson D, Rasmussen C, Silver WL, Sulman BN, Weintraub S, Wieder W. (2021). Soil organic carbon is not just for soil scientists: measurement recommendations for diverse practitioners. Ecol Appl Apr;31(3):e02290. doi: 10.1002/eap.2290. Epub 2021 Feb 25. PMID: 33426701.

Broadhurst, L. M., Jones, T. A., Smith, F. S., North, T., \& Guja, L. (2015). Maximizing Seed Resources for Restoration in an Uncertain Future. BioScience, 66(1), 73-79. doi:10.1093/biosci/biv155

Brudvig, L. A., Mabry, C. M., \& Mottl, L. M. (2010). Dispersal, not Understory Light Competition, Limits Restoration of Iowa Woodland Understory Herbs. Restoration Ecology, 19(101), 24-31. doi:10.1111/j.1526-100x.2010.00675.x

Bucharova, A., Bossdorf, O., Hölzel, N., Kollmann, J., Prasse, R., \& Durka, W. (2018). Mix and match: regional admixture provenancing strikes a balance among different seed-sourcing strategies for ecological restoration. Conservation Genetics. doi:10.1007/s10592-018-1067-6 
Chen, J., van Groenigen, K. J., Hungate, B. A., Terrer, C., van Groenigen, J., Maestre, F. T., Elsgaard, L. (2020). Long-term nitrogen loading alleviates phosphorus limitation in terrestrial ecosystems. Global Change Biology. doi:10.1111/gcb.15218

City of Portland's Bureau of Planning and Sustainability. (2016). Portland Plant List. Accessed: 3/13/2020. https://www.portlandoregon.gov/citycode/article/322280

Clarke, R. K., P. J. Somerfield, M. G. Chapman. (2006). On resemblance measures for ecological studies, including taxonomic dissimilarities and a zero-adjusted Bray-Curtis coefficient for denuded assemblages. Jour. of Experimental Marine Biology and Ecology. 330:55-80.

Clements, H., and Bierzychudek, P. (2017). Can the persistent seed bank contribute to the passive restoration of urban forest fragments after invasive species removal? Ecological Restoration, 35:156-166.

Clewell, A. F. (1999). Restoration of riverine forest at Hall Branch on phosphate- mined land, Florida. Restoration Ecology 7:1-14.

Cordell, S., Ostertag, R., Rowe, B., Sweinhart, L., Vasquez-Radonic, L., Michaud, J., Cole, T.C., Schulten, J.R. (2009). Evaluating barriers to native seedling establishment in an invaded Hawaiian lowland wet forest. Biological Conservation,142(12): 2997-3004. DOI:

10.1016/j.biocon.2009.07.033.

Cullina, W. (2000). Growing and propagating wildflowers of the United States and Canada. Houghton Mifflin Co., Boston, Massachusetts.

De Vitis, M., Hay, F. R., Dickie, J. B., Trivedi, C., Choi, J., \& Fiegener, R. (2020). Seed storage: maintaining seed viability and vigor for restoration use. Restoration Ecology. doi:10.1111/rec.13174

Dormann, C. F., Elith, J., Bacher, S., Buchmann, C., Carl, G., Carré, G., Lautenbach, S. (2012). Collinearity: a review of methods to deal with it and a simulation study evaluating their performance. Ecography, 36(1), 27-46. doi:10.1111/j.1600-0587.2012.07348.x

Eisenhauer, N., Scheu, S. (2008). Invasibility of experimental grassland communities: the role of earthworms, plant functional group identity and seed size. Oikos 117, 1026-1036..

doi:10.1111/j.0030-1299.2008.16812.x

Eisenhauer, N., Straube, D., Johnson, E. A., Parkinson, D., \& Scheu, S. (2009). Exotic Ecosystem Engineers Change the Emergence of Plants from the Seed Bank of a Deciduous Forest. Ecosystems, 12(6), 1008-1016. doi:10.1007/s10021-009-9275-z 
Elser, J.J., Bracken, M.E.S., Cleland, E.E., Gruner, D.S., Harpole, W.S., Hillebrand, H., Ngai, J.T., Seabloom, E.W., Shurin, J.B., Smith, J.E. (2007). Global analysis of nitrogen and phosphorus limitation of primary producers in freshwater, marine and terrestrial ecosystems, 10(12), 1135-1142. doi:10.1111/j.1461-0248.2007.01113.x

Fox, J. (2003). Effect Displays in R for Generalised Linear Models. Journal of Statistical Software, 8(15), 1-27. URL https://www.jstatsoft.org/article/view/v008i15.

Franczyk, J., Chang, H. (2009). The effects of climate change and urbanization on the runoff of the Rock Creek basin in the Portland metropolitan area, Oregon, USA. Hydrological Processes 23, 805-815.. doi:10.1002/hyp.7176

Frelich, L.E., Hale, C.M., Scheu, S., Holdsworth, A.R., Heneghan, L., Bohlen, P.J., Reich, P.B. (2006). Earthworm invasion into previously earthworm-free temperate and boreal forests. Biological Invasions 8, 1235-1245.. doi:10.1007/s10530-006-9019-3

Gerken Golay, Michaeleen E. (2013). Assessing the composition and function of hardwood forest herbaceous flora: implications and applications for forest restoration. Graduate Theses and Dissertations. 13031.https://lib.dr.iastate.edu/etd/13031

Gilliam, F. (2007). The Ecological Significance of the Herbaceous Layer in Temperate Forest Ecosystems, BioScience, 57(10): 845-858

Gilliam F.S., Roberts M.R. (2003). The Herbaceous Layer in Forests of Eastern North America. New York Oxford University Press.

Gilliam, F. S., Welch, N. T., Phillips, A. H., Billmyer, J. H., Peterjohn, W. T., Fowler, Z. K., ... Adams, M. B. (2016). Twenty-five-year response of the herbaceous layer of a temperate hardwood forest to elevated nitrogen deposition. Ecosphere, 7(4), e01250.

doi:10.1002/ecs 2.1250

Gonzales, K., \& Yanai, R. (2019). Nitrogen-phosphorous interactions in young northern hardwoods indicate $\mathrm{P}$ limitation: foliar concentrations and resorption in a factorial $\mathrm{N}$ by $\mathrm{P}$ addition experiment. Oecologia. doi:10.1007/s00442-019-04350-y

Gress, S. E., Nichols, T. D., Northcraft, C. C., \& Peterjohn, W. T. (2007). Nutrient Limitation in Soils Exhibiting Differing Nitrogen Availabilities: What Lies Beyond Nitrogen Saturation? Ecology, 88(1), 119-130. doi:10.1890/0012-9658(2007)88[119:nlised]2.0.co;2

Groffman, P. M., J. M. Tiedje, G. P. Robertson, and S. Christensen. (1987). Denitrification at different temporal and geographical scales: Proximal and distal controls, in Advances in Nitrogen Cycling in Agricultural Ecosystems, edited by J. R. Wilson, pp. 174-192, CAB International, Oxon, UK. 
Harrison, X.A., Donaldson, L., Correa-Cano, M.E., Evans, J., Fisher, D.N., Goodwin, C., Robinson, B., Hodgson, D.J., Inger, R. (2017). Best practice in mixed effects modelling and multi-model inference in ecology. doi:10.7287/peerj.preprints.3113v1

Harrison, X. A., Donaldson, L., Correa-Cano, M. E., Evans, J., Fisher, D. N., Goodwin, C. E. D., Inger, R. (2018). A brief introduction to mixed effects modelling and multi-model inference in ecology. PeerJ, 6, e4794. doi:10.7717/peerj.4794

Hartig, F. (2020). DHARMa: Residual Diagnostics for Hierarchical (Multi-Level / Mixed) Regression Models. R package version 0.3.3.0. https://CRAN.R-project.org/package=DHARMa

Hedwall, P.-O., Bergh, J., \& Brunet, J. (2017). Phosphorus and nitrogen co-limitation of forest ground vegetation under elevated anthropogenic nitrogen deposition. Oecologia, 185(2), 317326. doi:10.1007/s00442-017-3945-X

Henderson, G.S, McFee, W. W., Kelly, J. M. (1995). Soil Organic Matter: A Link Between Forest Management and Productivity. ACSESS Publications. doi:10.2136/1995.carbonforms.c19

Holl, K. D., and Aide, T. M. (2011). When and where to actively restore ecosystems? For. Ecol. Manage. 261, 1558-1563. doi: 10.1186/s13062-015-0094-1

Holl, K. D. and Crone, E.E. (2004). Applicability of landscape and island biogeography theory to restoration of riparian understorey plants. Journal of Applied Ecology 41:922-933.

Huang, L., Zhu, W., Ren, H., Chen, H., Wang, J. (2012). Impact of atmospheric nitrogen deposition on soil properties and herb-layer diversity in remnant forests along an urban-rural gradient in Guangzhou, southern China. Plant Ecol 213, 1187-1202. doi:10.1007/s11258-0120080-y

Hulme, P.E. (2006). Beyond control: wider implications for the management of biological invasions. Journal of Applied Ecology 43, 835-847.. doi:10.1111/j.1365-2664.2006.01227.x

Hrivnák, R., Slezák, M., Jarčuška, B., Jarolímek, I., \& Kochjarová, J. (2015). Native and Alien Plant Species Richness Response to Soil Nitrogen and Phosphorus in Temperate Floodplain and Swamp Forests. Forests, 6(12), 3501-3513. doi:10.3390/f6103501

Jakobsson, A. and Eriksson, O. (2002). Seed size and frequency patterns of understory plants in Swedish deciduous forests. EcoScience 9: 74-78.

Kettenring, K.M. and Adams, C.R. (2011), Lessons learned from invasive plant control experiments: a systematic review and meta-analysis. Journal of Applied Ecology, 48: 970-979. doi:10.1111/j.1365-2664.2011.01979.x

Ladouceur, E., Jiménez-Alfaro, B., Marin, M., De Vitis, M., Abbandonato, H., Iannetta, P. P. M. Pritchard, H. W. (2017). Native Seed Supply and the Restoration Species Pool. Conservation Letters, 11(2), e12381. doi:10.1111/conl.12381 
Li, Y., Niu, S., \& Yu, G. (2016). Aggravated phosphorus limitation on biomass production under increasing nitrogen loading: a meta-analysis. Global Change Biology, 22(2), 934-943.

doi:10.1111/gcb.13125

Li, Z., Schneider, R.L., Morreale, S.J., Xie, Y., Li, J., Li, C., Ni, X. (2019) Using woody organic matter amendments to increase water availability and jump-start soil restoration of desertified grassland soils of Ningxia, China. Land Degrad Dev.; 30: 1313- 1324.

https://doi.org/10.1002/ldr.3315

Mabry, C. M. (2004). The number and size of seeds in common versus restricted woodland herbaceous species in central Iowa, U.S.A. Oikos 107:497-504.

McCay, T. (2013). Factors affecting the distribution of North American earthworms sampling protocol. Ecological Research as Education Network. http://erenweb.org/wpcontent/uploads/2013/10/EREN-Worm-Protocol.pdf

McClain, C.D., Holl, K.D. and Wood, D.M. (2011), Successional Models as Guides for Restoration of Riparian Forest Understory. Restoration Ecology, 19: 280-289. doi:10.1111/j.1526-100X.2009.00616.x

McManamen, C., Nelson, C.R. and Wagner, V. (2018), Timing of seeding after herbicide application influences rates of germination and seedling biomass of native plants used for grassland restoration. Restor Ecol, 26: 1137-1148. doi:10.1111/rec.12679

Morse, J. L., Ardón, M., \& Bernhardt, E. S. (2012). Using environmental variables and soil processes to forecast denitrification potential and nitrous oxide fluxes in coastal plain wetlands across different land uses. Journal of Geophysical Research: Biogeosciences, 117(G2), n/a-n/a. doi:10.1029/2011jg001923

Mottl, L. M., Mabry, C. M., \& Farrar, D. R. (2006). Seven-Year Survival of Perennial Herbaceous Transplants in Temperate Woodland Restoration. Restoration Ecology, 14(3), 330 338. doi:10.1111/j.1526-100x.2006.00141.x

Murphy, G.E., Romanuk, T.N. (2014). A meta-analysis of declines in local species richness from human disturbances. Ecology and Evolution, 4(1): 91- 103.

Muller, R.N. (2003). Nutrient relations of the herbaceous layer in deciduous forest ecosystems. Pages 15-37 in Gilliam FS, Roberts MR, eds. The Herbaceous Layer in Forests of Eastern North America. New York: Oxford

Nuzzo, V., Dávalos, A. and Blossey, B. (2015), Invasive earthworms shape forest seed bank composition. Diversity Distrib., 21: 560-570. doi:10.1111/ddi.12322

Overdyck, E. \& Clarkson, B.D. (2012) Seed rain and soil seed banks limit native regeneration within urban forest restoration plantings in Hamilton City, New Zealand. New Zealand journal of Ecology, 36(2), 177-190. 
Oksanen, J., Blanchet, F.G., Friendly, M., Kindt, R., Legendre, P., McGlinn, D., Minchin, P.R., O'Hara, R. B., Simpson, G.L., Solymos, P., Henry, M., Stevens, H., Szoecs E., and Wagner H. (2020). vegan: Community Ecology Package. R package version 2.5-7. https://CRAN.Rproject.org/package $=$ vegan

Palma, A. C., \& Laurance, S. G. W. (2015). A review of the use of direct seeding and seedling plantings in restoration: what do we know and where should we go? Applied Vegetation Science, 18(4), 561-568. doi:10.1111/avsc.12173

Pavao-Zuckerman, M.A. (2008). The Nature of Urban Soils and Their Role in Ecological Restoration in Cities. Restoration Ecology, 16: 642-649.

Pedrini, S., Balestrazzi, A., Madsen, M.D., Bhalsing, K., Hardegree, S.P., Dixon, K.W., Kildisheva, O.A. (2020). Seed enhancement: getting seeds restoration-ready. Restoration Ecology 28. doi:10.1111/rec.13184

Perakis, S. S., Maguire, D. A., Bullen, T. D., Cromack, K., Waring, R. H., \& Boyle, J. R. (2006). Coupled Nitrogen and Calcium Cycles in Forests of the Oregon Coast Range. Ecosystems, 9(1), 63-74. doi:10.1007/s10021-004-0039-5

Pimentel, D., Zuniga, R., Morrison, D. (2005). Update on the environmental and economic costs associated with alien-invasive species in the United States. Ecological Economics, 52(3) 273288.

Pouyat, R., Groffman, P., Yesilonis, I., \& Hernandez, L. (2002). Soil carbon pools and fluxes in urban ecosystems. Environmental Pollution, 116, S107-S118. doi:10.1016/s02697491(01)00263-9

R Core Team. (2021). R: A language and environment for statistical computing. R Foundation for Statistical Computing, Vienna, Austria. URL https://www.R-project.org/.

Schuster, MJ, Wragg, PD, Reich, PB. (2018). Using revegetation to suppress invasive plants in grasslands and forests. J Appl Ecol.; 55: 2362-2373. doi:10.1111/1365-2664.13195

Sharp, M. M. (2002). Effects of physical soil properties on the coverage of native and non-native plants in urban riparian areas. M.S. thesis. Environmental Science, Portland State University, Portland, Oregon.

Shaw, N.L., Lambert, S.M., DeBolt, A.M., Pellant M. (2005) Increasing native forb seed supplies for the Great Basin. In: Dumroese RK, Riley LE, Landis TD, technical coordinators (eds) National proceedings: forest and conservation nursery associations - 2004. RMRS-P-35. USDA Forest Service, Rocky Mountain Research Station, Fort Collins, Colorado.

Simmons, Brady L., Hallett, Richard A., Sonti, Nancy Falxa, Auyeung, D. S.N., Lu, Jacqueline W.T. (2016) Long-term outcomes of forest restoration in an urban park. Restoration Ecology, 24(1): 109-118. 
Small, C.J., McCarthy, B.C., (2002). Spatial and temporal variability of herbaceous vegetation in an eastern deciduous forest. Plant Ecology 164, 37-48.

Small C.J., McCarthy B.C. (2005). Relationship of understory diversity to soil nitrogen, topographic variation, and stand age in an eastern oak forest, USA. Forest Ecology and Management 217: 229-243.

Szlavecz, K., Placella, S. A., Pouyat, R. V., Groffman, P. M., Csuzdi, C., \& Yesilonis, I. (2006). Invasive earthworm species and nitrogen cycling in remnant forest patches. Applied Soil Ecology, 32(1), 54-62. doi:10.1016/j.apsoil.2005.01.006

Tejada, M., Hernandez, M.T., Garcia, C. (2006). Application of Two Organic Amendments on Soil Restoration: Effects on the Soil Biological Properties. Journal of Environmental Quality 35, 1010-1017. doi:10.2134/jeq2005.0460

Thouvenot, L., Ferlian, O., Beugnon, R., Künne, T., Lochner, A., Thakur, M.P., Türke, M., Eisenhauer, N. (2021). Do Invasive Earthworms Affect the Functional Traits of Native Plants? Frontiers in Plant Science 12. doi:10.3389/fpls.2021.627573

Thrippleton, T., Bugmann, H., Kramer-Priewasser, K., \& Snell, R. S. (2016). Herbaceous Understorey: An Overlooked Player in Forest Landscape Dynamics? Ecosystems, 19(7), 12401254. doi:10.1007/s10021-016-9999-5

Van Der Heijden, M.G.A., Bardgett, R.D. and Van Straalen, N.M. (2008). The unseen majority: soil microbes as drivers of plant diversity and productivity in terrestrial ecosystems. Ecology Letters, 11: 296-310. doi:10.1111/j.1461-0248.2007.01139.x

Van Der Valk, A.G., Bremholm, T.L., Gordon, E. (1999). The restoration of sedge meadows: seed viability, seed germination requirements, and seedling growth of Carex species. Wetlands 19, 756-764.. doi:10.1007/bf03161782

Vidal, C.Y., Naves, R.P., Viani, R.A.G., Rodrigues, R.R. (2020). Assessment of the nursery species pool for restoring landscapes in southeastern Brazil. Restoration Ecology 28, 427-434.. doi:10.1111/rec.13096

Vitousek, P.M., Porder, S., Houlton, B.Z., Chadwick, O.A. (2010) Terrestrial phosphorus limitation: mechanisms, implications, and nitrogen-phosphorus interactions. Ecol Appl 20:5-15. doi:10.1890/08-0127.1

Wavrek, M., Heberling, J.M., Fei, S. (2017). Herbaceous invaders in temperate forests: a systematic review of their ecology and proposed mechanisms of invasion. Biol Invasions 19, 3079-3097. doi:10.1007/s10530-017-1456-7

Weigel, R, Gilles, J, Klisz, M, Manthey, M, Kreyling, J. (2019). Forest understory vegetation is more related to soil than to climate towards the cold distribution margin of European beech. Journal Veg Sci.; 30: 746- 755. doi:10.1111/jvs.12759 
Westoby, M., Falster, D. S., Moles, A. T., Vesk, P. A., \& Wright, I. J. (2002). Plant Ecological Strategies: Some Leading Dimensions of Variation Between Species. Annual Review of Ecology and Systematics, 33(1), 125-159. doi: 10.1146/annurev.ecolsys.33.010802.150452

White, A., Fant, J. B., Havens, K., Skinner, M., \& Kramer, A. T. (2018). Restoring species diversity: assessing capacity in the U.S. native plant industry. Restoration Ecology, 26(4), 605611. doi:10.1111/rec. 12705

Willie, J. (2014). Conservation relevance of terrestrial herbaceous vegetation studies. Plant Science Today, 1(4), 188-191. doi:10.14719/pst.2014.1.4.66

Withrow-Robinson, B., Bennett, M., Ahrens, G. (2011). A guide to Riparian Tree and Shrub Planting in the Willamette Valley: Steps to Success. Oregon State University Extension Service Catalog, EM 9040. 


\section{Appendices}

Appendix A: Sites by Set

\begin{tabular}{|l|l|l|l|}
\hline \multicolumn{1}{|c|}{ Riparian 2016 } & \multicolumn{1}{|c|}{ Upland 2016 } & \multicolumn{1}{c|}{ Upland 2017 } & \multicolumn{1}{c|}{ Upland 2018 } \\
\hline Corral Creek & Chehalem & River View 2 & WM-B \\
Ramsey & River View 1 & Tryon Creek 1 & WM-C \\
& Thomas Dairy & Tryon Creek 2 & WM-E \\
& & & WM-H \\
& & & WM-K \\
& & & WM-M \\
& & & WM-S \\
\hline
\end{tabular}




\begin{tabular}{|llll|}
\hline \multicolumn{4}{|c|}{ Upland Seed Mixes by Year of Plot Installation } \\
\hline Species & $\mathbf{2 0 1 6}$ & $\mathbf{2 0 1 7}$ & $\mathbf{2 0 1 8}$ \\
\hline Adenocaulon bicolor & 1.42 & 1.43 & 1.37 \\
\hline Aquilegia Formosa & 0.61 & 0.65 & 0.6 \\
\hline Bromus vulgaris & 1.51 & 1.77 & 1.45 \\
\hline Carex leptopoda & 0.79 & 0.82 & 0.71 \\
\hline Circaea alpine & 0 & 0 & 0.53 \\
\hline Claytonia perfoliata & 0.95 & 0.88 & $<0.8$ \\
\hline Claytonia sibirica & 1.19 & 1.21 & 0 \\
\hline Elymus glaucus & 1.16 & 1.36 & 1.36 \\
\hline Festuca occidentalis & 0.25 & 0.39 & 0.21 \\
\hline Geum macrophyllum & 0.8 & 0 & 0.72 \\
\hline Hydrophyllum tenuipes & 16.6 & 16.2 & 14.58 \\
\hline Nemophila parviflora & 1.09 & 1 & 0.88 \\
\hline Osmorhiza berteroi & 4.54 & 3.99 & 3.56 \\
\hline Penstemon ovatus & 0.18 & 0.17 & 0.18 \\
\hline Tellima grandiflora & 0.12 & 0.13 & 0.07 \\
\hline Tolmiea menziesii & 0 & 0 & 0.18 \\
\hline Vancouveria hexandra & 0 & 0 & 0.87 \\
\hline
\end{tabular}

\begin{tabular}{|lc|}
\hline & Riparian Seed Mix \\
\hline Species & $\mathbf{2 0 1 6}$ \\
\hline Claytonia sibirica & 1.79 \\
\hline Carex obnupta & 0.5 \\
\hline Hydrophyllum tenuipes & 11.09 \\
\hline Juncus patens & 0.03 \\
\hline Scrophularia californica & 0.42 \\
\hline Stachys chamissonis v. cooleyae & 0.72 \\
\hline Thalictrum polycarpum & 1.84 \\
\hline Tolmiea menziesii & 0.19 \\
\hline Urtica dioica & 0.07 \\
\hline
\end{tabular}

****Amounts in pure live seed (PLS) grams per plot 
Appendix C: Seed Sources for Mix

\begin{tabular}{|c|c|c|c|c|c|}
\hline $\begin{array}{l}\text { Seeding } \\
\text { Year } \\
\end{array}$ & Species & Agency & Grams & Location & $\begin{array}{l}\text { Collection } \\
\text { year }\end{array}$ \\
\hline 2017 & Adenocaulon bicolor & & 3.1 & Cumberland & 2016 \\
\hline 2017 & Adenocaulon bicolor & CWS & 3.1 & Gales Creek & 2016 \\
\hline 2017 & Adenocaulon bicolor & Metro & 3.1 & Canemah & \\
\hline 2017 & Adenocaulon bicolor & Metro & 3.1 & Graham oaks & \\
\hline 2017 & Adenocaulon bicolor & Metro & 3.1 & Peach Cove Fen & \\
\hline 2017 & Aquilegia Formosa & Metro & 6.54 & NPC-CC & 2016 \\
\hline 2017 & Carex leptopoda & & 2.8 & Bald Peak & 2016 \\
\hline 2017 & Carex leptopoda & CWS & 2.8 & Hillsboro Farm & 2016 \\
\hline 2017 & Carex leptopoda & Metro & 2.8 & Mt Talbert & 2017 \\
\hline 2017 & Circaea alpina & & 0.7 & Cumberland & 2016 \\
\hline 2017 & Circaea alpina & CWS & 0.7 & Jordan Woods & 2017 \\
\hline 2017 & Circaea alpina & Metro & 0.7 & Canemah & 2016 \\
\hline 2017 & Claytonia perfoliata & City of Portland & 10.29 & PDX-MHK & \\
\hline 2017 & Claytonia sibirica & City of Portland & 8.36 & FP. Firelane & 2016 \\
\hline 2017 & Claytonia sibirica & City of Portland & 8.05 & Ridgeview & 2016 \\
\hline 2017 & Claytonia sibirica & Metro & 8.05 & Graham oaks & \\
\hline 2017 & Claytonia sibirica & Metro & 8.05 & NPC-multi & \\
\hline 2017 & Hydrophyllum tenuipes & CWS & 199.6 & $\begin{array}{r}\text { Jordan Woods and } \\
\text { Banister Cr }\end{array}$ & \\
\hline 2017 & Hydrophyllum tenuipes & Metro & 99.8 & Graham oaks & 2017 \\
\hline 2017 & Nemophila parviflora & Metro & 11.82 & Nelson Vaughn & \\
\hline 2017 & Osmorhiza berteroi & & 12.2 & Bald Peak & 2016 \\
\hline 2017 & Osmorhiza berteroi & Metro & 12.2 & Graham oaks & \\
\hline 2017 & Osmorhiza berteroi & Metro & 12.2 & Nelson Vaughn & \\
\hline 2017 & Peach Cove Fen & Metro & 12.2 & Nelson Vaughn & \\
\hline 2017 & Penstemon ovatus & City of Portland & 2 & N. Will - PDX bluffs & 2016 \\
\hline 2017 & Scrophularia californica & City of Portland & 2.5 & FP. Firelane & 2016 \\
\hline 2017 & Scrophularia californica & CWS & 1.9 & Gales Creek & 2017 \\
\hline 2017 & Tellima grandiflora & City of Portland & 0.63 & Will Ag. Station & 2016 \\
\hline 2017 & Tellima grandiflora & Metro & 0.63 & NPC - Cooper & \\
\hline 2017 & Thalictrum polycarpum & CWS & 9.92 & Hillsboro Farm & 2016 \\
\hline 2017 & Thalictrum polycarpum & CWS & 9.92 & Rock Creek & 2016 \\
\hline 2017 & Tolmiea menziesii & CWS & 0.7 & Gales Creek & 2016 \\
\hline 2017 & Tolmiea menziesii & CWS & 0.7 & Yamhill & 2016 \\
\hline 2017 & Tolmiea menziesii & Metro & 0.8 & NPC - Canemah & 2017 \\
\hline 2017 & Urtica dioica & City of Portland & 0.4 & FP. Firelane & 2016 \\
\hline 2017 & Urtica dioica & CWS & 0.4 & Jordan Woods & 2016 \\
\hline 2018 & Adenocaulon bicolor & City of Portland & 26.5 & FPAT & 2018 \\
\hline 2018 & Adenocaulon bicolor & Metro & 3.78 & NPC - Canemah & 2015 \\
\hline
\end{tabular}




\begin{tabular}{|c|c|c|c|c|c|}
\hline $\begin{array}{l}\text { Seeding } \\
\text { Year }\end{array}$ & Species & Agency & Grams & Location & $\begin{array}{l}\text { Collection } \\
\text { year }\end{array}$ \\
\hline 2018 & Aquilegia formosa & Metro & 7.15 & NPC - Clear Creek & 2015 \\
\hline 2018 & Bromus vulgaris & Metro & 26.55 & & 2015 \\
\hline 2018 & Carex leptopoda & City of Portland & 5.1 & RV & 2018 \\
\hline 2018 & Carex leptopoda & Metro & 4.5 & $\mathrm{NPC}-\mathrm{MT}$ & 2017 \\
\hline 2018 & Carex leptopoda & Tryon & 4.5 & $\begin{array}{c}\text { Tryon Creek State } \\
\text { Park }\end{array}$ & 2018 \\
\hline 2018 & Circaea alpina & City of Portland & 5 & $\mathrm{MP}$ & 2018 \\
\hline 2018 & Circaea alpina & CWS & 5 & $\begin{array}{c}\text { Portland, Multnomah } \\
\text { County }\end{array}$ & 2018 \\
\hline 2018 & Claytonia perfoliata & City of Portland & 7.5 & Powell's & 2018 \\
\hline 2018 & Claytonia perfoliata & Metro & 7.5 & Marsha's yard & 2018 \\
\hline 2018 & Elymus glaucus & City of Portland & 23.4 & Heritage & 2018 \\
\hline 2018 & Festuca occidentalis & City of Portland & 22.4 & Oregon Wholesale & 2015 \\
\hline 2018 & Geum macrophyllum & City of Portland & 10.4 & NW & 2018 \\
\hline 2018 & Geum macrophyllum & CWS & 3.6 & $\begin{array}{r}\text { Pacific University } \\
\text { Arboretum }\end{array}$ & 2017 \\
\hline 2018 & Hydrophyllum tenuipes & City of Portland & 50.5 & $\mathrm{TP}$ & 2018 \\
\hline 2018 & Hydrophyllum tenuipes & CWS & 50.5 & 10 & 2017 \\
\hline 2018 & Hydrophyllum tenuipes & CWS & 50.5 & $\begin{array}{c}\text { Multnomah County } \\
\text { Portland }\end{array}$ & \\
\hline 2018 & Hydrophyllum tenuipes & Tryon & 50.5 & $\begin{array}{r}\text { Tryon Creek State } \\
\text { Park North }\end{array}$ & 2018 \\
\hline 2018 & Hydrophyllum tenuipes & Tryon & 50.5 & $\begin{array}{r}\text { Tryon Creek State } \\
\text { Park Inner }\end{array}$ & 2018 \\
\hline 2018 & Nemophila parviflora & City of Portland & 8.8 & RV & 2018 \\
\hline 2018 & Nemophila parviflora & Metro & 8.8 & NKNV & 2016 \\
\hline 2018 & Osmorhiza berteroi & City of Portland & 11 & Forest Park AT & 2018 \\
\hline 2018 & Osmorhiza berteroi & City of Portland & 4 & MP & 2018 \\
\hline 2018 & Osmorhiza berteroi & Tryon & 49 & $\begin{array}{c}\text { Tryon Creek State } \\
\text { Park }\end{array}$ & 2018 \\
\hline 2018 & Penstemon ovatus & City of Portland & 3.35 & TY & 2018 \\
\hline 2018 & Tellima grandiflora & City of Portland & 0.64 & $\mathrm{JC}$ & 2018 \\
\hline 2018 & Tellima grandiflora & CWS & 0.64 & $\begin{array}{c}\text { Oakville OR, Linn } \\
\text { County }\end{array}$ & \\
\hline 2018 & Tellima grandiflora & Metro & 0.64 & $\begin{array}{c}\text { NPC - Cooper } \\
\text { Mountain }\end{array}$ & 2014 \\
\hline 2018 & Tellima grandiflora & Tryon & 0.64 & $\begin{array}{c}\text { Tryon Creek State } \\
\text { Park }\end{array}$ & 2018 \\
\hline 2018 & Tolmiea menziesii & City of Portland & 1.3 & Forest Park NRE & 2018 \\
\hline 2018 & Tolmiea menziesii & CWS & 1.3 & $\begin{array}{c}\text { Portland, Multnomah } \\
\text { County }\end{array}$ & \\
\hline 2018 & Tolmiea menziesii & Tryon & 1.3 & $\begin{array}{c}\text { Tryon Creek State } \\
\text { Park }\end{array}$ & 2018 \\
\hline 2018 & Vancouveria hexandra & City of Portland & 4.3 & Forest Park WG & 2018 \\
\hline
\end{tabular}




\begin{tabular}{|llllll|}
\hline $\begin{array}{l}\text { Seeding } \\
\text { Year }\end{array}$ & Species & Agency & Grams & Location & $\begin{array}{l}\text { Collection } \\
\text { year }\end{array}$ \\
\hline 2018 & Vancouveria hexandra & CWS & 4.3 & Gales Creek & 2017 \\
\hline 2018 & Vancouveria hexandra & CWS & 4.3 & Jordan Woods & 2017 \\
\hline 2018 & Vancouveria hexandra & Tryon & 4.3 & $\begin{array}{c}\text { Tryon Creek State } \\
\text { Park }\end{array}$ & 2018 \\
\hline
\end{tabular}




\section{Appendix D: Species Seed Weights}

\begin{tabular}{llc}
\hline Species & Codon & Seeds/gram \\
\hline Adenocaulon bicolor & ADBI & 222 \\
Aquilegia Formosa & AQFO & 546 \\
Bromus vulgaris & BRVU & 220 \\
Carex leptopoda & CALE & 1425 \\
Carex obnupta & CAOB & 2203 \\
Circaea alpine & CIAL & 1848 \\
Claytonia perfoliate & CLPE & 576 \\
Claytonia sibirica & CLSI & 891 \\
Elymus glaucus & ELGL & 286 \\
Festuca occidentalis & FEOC & 1333 \\
Geum macrophyllum & GEMA & 1996 \\
Hydrophyllum tenuipes & HYTE & 100 \\
Juncus patens & JUPA & 41850 \\
Nemophila parviflora & NEPA & 551 \\
Osmorhiza berteroi & OSBE & 134 \\
Penstemon ovatus & PEOV & 1322 \\
Scrophularia californica & SCCA & 1322 \\
Stachys chamissonis v. cooleyae & STCH & 831 \\
Tellima grandiflora & TEGR & 15419 \\
Thalictrum polycarpum & THPO & 606 \\
Tolmiea menziesii & TOME & 9978 \\
Urtica dioica & URDI & 33040 \\
Vancouveria hexandra & VAHE & 250 \\
\hline
\end{tabular}


Appendix E: Data collection method details

\section{$\underline{\text { Plot Level Predictors }}$}

Slope: Slope was measured using the clinometer scale on a compass while standing at the highest point in the plot and facing down slope. Values were read in degrees off of north.

Aspect: Aspect was measured by taking the heading from a compass while standing at the highest point in the plot and facing downhill.

Canopy Cover: Canopy cover was measured using a spherical crown densiometer. A reading was taken at the outer plot perimeter in every cardinal direction. The average of the four readings was then multiplied by 1.04 to give accurate percent cover.

Canopy Type: Percent canopy cover of coniferous versus deciduous is estimated visually so that together they equal $100 \%$. Canopy types were evaluated as coniferous or deciduous if they comprised $80 \%$ more of the total canopy, while scores below $80 \%$ of a given type were valued as mixed canopies.

Altitude: Altitude was assessed using plot GPS coordinates and The National Map Elevation tool from the USGS. Available at https://apps.nationalmap.gov/elevation/.

Compaction: Compaction measurements were taken using an agraTronix Soil Compaction Tester. The penetrometer was inserted, and the gauge read at depths of 3, 6, 9, and 12 inches. The penetrometer reports resistance of the soil in pounds per square inch (psi) with a scale from $0-300(+)$. Compaction measurements were taken by rounding to the nearest 25-psi value in 4 quadrants of each plot, resulting in a total of 16 readings per plot. For statistical analyses, an average of these readings was used. 


\section{$\underline{\text { Site Level Predictors }}$}

Soil Moisture: Soil moisture measurements were collected using in-situ soil probes attached to a data logger to adequately capture soil moisture variation within our sites over a 7-month period. The landscape variables (slope, aspect, canopy cover and type) for each group of plots along with a visual assessment were used to determine an adequately representative location for the installation of one soil moisture station. At each station, one Meter Group Teros 11 Soil Moisture and Temperature probe and one Meter Group GS3 Soil Moisture and Temperature probe attached to a Meter ZL6 data logger or a EM50 data logger (originally manufactured by Decagon) were deployed. Probes were inserted vertically at a depth of 4 and 8 inches, respectively. The probes were inserted within the soil by creating a small hole with a pointed spade shovel and ensuring full soil contact before filling the hole. Data loggers were attached to a metal fence post and set to record measurements every 15 minutes. Monitoring stations were deployed beginning from late-April to early-May (some sites delayed due to COVID) and ending in mid-November when the fall batch of PRS probes were retrieved. The data for each site was used to calculate summary statistics including minimum, maximum, mean, coefficient of variation, and range of both soil moisture and temperature at depths of 4 and 8 inches.

Worm Surveys: Worm surveys were performed using a modified version of the Great Lakes Worm Watch "multi plot" protocol, as described by McCay 2013. This method utilizes a mustard vermifuge mixture made by combining 60 grams of mustard powder with 6 liters of water. A center location for the three sub-plots were identified at random by standing in a central location to vegetation plots and having a volunteer throw a pin flag. Three subplots were laid 5 meters from the center point at approximately 120-degree intervals. Litter was moved from the plot area before 3 liters of the mixture was poured into a $.1089 \mathrm{~m}^{2}$ wood frame $(33 \mathrm{~cm}$ x $33 \mathrm{~cm})$. All 
worms that emerge were collected by hand, identified to the genus level if possible, marked as juvenile or adults, tallied into size classes and removed from the survey plot to avoid recounts. After 5 minutes, the second half of the mixture was poured into the plot which was observed for an additional 5 minutes. This protocol did not collect specimens for later identification at a lab. Surveys were performed in fall, as this is the best for finding mature stages of species with an annual life cycle, temperatures were not very cold, and soils were sufficiently moist. Due to a discrepancy in the frame size used by West Multnomah and USIP, worm counts were scaled to represent a total area of 0.25 square meters.

\section{$\underline{\text { Site }+ \text { Treatment Level Predictors }}$}

Plant Available Nutrients: Plant available nutrients were analyzed using Plant Root Simulator (PRS) probes purchased from Western Ag. These probes specifically measure bioavailable nutrients via ion-exchange membranes. Two types of probes were used: a cation probe to capture the availability of positively charged ions, including ammonium $\left(\mathrm{NH}_{4}^{+}\right)$, potassium $\left(\mathrm{K}^{+}\right)$, calcium $\left(\mathrm{Ca}^{2+}\right)$, and magnesium $\left(\mathrm{Mg}^{2+}\right)$, and an anion probe to capture the availability of negatively charged ions including nitrate $\left(\mathrm{NO}_{3}^{-}\right)$, phosphate $\left(\mathrm{H}_{2} \mathrm{PO}_{4}^{-}, \mathrm{HPO}_{4}{ }^{2-}\right)$, and sulphate $\left(\mathrm{SO}_{4}{ }^{2-}\right)$. The probes were vertically inserted into the uppermost layer of the soil and remained buried for a period of 4 weeks. Due to natural seasonal variations in plant available nutrients, probes will be buried in two distinct periods to capture nutrient availability in spring and fall.

For each group of plots, one composite set of probes was deployed to represent seeded plots and one to represent control plots. The sample, or composite set of probes, consisted of four cation and anion probes each, resulting in a total of 16 probes being deployed per site. Prices are based on sample rather than number of probes, and therefore using multiple probes in a single sample gives a similar result as a composite soil sample where multiple collections are 
homogenized and taken to represent the area at large. A shovel was used to create a small slot for the probe directly adjacent to the plot's outer perimeter. After inserting the probe so that only the top 2-3 centimeters was above ground, a 'back-cut' was applied using the shovel to ensure complete contact between the ion exchange membrane and soil. A small pin-flag was then placed to assist in recovering probes at the end of a four-week period. After retrieving the probes, they were immediately placed within a labeled Ziplock for transport back to the Morse Biogeochemistry lab where they remained refrigerated. Probes were thoroughly cleaned with deionized water, placed in a new ziplock labelled with the corresponding sample identification, and priority mailed to Western Ag for analysis. At one site (Thomas Dairy), it was discovered that all pin flags had been removed from the site by the end of the fall burial. The cause and/or reason for this remains unknown but due to difficulties locating the probes, only $2 / 4$ control and $3 / 4$ seeded sets of probes were retrieved and sent for analysis. Statistical analysis explored the mean and flux of spring and fall nutrient measurements, as well as each season separately.

Soil Samples: Soil samples were collected using a one-inch diameter soil corer. For each plot, four soil cores (one from each quadrant), were taken from a depth of 0-15 $\mathrm{cm}$ below the litter layer. Composite soil samples were created for each unique site + treatment combination by homogenizing the 12 resulting soil cores in a 5 -gallon bucket (4 per plot x 3 plots). Samples were split into two bags- one of which was air dried in the Morse Lab for 3 days and the other was archived due to having a much larger quantity of soil than was necessary for analysis. After three days of air drying, soils were placed into clean and clearly labelled ziplocks, with two replicates per sample. These were sent to Oregon State University's Soil Health Laboratory to be analyzed for $\mathrm{pH}$, texture, and total Carbon, Nitrogen, and Sulfur (CNS). Total CNS was used to calculate C:N ratio and an organic matter estimate ( $2 \mathrm{x}$ total $\mathrm{C})$. 
Germination (stem counts 1-2 years post-seeding)

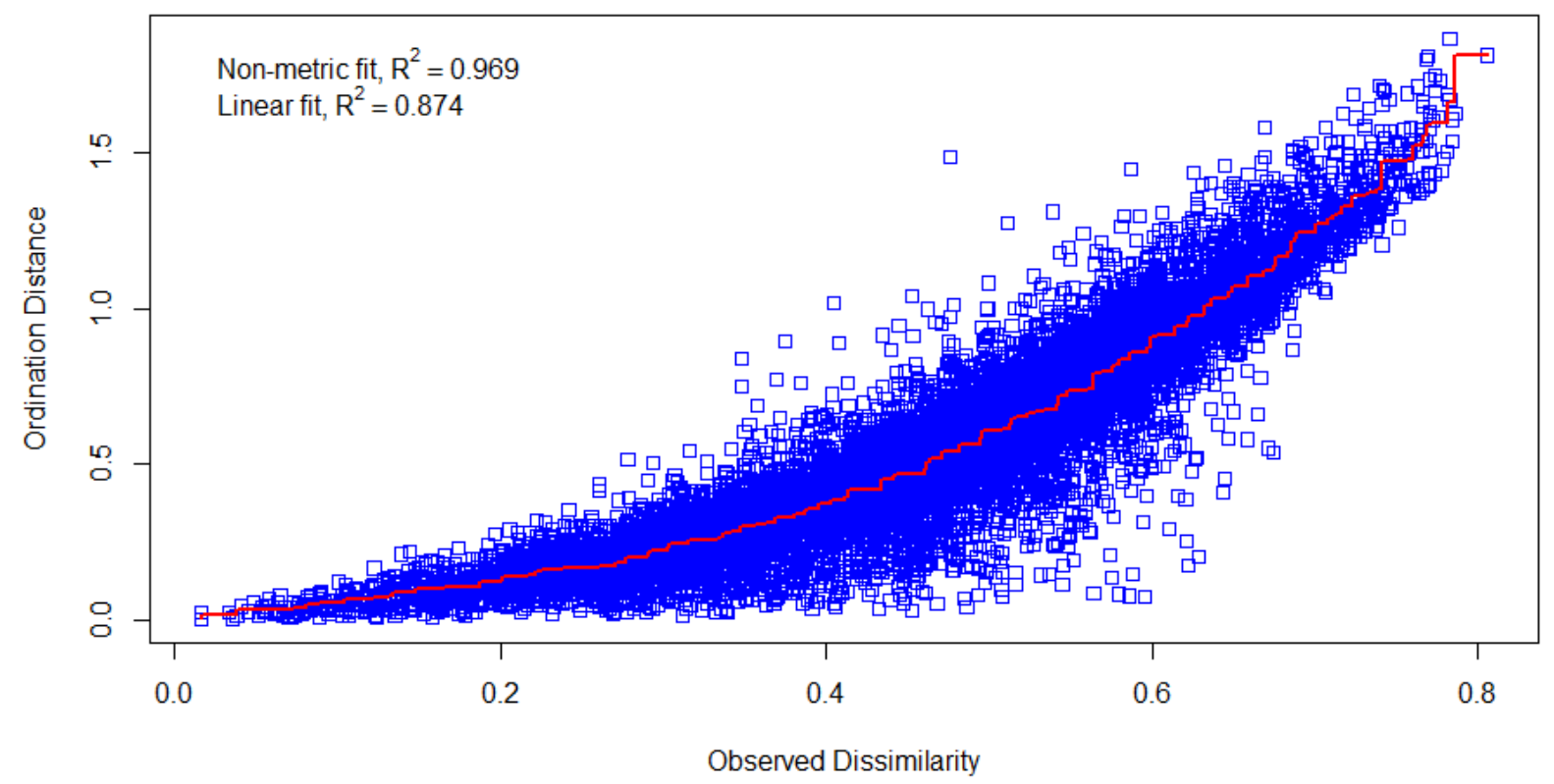

Cover (USIP plots 2020)

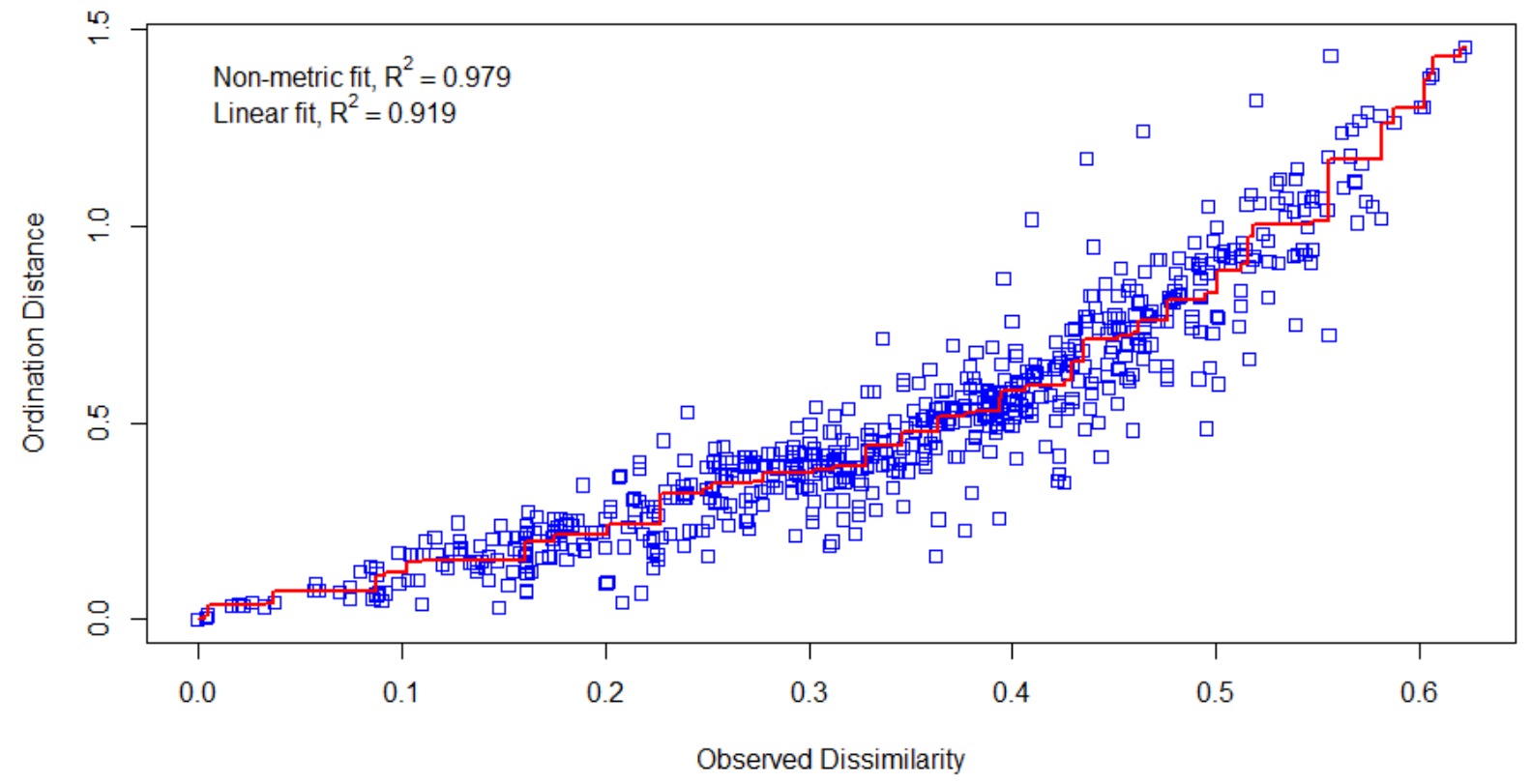


Appendix G: Species Performance Metric (1-2 years post-seeding data only)

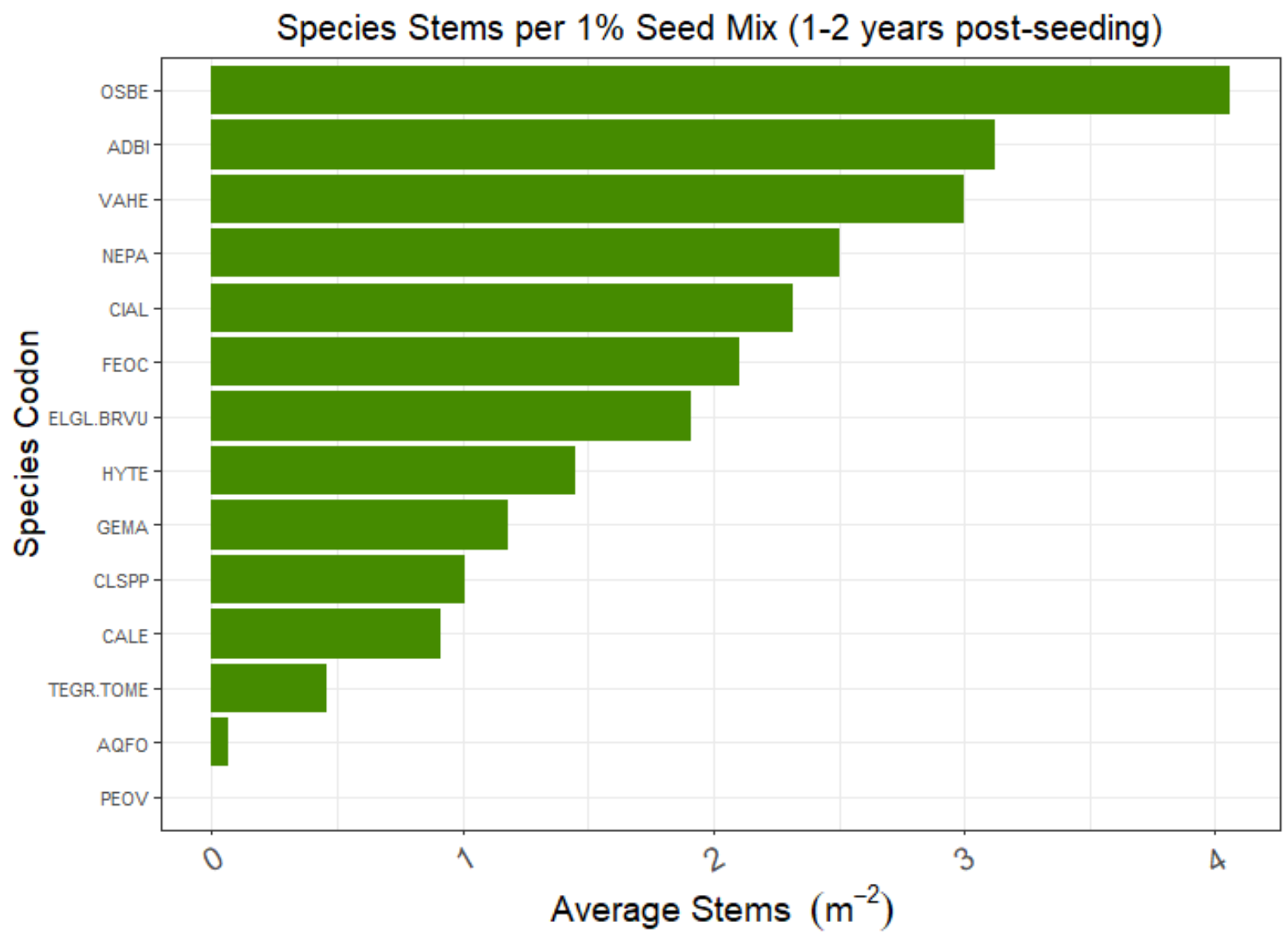




\section{Appendix H: Additional Germination Graphs for GLMM predictors}
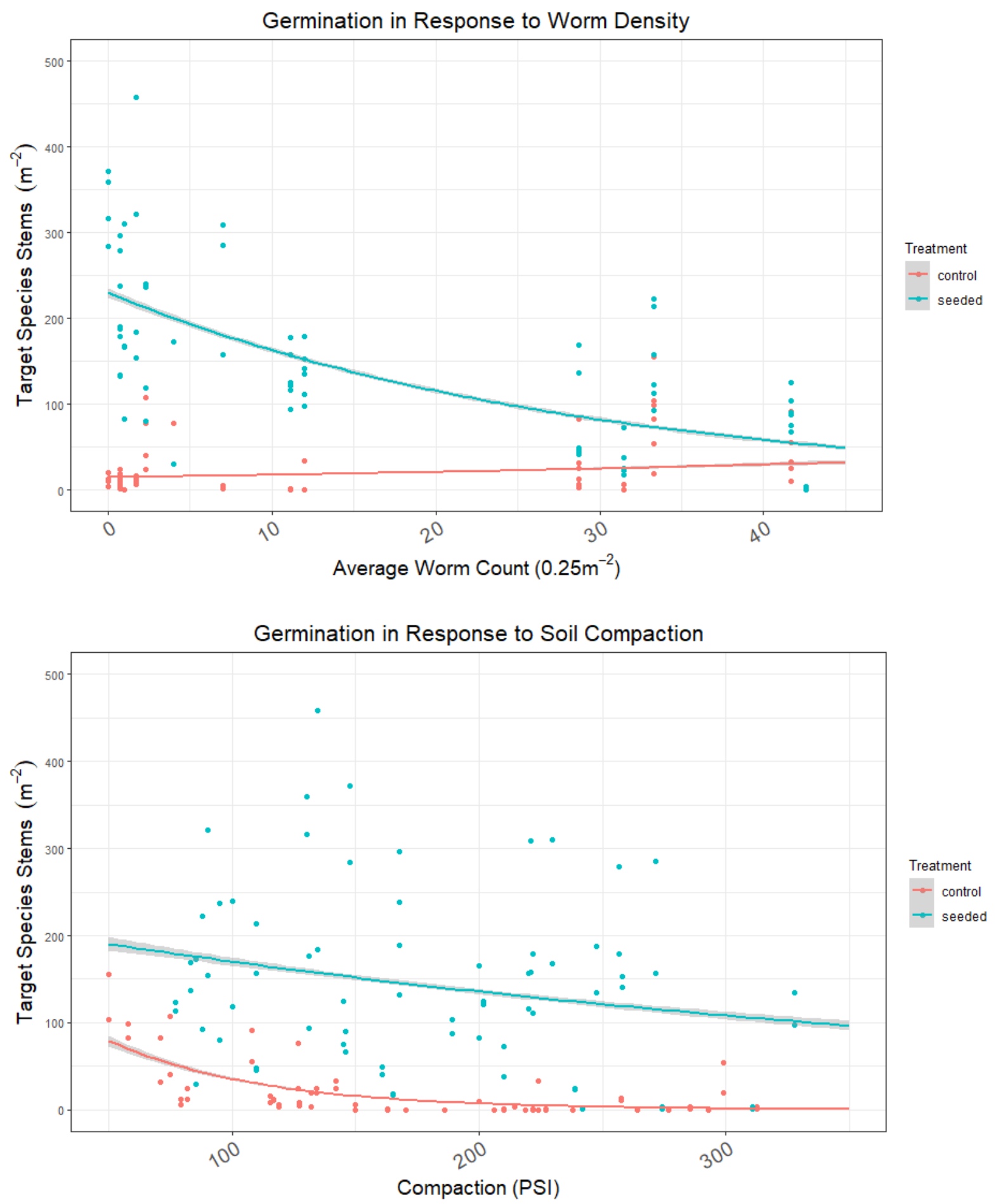


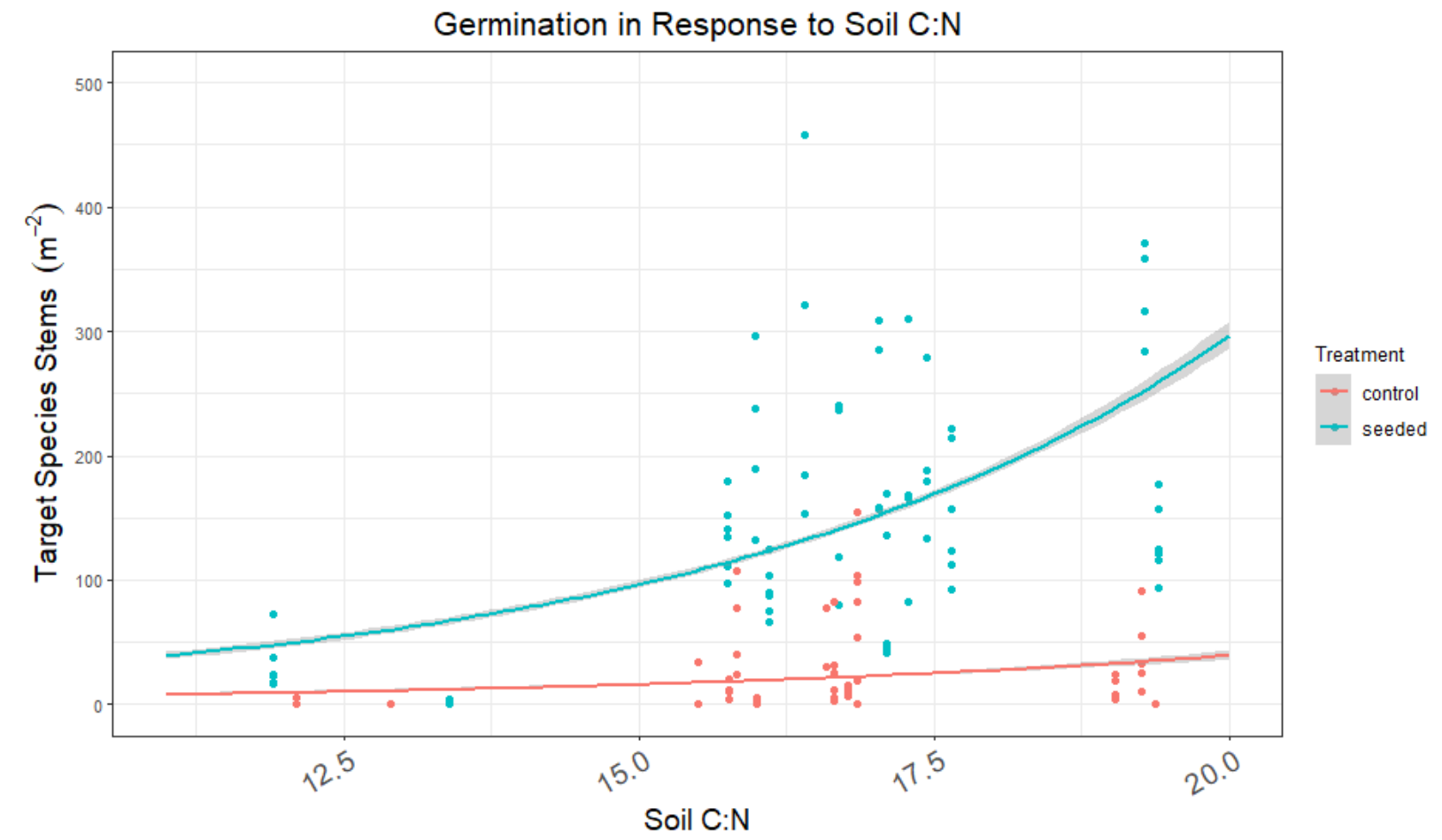




\section{Appendix I: Germination GLMM Best Model DHARMa Diagnostics}

\section{DHARMa residual diagnostics}
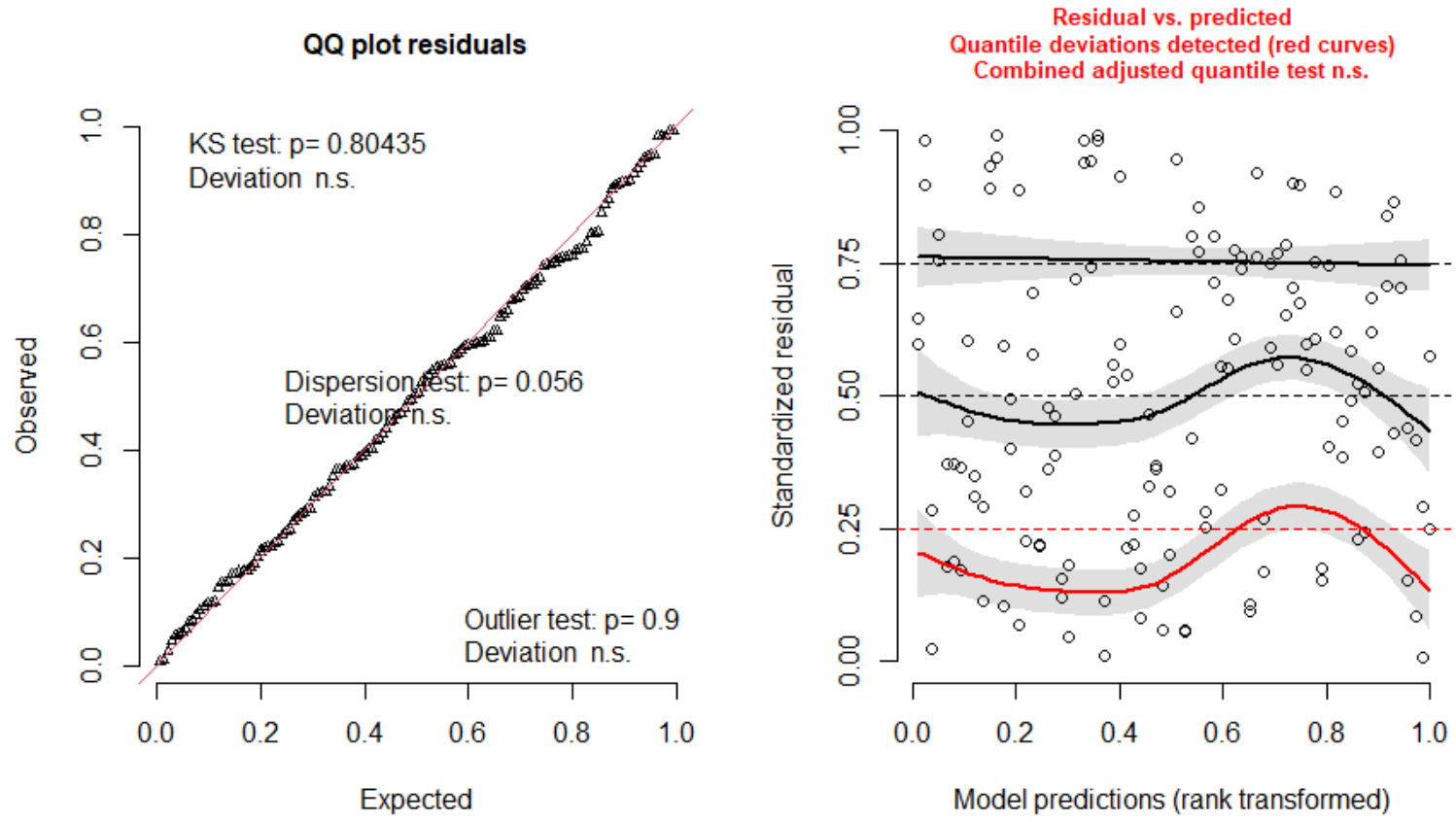

DHARMa zero-inflation test via comparison to expected zeros with simulation under $\mathrm{H} 0=$ fitted model

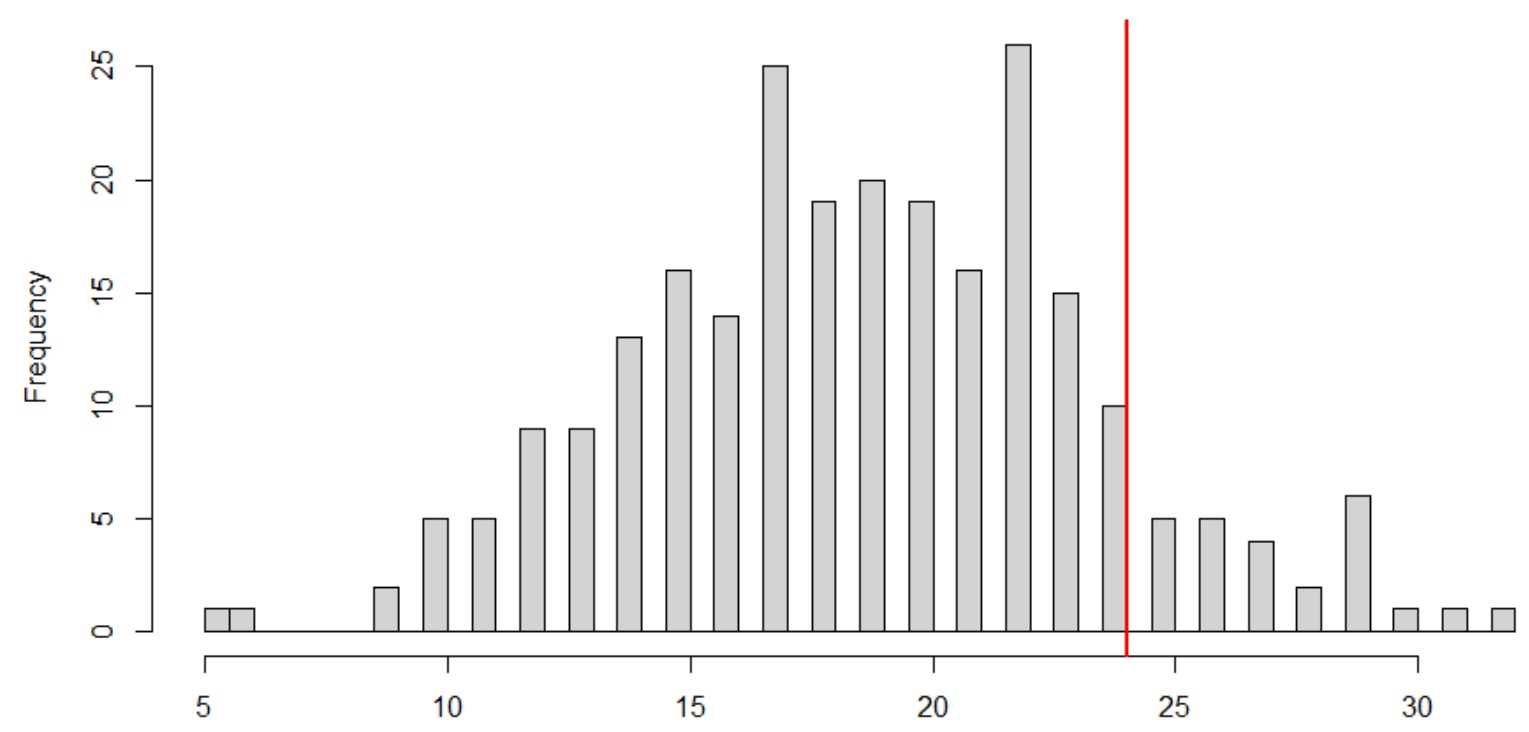

Simulated values, red line $=$ fitted model. $\mathrm{p}$-value $($ two sided $)=0.28$ 


\section{Germination Model}

\begin{tabular}{lcc}
\hline Model & AIC & $\Delta$ AIC \\
\hline Target Stems $\sim(1 \mid$ site $)+(1 \mid$ plot $)$ & 1436 & \\
Target Stems $\sim$ treatment $+(1 \mid$ site $)+(1 \mid$ plot $)$ & 1361.5 & 74.5 \\
Target Stems $\sim$ treatment $+(1 \mid$ site $)+(1 \mid$ plot $)+$ compaction & 1297.2 & 64.3 \\
Target Stems $\sim$ treatment+(1|site $+(\mathbf{1} \mid$ plot $)+$ compaction + worm & 1291.1 & 6.1 \\
\hline
\end{tabular}

\section{Cover Model}

\begin{tabular}{lcc}
\hline Model & AIC & $\Delta$ AIC \\
\hline Target Cover $\sim(1 \mid$ site $)$ & 267 & \\
Target Cover $\sim(1 \mid$ site $)+$ treatment & 262.5 & 4.5 \\
Target Cover $\sim$ (1|site) + OM & $\mathbf{2 5 8 . 4}$ & $\mathbf{8 . 6}$ \\
Target Cover $\sim(1 \mid$ site $)+$ OM+ treatment & 252.8 & 5.6 \\
Target Cover $\sim(1 \mid$ site $)+$ OM+ canopy type & 257 & 1.4 \\
Target Cover $\sim(1 \mid$ site $)+$ OM+ compaction & 255 & 3.4 \\
Target Cover $\sim(1 \mid$ site $)+$ K & 255.4 & 11.6 \\
Target Cover $\sim(1 \mid$ site $)+$ K+ treatment & 253.8 & 1.6 \\
Target Cover $\sim(1 \mid$ site $)+$ K+ canopy type & $\mathbf{2 4 9 . 3}$ & $\mathbf{6 . 1}$ \\
Target Cover $\sim(1 \mid$ site $)+$ K+ canopy type + compaction & 246.1 & 3.2 \\
\hline
\end{tabular}




\section{Appendix K: Additional Cover Graphs for significant GLMM predictors}
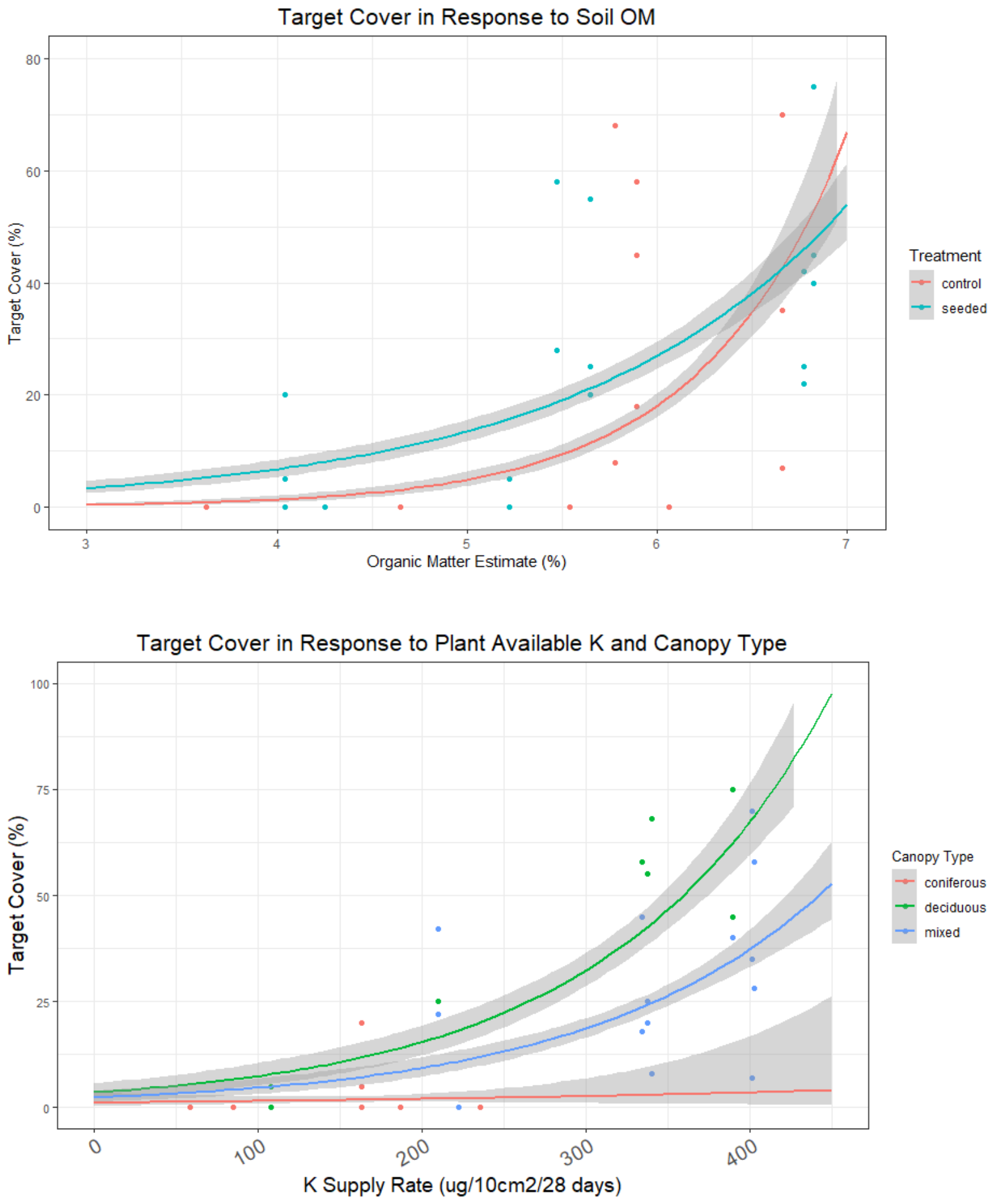


\section{Appendix L: Cover GLMM Best Model DHARMa Diagnostics}

\section{Plant-available K and Canopy Type Model:}
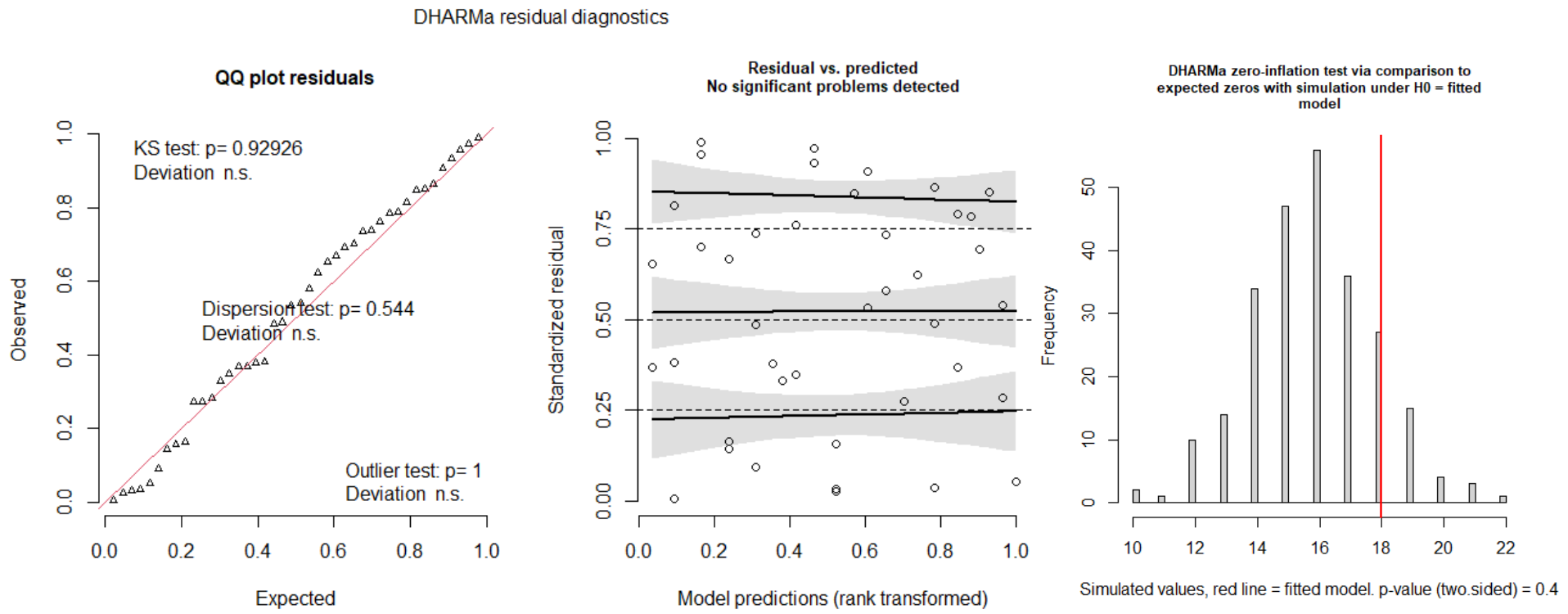

\section{Organic Matter Model:}

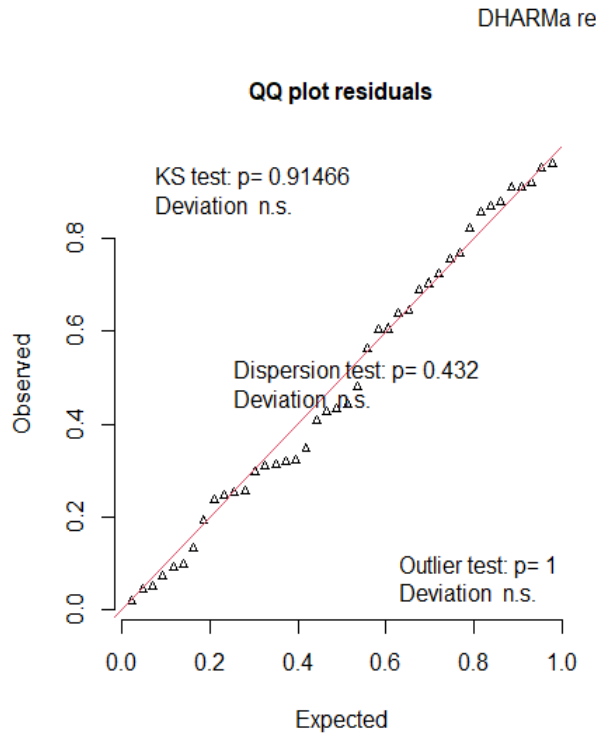

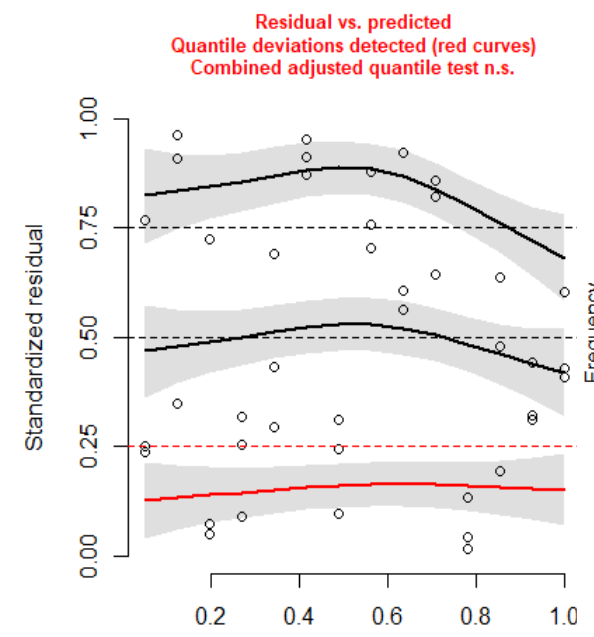

Model predictions (rank transformed)

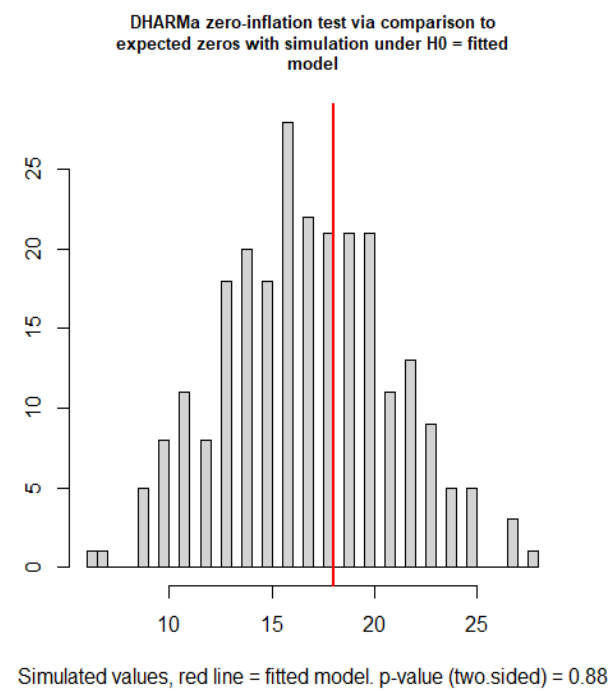




\section{Appendix M: Commercial Vendor Survey}

Please use this table to indicate certain species in relation to questions 1-3.

For Agree/Disagree responses, you may use the following shorthand:
SA = Strongly Agree
A $=$ Agree
$\mathrm{N}=$ Neutral
$\mathrm{D}=$ Disagree
$\mathrm{SD}=$ Strongly Disagree

\begin{tabular}{|c|c|c|c|c|c|c|c|c|c|}
\hline \multirow{2}{*}{$\begin{array}{c}\text { Species } \\
\text { Codon }\end{array}$} & \multicolumn{9}{|c|}{ Questions } \\
\hline & 1 & 2 & 2.a & 2.b & $2 . \mathrm{c}$ & 2.d & 2.e & $2 . f$ & 3 \\
\hline \multicolumn{10}{|l|}{ ADBI } \\
\hline \multicolumn{10}{|l|}{ AQFO } \\
\hline \multicolumn{10}{|l|}{ BRVU } \\
\hline \multicolumn{10}{|l|}{ CALE } \\
\hline \multicolumn{10}{|l|}{$\mathrm{CAOB}$} \\
\hline \multicolumn{10}{|l|}{$\mathrm{ClAL}$} \\
\hline \multicolumn{10}{|l|}{ CLPE } \\
\hline \multicolumn{10}{|l|}{ CLSI } \\
\hline \multicolumn{10}{|l|}{ DIFO } \\
\hline \multicolumn{10}{|l|}{ ELGL } \\
\hline \multicolumn{10}{|l|}{ FEOC } \\
\hline \multicolumn{10}{|l|}{ GEMA } \\
\hline \multicolumn{10}{|l|}{ HYTE } \\
\hline \multicolumn{10}{|l|}{ JUPA } \\
\hline \multicolumn{10}{|l|}{ MESU } \\
\hline \multicolumn{10}{|l|}{ NEPA } \\
\hline \multicolumn{10}{|l|}{ OSBE } \\
\hline \multicolumn{10}{|l|}{ PEOV } \\
\hline \multicolumn{10}{|l|}{ SCCA } \\
\hline \multicolumn{10}{|l|}{$\mathrm{STCH}$} \\
\hline \multicolumn{10}{|l|}{ TEGR } \\
\hline \multicolumn{10}{|l|}{ THPO } \\
\hline \multicolumn{10}{|l|}{ TOME } \\
\hline \multicolumn{10}{|l|}{ URDI } \\
\hline \multicolumn{10}{|l|}{ VAHE } \\
\hline VIGL & & & & & & & & & \\
\hline
\end{tabular}

\section{Survey Questions}

1. Do you currently produce any of the target species? Please identify them in the above table.

YES

NO

2. Agree/Disagree: The production of additional target species is challenging.

Strongly Agree

Agree

Neutral

Disagree

Strongly Disagree 
This challenge arises from:

a. Lack of demand

\begin{tabular}{|c|c|c|c|c|}
\hline Strongly Agree & Agree & Neutral & Disagree & Strongly Disagree \\
\hline
\end{tabular}

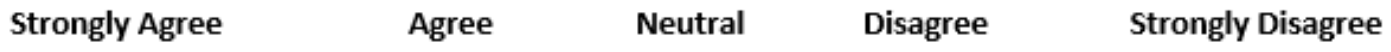

c. Lack of knowledge regarding propagation

$\begin{array}{lllll}\text { Strongly Agree } & \text { Agree } & \text { Neutral } & \text { Disagree } & \text { Strongly Disagree }\end{array}$

d. Lack of time and personnel resources

$\begin{array}{llll}\text { Strongly Agree } & \text { Agree } & \text { Neutral Disagree } & \text { Strongly Disagree }\end{array}$

e. Lack of necessary shade infrastructure for herbaceous species

$\begin{array}{llll}\text { Strongly Agree } & \text { Agree } & \text { Neutral Disagree } & \text { Strongly Disagree }\end{array}$

f. Difficulties using machinery to harvest herbaceous seed

Strongly Agree $\quad$ Agree Neutral Disagree $\quad$ Strongly Disagree

3. Would you be willing to contract grow herbaceous species that are not currently in production? If there are certain species you would be willing to work with, please indicate them in the table on page 2 .

YES NO

If YES, proceed to questions 4-6.

If NO, please skip to question 7.

4. Is there a minimum land area requirement for contract growing herbaceous species?

5. What quantity of initial seed would be necessary to contract grow new herbaceous species?

6. What (if any) level of propagation information would you prefer to receive for new herbaceous species?

7. Please describe any additional information pertinent to the challenges/opportunities/needs for increasing the production of target herbaceous species in your business.

We thank you for your participation. 